\section{ORGDP FUEL REPROCESSING STUDIES SUMMARY PROGRESS REPORT \\ FISCAL YEAR 1964 THROUGH FISCAL YEAR 1965}

AUTHORS:

S. H. Smiley

D. C. Brater

J. H. Pashley

RELEASED FOR ANNOUNCEMENT

IN RUCLEAR SCIENCE ABSTRACTS
UNION CARBIDE

\section{UNION CARBIDE CORPORATION} NUCLEAR DIVISION

Operating the

OAK RIDGE GASEOUS DIFFUSION PLANT

OAK RIDGE Y-12 PLANT

- oAK RIDGE national LabORATORY

- PADUCAH gaSEOUS DIFFUSION PLANT 


\section{DISCLAIMER}

This report was prepared as an account of work sponsored by an agency of the United States Government. Neither the United States Government nor any agency Thereof, nor any of their employees, makes any warranty, express or implied, or assumes any legal liability or responsibility for the accuracy, completeness, or usefulness of any information, apparatus, product, or process disclosed, or represents that its use would not infringe privately owned rights. Reference herein to any specific commercial product, process, or service by trade name, trademark, manufacturer, or otherwise does not necessarily constitute or imply its endorsement, recommendation, or favoring by the United States Government or any agency thereof. The views and opinions of authors expressed herein do not necessarily state or reflect those of the United States Government or any agency thereof. 


\section{DISCLAIMER}

Portions of this document may be illegible in electronic image products. Images are produced from the best available original document. 
Printed in USA. Price $\$ 4.00$. Available from the Clearinghouse tor Federul Scientific and Technical Information, National Bureau of Standards, U.S. Department of Commerce, Springfield, Virginio

\section{LEGAL NOTICE}

This report was prepared as an account of Government sponsored work. Neither the United States, nor the Commission, nor any person acting on behalf of the Commission:

A. Makes any warranty or representation, expressed or implied, with respect to the accuracy, completeness, or usefulness of the information contained in this report, or that the use of any information, apparatus, method, or process disclosed in this report may not infringe privately owned rights; or

B. Assumes any liabilities with respect to the use of, or for damages resulting from the use of any information, apparatus, method, or process disclosed in this report.

As used in the above, "person acting on behalf of the Commission" includes any employee or contractor of the Commission, or emplayee of such contractor, to the extent that such employee or contractor of the Commission, or employee of such contractor prepares, disseminates, or provides access to, any information pursuant to his employment or contract with the Commission, or his employment with such contractor. 
Date of Issue: October 29, 1965

$\begin{aligned} \text { Subject Category: } & \text { Chemical Separations } \\ & \text { Processes for } \\ & \text { Plutonium and Uranium } \\ & \text { TID-4500 (45th Ed.) }\end{aligned}$

ORGDP FUEL REPROCESSING STUDIES

SUMMARY PROGRESS REPORT

Fiscal Year 1964 Through Fiscal Year 1965

S. H. Smiley

D. C. Brater

J. H. Pashley

Engineering Development Department

Technical Division 
THIS PAGE WAS INTENTIONALLY LEFT BLANK 
$\underline{A} \underline{B} \underline{\mathrm{S}} \underline{\underline{T}} \underline{\mathrm{R}} \underline{A} \underline{\mathrm{C}} \underline{\mathrm{T}}$

During the past several years, the Atomic Energy Commission has been sponsoring technical and scientific studies of a group of processes aimed at recovering valuable uranium and plutonium from spent nuclear reactor fuels by dry gas techniques. In essence, these elements are volatilized as the hexafluorides, and most of the undesirable fission products are left behind. Purification from volatile fission products is accomplished by distillation or selective sorption.

Basic technology for recovering both high and low enrichment fuels by volatility methods is being provided by the Argonne, Oak Ridge, and Brookhaven National Laboratories. During the past two years, the Oak Ridge Gaseous Diffusion Plant Technical Division has supported the main effort of the National Laboratories in two ways. First, conceptual plant studies have been performed, including economic comparisons of alternative process flow sheets. These evaluations have attempted to define process problem areas and to point to the optimum route to a successful commercial enterprise. Second, a components development program has been initiated covering scale-up and testing of crucial process equipment and auxiliarles. The report which follows is primarily a summary presentation of the Oak Ridge Gaseous Diffusion Plant work carried out during fiscal years 1964 and 1965. 


\section{THIS PAGE}

\section{WAS INTENTIONALLY \\ LEFT BLANK}


TABLE OF CONTEIVTS

$\underline{\text { Page }}$

INTRODUCTION . . . . . . . . . . . . . . . . . . . . 17

SUMMARY . . . . . . . . . . . . . . . . . . . 18

ENGINEERING STUDIES . . . . . . . . . . . . . . . 18

HIGH ENRICHMENT FUELS . . . . . . . . . . . . . . 18

LOW ENRICHMENT POWER REACTOR FUELS . . . . . . . . . . . 19

Zircaloy-Clad Fuel Process . . . . . . . . . . . . . 19

Stainless Steel-Clad Fuel Process . . . . . . . . . 19

Interhalogen Flow sheet . . . . . . . . . . . . 20

Head End Fluld-Bed Reactor . . . . . . . . . . . 20

Radioactive Heat Generation .. . . . . . . . 20

Alumina Diluent and Bed Storage Costs

CRITICALITY CALCULATIONS . . . . . . . . . . . . . . 21

High Enrichment Fuels ................. 21

Low Enrichment Fuels . . . . . . . . . . . . 21

Plutoniurn . . . . . . . . . . . . . . . . 21

COLD TRAPS . . . . . . . . . . . . . . . . . . . 21

PROTOTYPE TESTING AND EVALUATION : . . . . . . . . . . . . 21

MATERIALS OF CONSTRUCTION - CORROSION
TESTING AND RELATED STUDIES . . . . . . . . . . . . . . . . 22

PROCESS AND REACTOR STUDIES . . . . . . . . . . . . 23

OUTLET GAS FILTER STUDIES . . . . . . . . . . . . . 24

PRODUCT PURIFICATION, SORPTION-DESORPTION SYSTEM . . . . . 24

CONNECTORS . . . . . . . . . . . . . . . . . . . 25

COMPRESSORS . . . . . . . . . . . . . . . . . . 25 
THIS PAGE

\section{WAS INTENTIONALLY LEFT BLANK}


TABLE OF CONTENTS (Contd.)

$\underline{\text { Page }}$

REACTOR FABRICATION PROCEDURES - WELDING STUDIES . . . . 25

DISCUSSION . . . . . . . . . . . . . . . 26

ENGINEERING STUDIES . . . . . . . . . . . . . . . 26

HIGH ENRICHMENT FUELS . . . . . . . . . . . . 26

LOW ENRICHMENT POWER REACTOR FUELS . . . . . . . . 30

Zircaloy-Clad Fuel Process . . . . . . . . . . 30

Stainless Steel-Clad Fuel Process . . . . . . . 34

Interhalogen Flow sheet .......... 35

Head End Fluid-Bed Reactor . . . . . . . . . . 39

Radioactive Heat Generation . . . . . . . 41

Alumina Diluent and Bed Storage Costs

for Power Reactor Fuel Processing . . . . . . . . 43

CRITICALITY CALCULATIONS . . . . . . . . . . . . 45

High Enrichment Fuels............. . 45

Low Enrichment Fuels . . . . . . . . . . . . 47

Plutonium ..................... 49

COLD TRAPS . . . . . . . . . . . . . . . . . . 50

PROTOTYPE TESTTING AND EVALUATION . . . . . . . . . 53

MATERIALS OF CONSTRUCTION - CORROSION

TESTING AND RELATED STUDIES ............ 53

Filter Materials . . . . . . . . . . . 53

Flange and Reactor Materials . . . . . . . 59

PROCESS AND REACTOR STUDIES ............... . . 62

Decladding and Fluorination Studies ....... 67

Inert Gas Fluidization . . . . . . . . . 67 
THIS PAGE

\section{WAS INTENTIONALLY \\ LEFT BLANK}


TABLE OF CONTENTS (Cont'd.).

Page

Semiworks Reactor ............. 68

OUTLET GAS FILTER STUDIES . . . . . . . . . . 70

PRODUCT PURIFICATIONS, SORPTION-DESORPTION SYSTEM . . . . 74

Cylindrical Pellet Trap . . . . . . . . . 74

Annular Pellet Trap ............. 80

Fluidized Bed ............. 80

CONNECTORS ................... 85

Marman Conoseal ............. . . 85

Flat-Faced Flange Connectors . . . . . . . 89

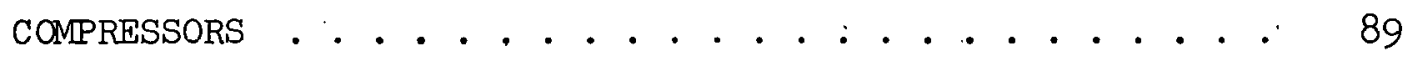

Peripheral Compressor . . . . . . . . . . 96

Seal Development. . . . . . . . . . . 98

Compressor Aerodynamics . . . . . . . . . 98

Test Rig Evaluation of Design Features . . . . . 104

Diaphragm Compressor . . . . . . . . . . 106

REACTOR FABRICATION PROCEDURES - WELDING STUDIES . . . . . 107 
THIS PAGE

\section{WAS INTENTIONALLY LEFT BLANK}




\section{LIST OF TABLES}

Table

$\underline{\text { Page }}$

I

Cycle Times for Zirconium and Aluminum Fuels . . . . 28

II

Physical Properties of Bromine Pentafluoride, Bromine Trifluoride, and Uranium Hexafluoride . . . 37

III Temperature Rise in a 20-Inch Diameter Settled

Bed with Volume Heat Generation . . . . . . . . 42

IV Element Temperature Transients in Settled Bed

for $14 \times 14$ Pseudo-Westinghouse Module in

16-Inch Diameter Bed . . . . . . . . . . 44

Alumina Usage Economics . . . . . . . . . 45

VI Critical Size of Urano-Uranic Oxide Spheres

for Different Multiplication Factors, k eff . . . . 46

VII Infinite Medium Neutron Multiplication Constants

for Uranium Dioxide-Alumina Mixtures . . . . . . . 47

VIII Critical Radii of Infinite Cylinders Containing

Uranium Dioxide-Water Mixtures . . . . . . . 48

IX Critical Spheres of Uranium Dioxide-Ẁater Mixtures . . 49

X Critical Mass of Plutonium Dioxide Spheres

Reflected with Alumina . . . . . . . . . 50

XI Calculated Uranium Hexafluoride Capacity for

10-Inch Diameter, "Egg-Crate" Type Cold Trap . . . . 52

XII Results of Corrosion Tests . . . . . . . . 54

XIII Results of 4-Inch Dlameter Sodium Fluoride Trap
Sorption Tests........................ 76

Xffect of Preparation Temperature on Sodium
Fluoride Pellet Characteristics . . . . . . . . 77

XV . Results of Annular Trap Sorption Tests . . . . . . 84

XVI Design Criteria for Fluid-Bed Volat1lity Loop
Compressors, I Tonne of Uranium Per Day Line . . . . . 96

XVII Performance of 1.9375-Inch Diameter Bushing Seal : . 104

XVIII Corblin Compressor Performance Specification . . . . 106 
THIS PAGE

\section{WAS INTENTIONALLY LEFT BLANK}




\section{LIST OF FIGURES}

Figure

Page

1 Decladding and Chemical Pretreatment . . . . . . . 31

$2 \quad$ Fluorination and Product Recovery . . . . . . . . 32

3 Power Reactor Fuel Reprocessing Plant . . . . . . 33

4 Interhalogen Reference Flow Sheet . . . . . . . . 36

5 Corrosion of Porous Nickel . . . . . . . . . 57

6 Porous Nickel Exposed to Fluorine at $550^{\circ} \mathrm{C}$. ...... 58

7 Electroless Nickel Plate Corrosion Attack ... . . . 60

8 Duranickel Corrosion Attack ............ 61

9 Corrosion Results (Test No. 8).......... 63

10 Corrosion Results (Test No. 8).......... 64

11 Corrosion Results (Test No. 7) . ......... 65

12 Corrosion Results (Test No. 7) . . . . . . . . 66

13 Semiworks Fluid-Bed Reactor . . . . . . . . . 69

14 DRD Filter Test Loop . . . . . . . . . . . 71

15 Porous Nickel Filter Failures . . . . . . . . 73

16 4-Inch Sorber Loop . . . . . . . . . . . 75

17 Sndium Fluoride Pellets .. . . . . . . . . . 79

18 Annular Trap ................. 81

19 Annular Trap Loop . . . . . . . . . . . . 82

20 Continuous $\mathrm{UF}_{6}^{\prime}$ Sorption System . . . . . . . . . 83

21 Marman Conoseal Single Seal . . . . . . . . . 86

22 Marman Conoseal Double Seal .......... . . 87

23 Nickel Marman Conoseal After Heat Cycling . . . . . . 90

24 Double Ring Gasket . . . . . . . . . . . . 91 
THIS PAGE

\section{WAS INTENTIONALLY \\ LEFT BLANK}




\section{LIST OF FIGURES (Conta.)}

Figure

Page

25 Serrated Gasket . . . . . . . . . . . 92

26 Milled Multiple Touchpoint Gasket . . . . . . . . . 93

27 Multiple Touchpoints on Flange - Flat Gasket . . . . . . 94

28 Duranickel Fractures . . . . . . . . . . . 95

29 Single Stage Peripheral Compressor . . . . . . . . . 97

30 Two-Stage Peripheral Compressor . . . . . . . . . 99

31 Peripheral Compressor Dual Stage Results . . . . . . . 100

32 Peripheral Compressor Dual Stage Results . . . . . . . 101

33 Peripheral Seals . . . . . . . . . . . . 102

34 Peripheral Compressor Channel Characteristics . . . . 1.03

35 Peripheral Compressor Impellers . . . . . . . . . . 105

36 Corblin Pump Loop . . . . . . . . . . . . 108

37 Corblin Compressor ............... . 109

38 Corblin Vibration Measurements . . . . . . . . 110

39 Corblin Fluorocarbon Oil Pressure Measurements . . . . 111 
THIS PAGE

WAS INTENTIONALLY

LEFT BLANK 
ORGDP FUEL REPROCESSING STUDIES

SUMMARY PROGRESS REPORT

Fiscal Year 1964 Through Fiscal Year 1965

\section{INTRODUCTION}

Competitive nuclear power depends upon the realization of certain technological and economic successes, and an important part of the overall picture is the fuel cycle. With the development and demonstration of economically sound systems for reprocessing nuclear fuels as its stated objective, the AEC's Chemical Separations and Development Branch has supported comprehensive development programs at the Argonne, Oak Ridge, and Brookhaven National Laboratories.

The design of the first commercial reprocessing plant to be built, i.e., Nuclear Fuel Services, was based on the aqueous separations technology which had a history of use at government plants at Hanford, Savannah River, and Idaho Falls and major long-term technical support from ORNL, ANL, and BNL, as well as from the processing sites themselves. During the past several years, the AEC has also been sponsoring technical and scientific studies of a basically different group of processes aimed at recovering valuable uranium and plutonium by dry gas techniques. In essence, these nuclear fuels are volatilized as the hexafluorides, and most undesirable fission products are left behind. Purification from volatile fission products is accomplished by distillation or selective sorption.

Basic technology for recovering both high and low enrichment fuels by volatility methods has been and is being provided by the three National Laboratories already named. Particularly, at this writing, participating groups are fully occupied exploring the chemical and technical feasibility of the various process alternatives for handling low enrichment fuels. Laboratory development programs on high enrichment fuels are essentially complete.

During the past two years, the Oak Ridge Gaseous Diffusion Plant Technical Division has supported the main effort of the National Laboratories in two ways. First, conceptual plant studies have been performed, including economic comparisons of alternative volatility process flow sheets. These evaluations have attempted to define process problem areas and to point to the optimum route to a successful commercial enterprise. Second, a components development program has been initiated covering scale-up and testing of crucial process equipment and auxiliaries. In some cases, e.g., the process recycle compressor, the complete development and design program has been undertaken at the ORGDP.

The report which follows is primarily a summary presentation of the work carried out during fiscal years 1964 and 1965. Bimonthly progress reports have been issued regularly during this period to a limited AEC distribution. Henceforth, ORGDP work will continue to be reported bimonthily and summarized semiannually. 
SUMMARY

ENGINEERING STUDIES

Studies of the economic and technical feasibility of processes for recovery of fissile material from irradiated nuclear fuels are being performed at the Oak Ridge Gaseous Diffusion Plant to provide guidance for the associated laboratory and engineering experimental programs supported by the Chemical Separations and Development Branch of the Division of Reactor Development. The tangible result of such evaluations is the development of conceptual plant designs with associated costs accompanied by realistic appraisals of potential scale-up problems. Coupled with this engineering effort is a comprehensive systems analysis study designed to summarize the large number of process alternatives and problems and to indicate those work areas that should be emphasized in the integrated overall DRD program.

A brief resume of ORGDP feasibility studies (both completed and in progress) concerned with reprocessing of spent high enrichment uranium fuels and power reactor clad uranium dioxide materials appears in this report. Included also are more detailed calculations relating to specific problems, such as alumina bed usage economics, bed temperature rises due to. radioactively generated heat, criticality considerations for high and low uranium enrichment fuels, and cold trapping equipment.

Historically, the ORGDP participation began with the evaluation of processes for high enrichment fuels, since National Laboratory development programs were considerably more advanced for this class of fuel. The emphasis: has now shifted almost completely to the low enrichment power. reactor fuels.; however, much of the component.work and, to a lesser extent; the engineering analyses is applicable to ei.ther high.or low en-. richment materials.

HIGH ENRICHMENTT FUELS

Survey analysés were first made for classified fuel flow sheets, including both different volatility process approaches and comparison aqueous routes. These engineering evaluations of technology and economics were used for program planning purposes. The major conclusions were that volatility processes were at least competitive with aqueous routes and that the fluid-bed volatility approach coupled more versatility than the major competitor, molten salt processing, with a high probability of ultimate success. Additionally, fluid-bed processes were deemed to be more adaptable to power reactor fuel treatment, including plutonium recovery.

Accordingly, it was requested by the AEC that a definitive evaluation covering aluminum, zirconium, and graphite-base fuels and using the latest estimates of generation rate be performed for a fluid-bed volatility plant. This study is now in progress. 
LOW ENRICHMENT POWER REACTOR FUELS

The present volatility program emphasis is on developing processes for recovery of uranium and plutonium by volatilization as the corresponding hexafluorides from low enrichment zircaloy and stainless steel-clad fuels. Since it appears that the zircaloy-clad fuels may predominate in the future, the initial study is aimed at these materials.

Many decisions regarding basic technology application still remain to be made, as well as others involving more strictly economic optimization. The discussion in the body of this report covers selected alternative process routes which may be considered reference flow sheets, since they have been accepted by the participating groups as such.

\section{Zircaloy-Clad Fuel Process}

The present f'low sheet for zircaloy-clad fuel calls for removal of the clad by volatilization. with hydrogen chloride gas at about $400^{\circ} \mathrm{C}$. The reaction with the fuel charge takes place in a head end reactor containing a fluid bed of alumina grain. Pyrohydrolysis at $350^{\circ} \mathrm{C}$. is used in a second fluid bed to convert the zirconium and tin compounds to the oxide form for storage as solide. Although the oxide fuel fragments will be relatively unattacked by the hydrogen chloride, some radioactive material will be volatilized during the hydrochlorination; however, except for the noble gases, these substances are expected to be retained in the hydrolysis reactor bed. The uranium oxide fuel fragments remaining in the head end fluid bed are oxidized to a fine powder at about $400^{\circ} \mathrm{C}$, and the resulting uranium and plutonium oxides are fluorinated using elemental fluorine at temperatures graded from 400 to $550^{\circ} \mathrm{C}$. Since most of the elements comprising the bulk of the fission product activity and transuranic elements (except neptunium and plutonium) form nonvolatile fluorides which remain in the fluid bed, considerable decontamination of the uranium and plutonium is achieved by the volatilization as the hexafluorides. Plutonium tetrafluoride is produced by thermal decomposition of the plutonium hexafluoride in the absence of fluorine. The uranium hexaftuoride is then purified of remaining fission products and traces of plutonium and neptunium by distillation and sorption on magnesium fluoride and hot sodium fluoride.

Although much basic information remains to be developed with regard to this flow sheet sequence, ANL work to date has given a degree of confidence that plutonium can indeed be volatilized and transferred. The uranium recovery aspect certainly appears technically feasible; however, additional scale-up work is required.

Stainless Steel-Clad Fuel Process

The present preferred process for stainless steel-clad uranium dioxide fuels utilizes a hydrogen fluoride-oxygen gas at $600^{\circ} \mathrm{C}$. to spall of $\mathrm{f}$ the cladding in rusty fragments. The uranium dioxide pellets are concurrently broken up into fine powder and are converted to uranyl fluoride and uranium tetrafluoride. 
The uranium and plutonium recovery and purification aspects of stainless steel-clad fuel reprocessing would be about the same as for the zircaloy materials.

Interhalogen Flow Sheet

Flow sheets employing bromine pentafluoride for removal of the uranium are now being evaluated. Uranium salts can be readily converted to uranium hexafluoride with this reagent, while for thermodynamic reasons, plutonium hexafluoride should not be formed. Thus, a clean separation of uranium and plutonium in the fluid-bed fluorinator:should be possible, and simplifications in the product handling system may be achievable:

Several flow sheets involving different arrangements of the bromine halide recycle and uranium hexafluoride purification equipment are being considered.

Head End Fluid-Bed Reactor

A two-diameter fluid-bed reactor is contemplated for the conceptual plant unit. The lower section would be of small diameter to allow attainment of higher gas velocities for improvement of heat transfer and powder carryout during the oxidation of pellet fragments and reaction of other fuel constituent pieces. The larger, upper diameter permits insertion of the fuel charge and sufficient reduction of exit gas velocities to prevent excessive elutriation.

Radioactive Heat Generation

Radioactive heat generation poses a problem in (a) fuel charging machinery, (b) the fluid bed in removal of heat from newly charged elements should fluidization fail, and (c) the contaminated bed solids if bed caking or settling occurs. Calculations made for various possibilities indicate that temperature rise at the bed centerline can be generally assumed to be adiabatic for the contemplated plant reactor size:

One conclusion from the calculations is that temperature rise rates are large enough to impose significant problems, particularly with short cooled, high burnup material. Temperature rise rates on the order of 50 to $100^{\circ} \mathrm{C}$. per hour may be typical. Obviously, this is not a serious problem in the same way that a nuclear reactor transient hot spot might be; however, it would require corrective action to "unstick" the bed in a fairly short time, in chemical plant operating terms.

\section{Alumina Diluent and Bed Storage Costs for Power Reactor Fuel. Processing}

Calculations have been made relating to the economics of bed recycling, including alumina cost, fuel cooling time before processing, and waste storage investment, using bin storage costs developed at the Idaho Chemical Processing Plant. Ultimately, waste disposal might require different hardware; however, storage in bins appears most reasonable at present. The conclusion is that waste storage capital costs are of the same order of magnitude as the value of plutonium losises of $1 \%$. 
There is a sizable incentive from both waste storage and plutonium loss economic viewpoints of holding the ratio of diluent alumina used to uranium throughput as low as possible. Presently, the target value for this ratio is 0.4 .

\section{CRITICALITY CALCULATIONS}

High Enrichment Fuels

Criticality calculations are presented for highly enriched uranium. Considerable operational advantage is derived from elimination of hydrogeneous moderation from the process system, and the minimum critical mass for a uranium density of $3.2 \mathrm{~g} . / \mathrm{cc}$. or less appears to be in excess of $109 \mathrm{~kg}$.

Low Enrichment F'uels

Critical mass calculations for uranium dioxide pellet charges for dry systems and in the presence of liquid water are presented for uranium-235 assays of 2 and 5\%. According to the calculations, dry systems are inherently safe for these enrichments, since the infinite medium neutron multiplication constants are less than 1 . With liquid water present, however, criticality could be achieved with masses substantially less than those proposed for batch charges. Precautions in design, such as avoidance of water cooling for the reactor and use of temperature interlocks, will essentially eliminate the possibility of water accumulation in the equipment.

Plutonium

Critical mass calculations were made for plutonium oxide spheres reflected with alumina to provide orientation for problems involved in power reactor fuel reprocessing. At a plutonium density of $4.6 \mathrm{~g} . / \mathrm{cc}$. with a $50 \mathrm{~cm}$. alumina reflector and assuming all plutonium is as the 239 isotope, the critical radius was indicated to be $10.79 \mathrm{~cm}$. with a corresponding critical mass of $24.2 \mathrm{~kg}$. of plutonium.

COLD TRAPE

Batch desublimers (cold traps) are used to collect uranium hexafluoride from gas streams. To aid in the design of such units, a desublimer design digital computer program is being developed. Preliminary computer results agree well with available experimental data.

\section{PROTOTYPE TESTING AND EVALUATION}

Development work is proceeding in a number of areas where additional information is required for design of a production facility. Of primary importance is extension of the Argonne National Laboratory, Oak Ridge National Laboratory, and Brookhaven National Laboratory work on volatility processes by studies in larger equipment. In some cases, scaleup from relatively small experimental equipment may be possible; in 
others, tests in up to half or even full size reactors will be required. Also of major importance are materials of construction, outlet gas filters, product purification systems, remotely operable connectors, gas compressors, cold traps, and reactor fabrication procedures. As the work progresses, need for investigation in other areas may become apparent.

At the time the ORGDP program was started, the AEC's primary interest was in design and evaluation of plants for reprocessing high enrichment fuels. Therefore, the initial studies were made in problem areas concerned mainly with the hydrogen chloride-fluorination procedure for reprocessing zircaloy and aluminum alloy fuels. A small amount of experimental work was also done on the oxidatior fluorination method of processing graphite type fuels. With the change of emphasis to low enrichment power reactor fuel recovery, the ORGDP components program is now centered on the three-step hydrogen chloride decladding, uranium dioxide pellet oxidation, and fluorination method developed for zircaloy clad uranium dioxide fuels. As time permits, experimental studies related to the hydrogen fluoride-oxygen decladding procedure for stainless steel or zircaloy clad fuels are also being carried out.

Program results and status are summarized below.

MATERIALS OF CONSTRUCTION - CORROSION TESTING AND RELATED STUDIES

Because of the unusual sequence of atmospheres in a single system, only scant corrosion data are available in the literature. For this reason, exposure tests are being made to determine which materials are suitable for the various volatility processes described earlier. To date, nickel201 appears to be the only choice for a fluid-bed reactor in which fluorination is to be carried out at temperatures up to $550^{\circ} \mathrm{C}$. Nickel-200 has good corrosion resistance, but the ASME pressure vessel code allows nickel only as the low carbon nickel-20l at the temperature level of the process. Both nickels appear satisfactory from a corrosion standpoint for alternating hydrogen chloride-fluorine atmospheres. Tests, have not yet been made to simulate the conditions for the three-step hydrogen chloride plus oxygen-fluorine process for low enrichment zircaloy-clad fuels.

Duranickel, a nickel alloy containing a small amount of aluminum, is slightly less corrosion resistant to the hydrogen chloride-fluorine exposure than nickel-200 and nickel-201 but should be acceptable for flange material. Flanges should operate at a somewhat lower temperature than that required for the reaction vessel.

Corrosion rates of nickel-201, nickel-200, and Duranickel are also adequately low under the process conditions expected in the hydrogen fluorideoxygen fluorination process.

Commercially available porous nickel filter material has good corrosion resistance in alternating hydrogen chloride-fluorine atmospheres. Monel filters are satisfactory for the hydrogen fluoride plus oxygen-fluorine system. 
Corrosion resistance of all molybdenum and chromium containing alloys was relatively poor in both the hydrogen chloride-fluorine and the hydrogen fluoride plus oxygen-fluorine atmospheres.

\section{PROCESS AND REACTOR STUDIES}

The program in this area is related to the various chemical methods involved in converting reactor fuels to the desired volatile form. Since the chemistry of the various processes has in general been proved feasible by National Laboratory investigations, ORGDP work will be concerned mainly with establishing firm engineering information regarding reactor performance, configuration, and sizing. In the course of this work and during evaluation of system components, information on the flow sheet reactions will also be accumulated.

In conjunction with studies of filters f'or a high enrichment zirconium alloy element reprocessing system, tests were made which indicated that the small amount of oxygen contaminant in nitrogen or argon diluents will convert uranium metal to a finely divided oxide in the presence of hydrogen chloride and hydrogen. In other filter tests related to the hydrogen fluoride plus oxygen-fluorine process, a by-product of the filter investigation was a verification of the stainless steel oxidation results obtained at Argonie and Brookhaven National Laboratories.

To aid in the design of larger fluid-bed reactors for low enrichment fuels, fluidization of the various materials concerned is being observed in transparent columns. In one test, it was shown that complete separation of alumina and stainless steel oxidation residue by elutriation was not feasible. Removal of the coarse stainless steel oxidation products before fluorination would probably have made control of that step easier in addition to lowering fluorine costs and decreasing certain contaminants which form volatile fluorides, such as chromium and molybdenum.

Another study with a bed of simulated oxide pellets and alumina indicated that movement of the alumina diluent around most of the pellets was very poor. Channeling of a major portion of the gas through a small part of the bed was observed, thus indicating that heat transfer and gas contact problems may be serious in a large reactor during the pellet oxidation step. Although the total quantity of heat released by this reaction is relatively small (compared with the fluorination step), National Laboratory experience has shown that temperature excursions can still occur and that incomplete attrition of the pellets results.

A semiworks scale head-end fluid-bed reactor is being designed and will be constructed to study the decladding, fuel pellet oxidation, and fluorination operations. The unit will be 10 inches in diameter by 11 feet high with a 3-1/2-foot long, 5-inch diameter section at the bottom. The purpose of the reduced diameter of the lower portion of the bed is to provide a relatively high gas velocity through the settled bed of oxide fuel pellets, thus improving heat transfer and mobility of the alumina diluent. Tests will also be made without the 5-inch diameter section for purposes of comparison, and if indicated desirable, various gas 
entrance configurations will be evaluated, as well as different bottom section designs. Outlet gas cooling and filtering will also be studied in this system. In addition to the semiworks fluid bed, an 8-inch diameter Plexiglas unit is being assembled to study gas entrance configurations and to observe fluidization characteristics with various types of fuel modules.

\section{OUTLET GAS FILTER STUUDIES}

Studies are being made in a small fluid-bed loop to evaluate sintered metal filters for use in the fluid-bed reactor gas outlet. Both benchscale corrosion tests and fluid-bed tests indicate that commercially available sintered nickel filter material will withstand cyclic exposure to hydrogen chloride and then to fluorine at the expected temperatures. Fabrication of a tube by rolling and welding appears to be a problem, however, as all welds have cracked after exposure. Preliminary tests on a molded (seamless) tube made by the Purolator Corporation are encouraging.

A test was also made which showed that sintered Monel filter tubes are suitable for the hydrogen fluoride plus oxygen-fluorine atmospheres required for stainless steel clad ceramic fuels.

PRODUCT PURIFICATION, SORPTION-DESORPTION- SYSTEM.

As contemplated, a portion of the fission product contamination will. be removed from the uranium hexafluoride product by sorption on sodium fluorride heated to $400^{\circ} \mathrm{C}$. Further purification is also possible by sorbing all the uranium hexafluoride on sodium fluoride held at $100^{\circ} \mathrm{C}$. and allowing other impurities to pass through the bed. Studies are being made to determine the best type of sodium fluoride pellet to use for a batch sorber, to optimize both sorption and desorption. conditions, and to evaluate traps designed for production.use: At the present time, a temperature of 100 to $120^{\circ} \mathrm{C}$. appears best for complete sorption of the uranium hexafluoride, while $400^{\circ} \mathrm{C}$. is ample for desorption. All types of sodium fluoride pellets studied to date gradually break down into powder with repeated sorption-desorption cycles. Tests are also in progress to evaluate a production-scale pellet trap of annular design.

A fluid-bed system which àpears capable of continuously sorbing large quantities of uranium hexafluoride has been developed for another project at the ORGDP. The uranium hexafluoride-containing gas is passed through a stirred fluid bed into which sodium fluoride powder is added continuously. Essentially complete stripping of the uranium hexafluoride is effected, and the powder overflow is transported to a ribbon flight screw where it is heated to recover the uranium hexafluoride. The regenerated sodium fluoride is then returned to the fluid bed to complete the cycle. The pilot-plant unit has been operated for a sufficient time to show that the process is workable; additional studies are required to determine capacity and optimum operating conditions. 


\section{CONNECTORS}

Remotely operable connectors capable of maintaining gas-tight seals under process conditions will be required on major equipment items. Flange and gasket type seals utilizing double gaskets with a pressured buffer to monitor leakage are being considered for this use. Age hardened Duranickel appears to have adequate corrosion resistance and hardness for use as a flange with a nickel gasket. Preliminary temperature cycling tests in an inert atmosphere indicate that commercially, available Marman Conoseal flanges made of this material are satisfactory for the alternating high and low temperature conditions. In view of the high cost of these units, however, studies are in progress to evaluate standard flat-faced flange designs.

\section{COMPRESSORS}

To reduce reactant usage in a reprocessing plant, gas recycle will probably be used in both the hydrochlorination and fluorination steps. The only commercially available compressor which will meet the process requirements is the diaphragm type unit. Such a machine, a Corblin compressor, has been purchased and is undergoing performance tests.

The diaphragm compressor has several undesirable features for use in a remote maintenance plant. These are (a) amplitudes of vibration are inherently high, making use of flexible connectors mandatory; (b) periodic replacement of diaphragms is necessary; and (c) flow rates are easily affected by malfunctioning of the check valves or by accumulations of small amounts of gas in the hydraulic fluids. In addition, flow rates are basically low, and relatively large and expensive units would be required.

A potentially better compressor from the standpoints of initial cost and maintenance is the peripheral type which is being studied at the ORGDP for other applications. Performance data have been obtained which demonstrate that a two-stage peripheral machine utilizing a 10-inch diameter impeller operating at $11,000 \mathrm{rpm}$. will meet the requirements for hydrogen chloride and filuorine recycle syslems. In dadition to the impcllcro, the compressor will include a shaft seal and an externally mounted bearing system and driving motor. Tests indjcate that a low clearance bushing seal and grease packed high precision angular contact bearings should give satisfactory performance. A prototype unit is presently under construction and will be evaluated under process conditions.

\section{REACTOR FABRICATION PROCEDURES - WELDING STUDIES}

A procedure has been developed for making welds of nickel-201 rod which will meet the conditions specified in pressure vessel codes. 


\section{ENGINEERING STUDIES}

J. H. Pashley, D. L. Breton, D. I. Dunthorn

J. A. Iacovino, C. C. Littlefield, J. R. Merriman

Studies of the economic technical feasibilities of various processes for recovery of fissile material from irradiated nuclear reactor fuels are being performed to provide guidance for the associated development programs. These studies are aimed at arriving at conceptual plant designs with estimates of cost and evaluations of potential scale-up problems.

Coupled with this effort is a systems analysis program designed to summarize the large number of process alternatives, and problems and to in-. dicate work areas which should be emphasized in the integrated overall program.

Engineering studies for power reactor fuels and high uranium enrichment materials are described briefly in this report. Included also are more detailed calculations relating to specific problems, such as alumina bed usage economics, bed temperature rises due to radioactively generated heat, and criticality considerations for high uranium enrichment fuels.

Historically, the ORGDP development programs began with evaluation of processes for the high enrichment fuels. This followed logically from the National Laboratory volatility programs which had been largely aimed at the spent high enrichment fuels because of their relatively early availability for processing. It is not surprising, however, that the volatility technology, engineering, and experimental results for high enrichment fuels are, to a substantial degree, useful in the low enrichment power reactor fuel program.

\section{HIGH ETRICHMENT FUELS}

Engineering studies have been performed for the aluminum-uranium, zirconium-uranium, :and graphite matrix high enrichment fuels. Processing of these materials using the fluid-bed reactor systems bears many similarities to work for low enrichment fuels. The major difference is, of course, the necessity for recovering_plutonium from the low enrichment fuels. Technology, however, for low enrichment fuels processing has been relatively incomplete because much remains to be learned about plutonium hexafluoride handling and conversion to solid product.

Initial engineering analyses were carried out on the technology and economics of high enrichment fuel processing: because of the advanced 
"state-of-the-art". The analyses were used primarily for program planning purposes. The general conclusions were that volatility processes were at least competitive with aqueous routes and that the fluid-bed volatility approach coupled a high probability of ultimate success with more versatility than is available with the major competitor, molten salt processing. Additionally, fluid-bed systems were recognized to be more adaptable than the molten salt sequence to low enrichment fuel treatment for plutonium recovery.

Following these initial analyses, a more comprehensive study was undertaken covering hignly enriched aluminum, zirconium, and graphite base fuels and using the latest estimations of generation rate. This study is now in progress, and a few details relating to the processing schemes and time cycles follow.

The processes for both the aluminum and zircaloy fuels involve hydrochlorination to-remove the aluminum or zirconium and tin as volatile chlorides. The hydrochlorination off-gas is. fed to a fluid-bed pyrohydrolyzer for conversion of the clad compound to solid oxide in oxychloride form. The uranium remains behind as a nonvolatile chloride and may be fluorinated immediately or after treatment of the bed with hydrogen fluoride to replace the chloride with fluoride. This latter step is included to prevent generation of chlorine trifluoride or chlorine which could lead to problems in the off-gas caustic scrub system. Both single-vessel and multiple-vessel reactor lines are being considered.

Some fission products, notably zirconium, ruthenium, niobium, iodine, and the noble gases, are expected to be wholly or partly volatilized in the hydrochlorination. The zirconium, ruthenium, and niobium are expected to be retained in the pyrohydrolysis reactor bed, while the noble gases will pass through to the vent. Iodine may tend to accumulate in the hydrogen chloride recycle system until blown down to the neutralization system.

Technetium, ruthenium, molybdenum, and tellurium, as well as plutonium and neptunium, are the primary contaminants expected to be found in the reactor off-gases during fluorination. A combination of sodium fluoride and magnesium fluoride sorption is expected to be effective in removing these elements excepting tellurium. Although tellurium is expected to be partially removed by caustic scrubbing and exposure to hot nickel or carbon, it may pose a vent problem.

In the single-vessel process, hydrochlorination, hydrofluorination, and fluorination steps are all carried out in the same fluid bed. The multiple vessel line originally considered had three separate units, one for each chemical step; however, it is now felt that equipment use scheduling will permit both hydrofluorination and fluorination to be carried out in the same vessel.

Table I compares time schedules for the two schemes. In each case, three charges of elements are hydrochlorinated before hydrofluorinating for chloride removal in the single-vessel case or transfer to the hydrofluorinator-fluorinator in the multiple-vessel case. 
TABLE I

CYCLE TTMES FOR ZIRCONIUM AND ALUMINUM FUELS

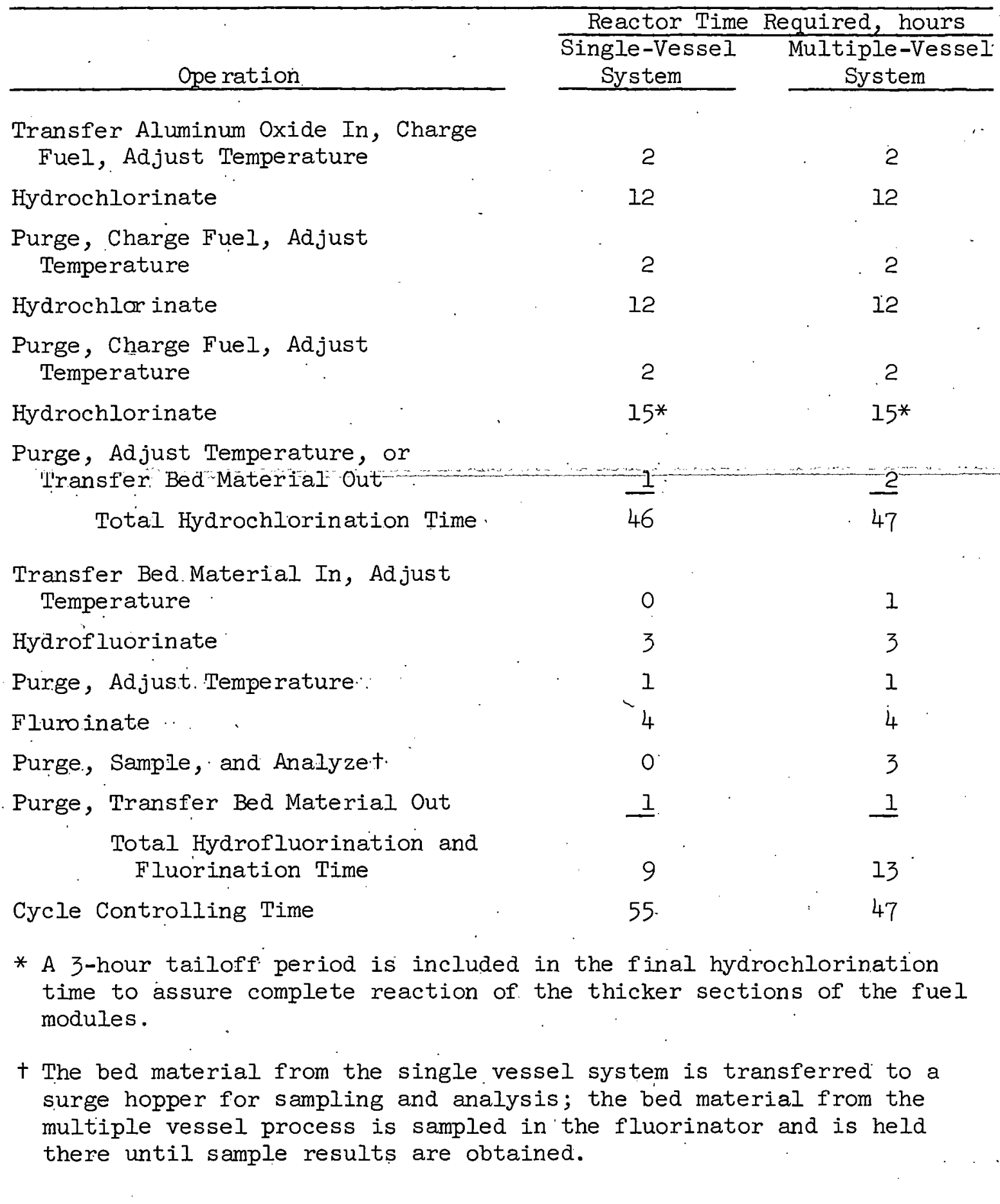


The overall cycle time for the single-vessel option is 55 hours. This allows processing of aluminum fuels in a single line at the rate of 5.13 $\mathrm{kg}$. of uranium per day. With an assumed load of 1,000 kg. of uranium per year from this source, about 195 on-stream days per year are thus required. Assuming only 260 on-stream days are available per year to allow for downtime for maintenance, inventory, and campaign accountability purposes, 65 on-stream days per year are left for the zirconium-base fuels. This appears sufficient, so a single line is used to handle both loads.

The overall cycle time for the hydrochlorinator in the two-vessel plant is only 47 hours. The hydrofluorinator-fluorinator reactor processing time is only 13 hours per overall cycle; thus, the hydrochlorinator scheduling i.s controlling. Using the same size reactor for the hydrochlorination step as in the single-vessel plant, the processing rate is $6.01 \mathrm{~kg}$. of uranium-235 per day for the aluminum fuels. This would apparently allow processing of about $17 \%$ more fuel in the two-vessel plant, thus making a nominal decrease in reactor size possible.

In the event that processing loads are increased, another possibility for the two-vessel flow sheet calls for one hydrofluorinator-fluorinator servicing two or more hydrochlorinators; however, this arrangement might be undesirable from the standpoints of accountability and criticality control. Perhaps the biggest advantage of the two-vessel system would be to remove some of the restrictions on the material of construction. For exumple, Inconel can be considered for use in both the reactor and porous metal filter systems for hydrochlorination if not subsequently exposed to fluorine. Sintered Inconel filter tubes have been used at AlvI in some of the hydrolyzer work. The corrosion performance of both porous and structural nickels may be improved if exposed only to hydrogen fluoride containing a small amount of hydrogen chloride and to fluorine. Monel may even be satisfactory for this last combination.

The graphite fuel reprocessing is best done in a separate line. The fuel may be broken into chunks and fed semicontinuously to a relatively small oxidizer fluid bed; i.e., perhaps 10 inches in diameter. Combustion proceeds readily at $700^{\circ} \mathrm{C}$, and little unconsumed graphite, other lhidn Hewly fed chunks, is present. When enough uranium has accumulated in the alumina diluent, the bed is transferred to a fluorination fluid bed. Most of the uranium comes off readily in fluorination; however, there is a decreasing rate at the end $\varepsilon \circ$ that several hours are required for the removal of the last few percent.

The present concept of a multipurpose volatility plant thus includes one reactor line for processing zircaloy and aluminum alloy fuels and a second reactor line for handling the graphite-base material. Each line would have its own specific auxiliaries, such as the pyrohydrolysis reactor and hydrogen chloride recycle for the zircaloy and aluminum alloy fuels and combustion off-gas system for the graphite-base materials. Since the lines would be expected to be ope rated at the same time during a substantial portion of the year, each would have its own cold trap system. 
Process flow sheets and conceptual equipment designs and layouts have been essentially completed. Estimates of cost and preparation of the report are in progress.

\section{LOW ENRICHMENT POWER REACTOR FUELS}

The present volatility program emphasis is on developing processes for recovery of uranium and plutonium by volatilization as the corresponding hexafluorides from low enrichment zircaloy and stainless steel-clad uranium dioxide power reactor fuels. Consistent with this goal, the major part of the engineering study effort is now being directed toward processes for the low enrichment fuels. Since it appears that the zircaloy-clad fuels may predominate in the future, the initial study is aimed at these materials. Before describing a tentative view of the conceptual plant system, a brief look at process alternatives is warranted. Figures 1 and 2 show the major potential flow sheet routes in simplified schematic fashion, omitting decisions which may be settled on an essentially economic basis; e.g., recycle requirements for gases and bed solids, process equipment necessities such as filters and heat exchangers, number of reactors in a processing line, and order of purification and recovery steps. The heavy connecting line shows the path of the present. reference 1 Iow sheet for the zircaloy-clad uranium dioxide fuels.

\section{Zircaloy-Clad Fuel Process}

In the present reference flow sheet for zircaloy-clad fuels, figure 3 , the initial processing step after mechanical removal of end hardware is hydrochlorination at $400^{\circ} \mathrm{C}$. with the fuel element(s) immersed in a fluidized bed of inert powder; i.e., alumina. This treatment volatilizes zirconium as the tetrachloride and tin. as the bichloride. Reaction with the uranium dioxide is expected to be minimal. The decladding off-gas is conducted to a second fluid-bed reactor where the volatile cladding compounds are reacted with water vapor at about $350^{\circ} \mathrm{C}$. to convert them to solids for ease in storage. Except for the noble gases and iodine, radioactive substances vaporized by the hydrochlorination would be expected to be fixed on the pyrohydrolysis bed material, thus leaving a relatively clean hydrogen chloride-containing effluent stream. Since the hydrogen chloride is not expected to attack the uranium dioxide to a significant degree, most of the fission product activity is not expected to be reacted. That remaining after fluorination could be volatilized in the subsequent hydrochlorination in the likely event that the bed material is reused. The hydrogen chloride consumed in the head-end fluid bed is reconstituted in the hydrolysis process and, along with the excess hydrogen chloride, may be recycled back to the head-end fluid bed.

After conclusion of the declad step, the uranium dioxide solids will be in an essentially static bed at the bottom of the reactor due to their high. density and relatively large size. A diluent oxygen stream is used to convert the uranium dioxide to fine urano-uranic oxide powder which will fluidize along with the diluent. The pellet breakup will also allow conversion of the plutonium and fission products to fine powders. Fluorine is used to react with these materials to produce the uranium hexafluoride 


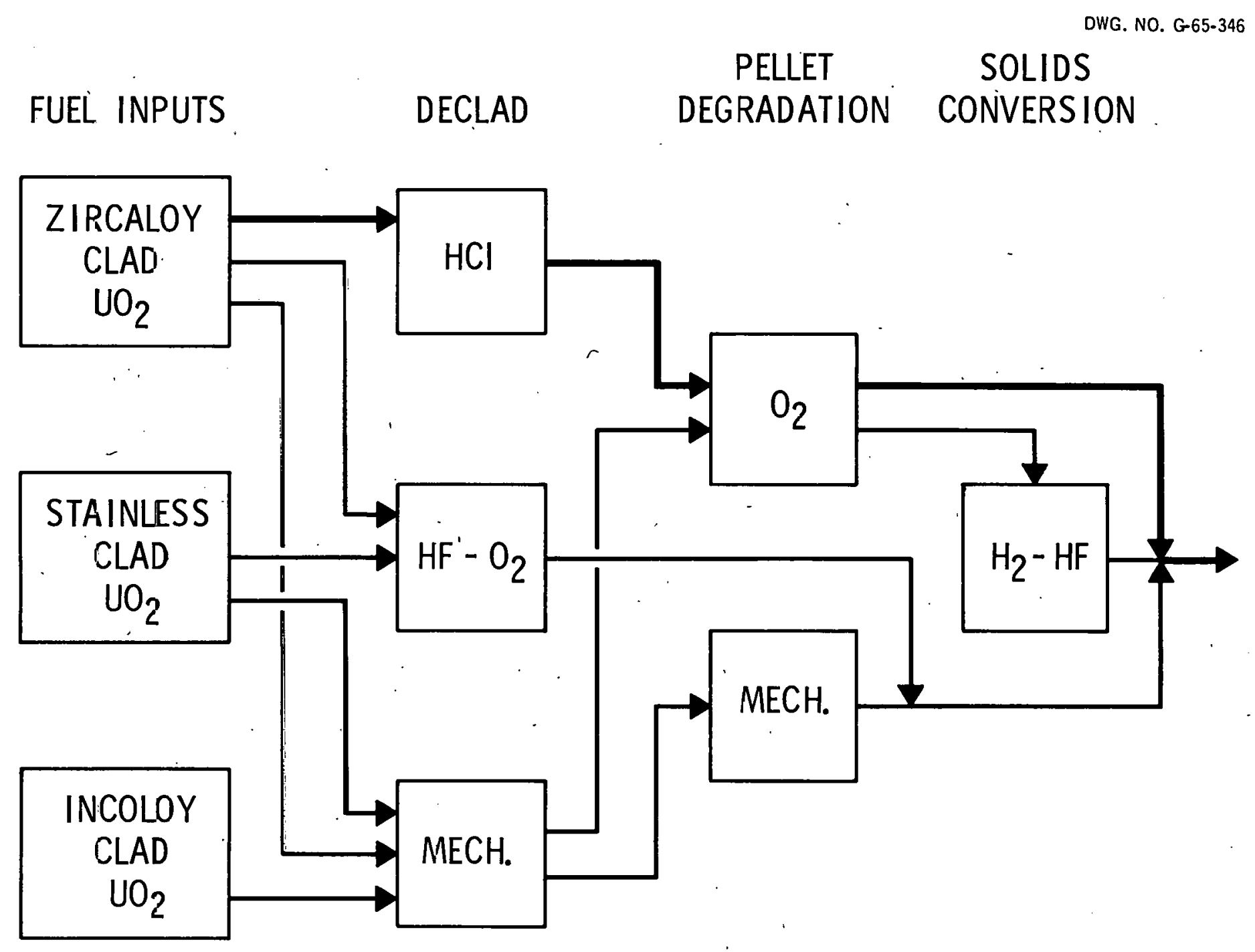

Figure 1

DECLADDING AND CHEMICAL PRETREATMENT 


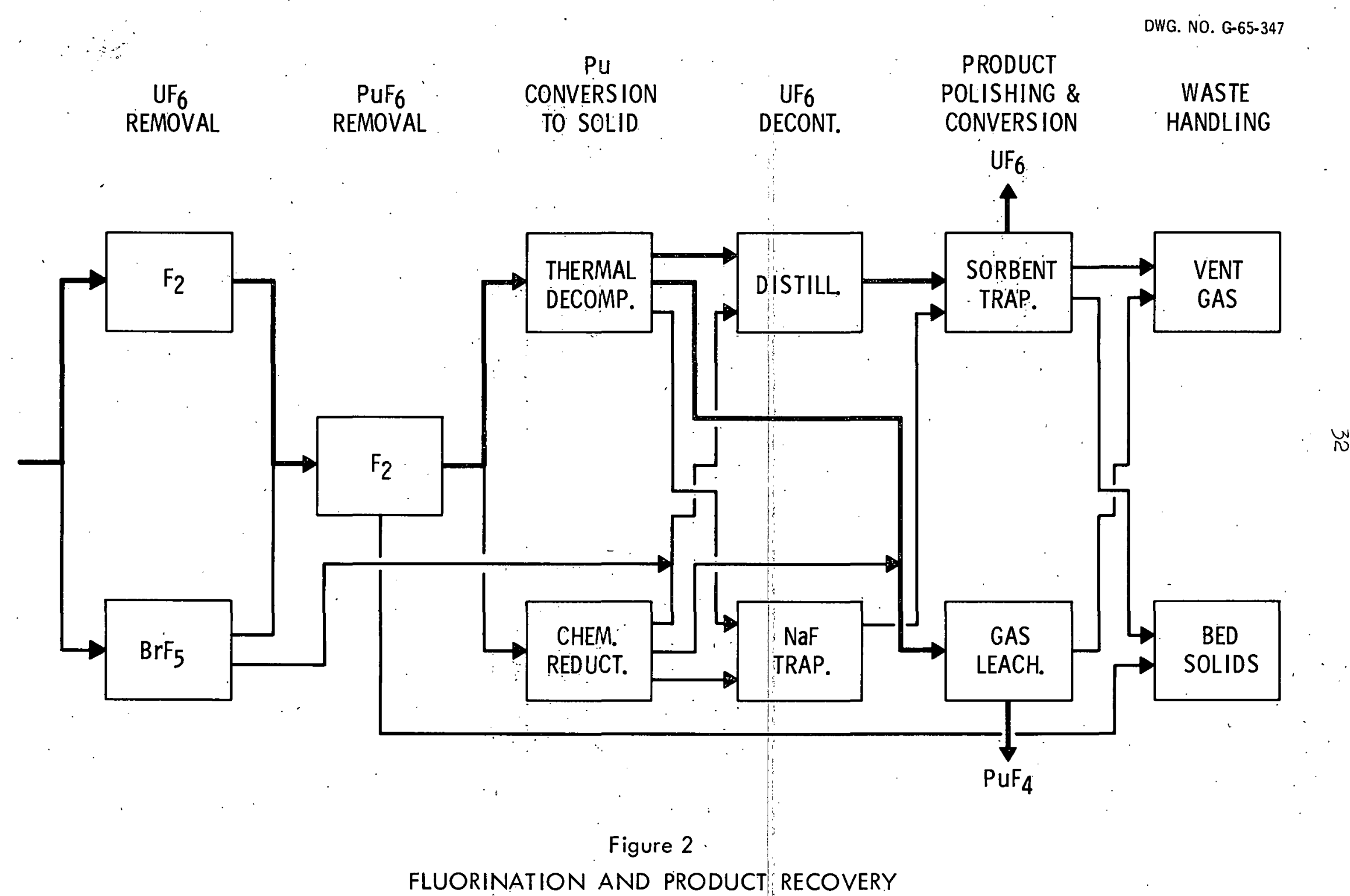




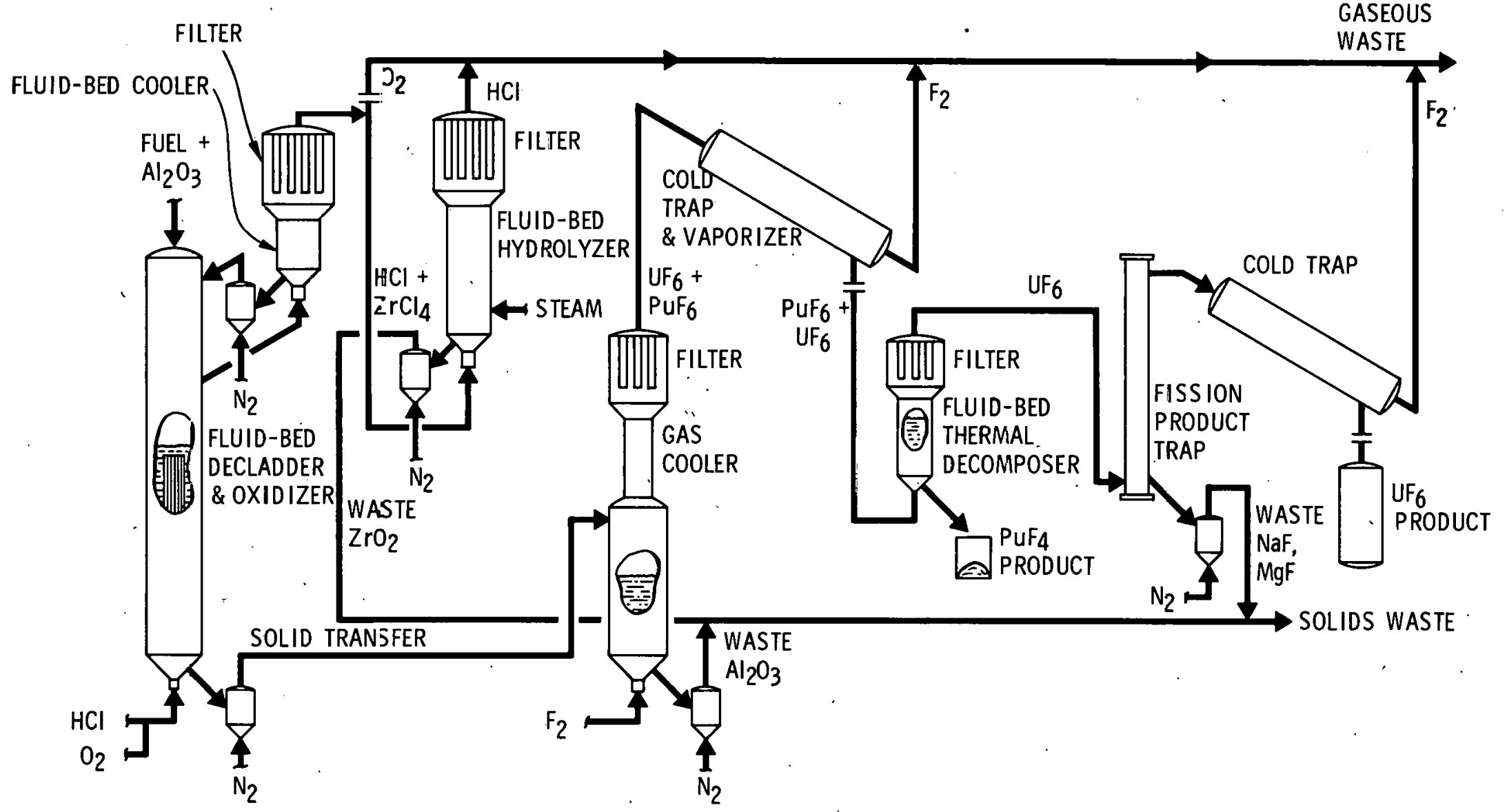

Figure 3

POWER REACTOR FUEL REPROCESSING PLANT 
and plutonium hexafluoride. The fluorination reaction is initially conducted at $400^{\circ} \mathrm{C}$. to remove most of the uranium along with a relatively small proportion of the plutonium. The temperature is then increased to 500 to $550^{\circ} \mathrm{C}$., and the remainder of the plutonium is volatilized.

As subsequently discussed in more detail, it is presently planned to use a two-diameter fluid bed such that high gas velocities can be utilized in the lower smaller diameter in which the pellets will fall after decladding. This high velocity should result in improved powder carryout and heat transfer in this zone, while at the same time, the velocity will be less in the upper bed section with the larger diameter so that excessive elutriation does not occur.

The product gas stream is passed through a cold-trapping system for removal of plutonium hexafluoride and uranium hexafluoride. The plutonium hexafluoride-uranium hexafluoride mixture, along with. fission product fluorides also removed at this point, is fed to a thermal decomposer in which plutonium tetrafluoride solid product is deposited. The uranium hexafluoride is then distilled, and the product fraction is passed through sorbent traps for final cleanup. The fission product streams from the distillation may be packaged for storage by chemisorption on a-suitable solid or by other suitable means.

Some basic information remains to be developea with regard to this flow sequence. The uranium processing aspect seems to be demonstrated from a technical standpoint, although additional information is needed for proper scale-up. The ANL work to date has also given a degree of confidence that the plutonium can indeed be volatilized and transferred. Additional effort will be required to show that actual fuel materials can be so treated and to provide better operational parameters. Further, studies of distillation of plutonium hexafluoride-bearing material and of the rmal decomposition for plutonium tetrafluoride production necessary to provide design data are incomplete. 'Fission product chemistry investigations on a process scale with irradiated fuel water are required to validate predictions as to which will be volatilized in each step and where these will come out in the process.

Stainless Steel-Clad Fuel Process

The present preferred process for stainless steel-clad uranium dioxide fuels utilizes a hydrogen fluoride-oxygen gas at $600^{\circ} \mathrm{C}$. to spall of $f$ the cladding and rusty fragments. The uranium dioxide pellets are con-. currently broken up by oxidation into fine powder and are then converted to uranyl fluoride and uranium tetrafluoride. The maximum reaction rate appears to occur when a $40 \%$ hydrogen fluoride concentration is employed; however, plant operation may require use of lower or higher concentration for reaction and heat release control. The clad is not volatilized except for a portion of the chromium converted to fluoride. A large part of the clad residue is relatively coarse, even containing slivers as long as $1 / 2$ inch or so. The degree of conversion of the clad and the uranium to oxyfluorides and fluorides depends on the length of exposure to hydrogen fluoride. The fluorination step proceeds readily enough, 
except that some difficulty may be encountered in control of reaction heat removal in the zone in which the coarse material accumulates. Use of the two-diameter fluid bed and careful control of the fluorine concentration in the early stages of the reaction should minimize operating difficulties. Fluorination breaks up the coarse clad material to a fine powder so that bed transfer should not be impeded.

The uranium and plutonium recovery and purification aspects of stainless steel-clad fuel reprocessing would be about as stated for the zircaloy materials.

\section{Interhalogen Flow Sheet}

Flow sheets employing bromine pentafluoride for removal of the uranium, as indicated by figure 4, are now being evaluated. The thermodynamics indicate that plutonium cannot be volatilized in significant amounts by reaction with bromine pentafl.uoride, while uranium can be essentially completely removed*. Plutonium would be volatilized by reaction with elemental fluorine in the subsequent step. Thus, a clean separation of uranium and plutonium in the fluid-bed fluorinator should be possible, and simplifications in the product handling system could be achievable as compared to that for the reference flow sheet which uses fluorine only. Additionally, the rate of fluorination of uranium salts with bromine pentafluoride is apparently faster than with fluorine, and the heat release is also lower. This last feature of use of bromine pentafluoride may not be exploitable in two-zone oxidation-fluorination, since the oxidation step may well be controlling. Against these advantages must be weighed the complications involved in having (a) an off-gas stream containing bromine pentafluoride, bromine trifluoride, and uranium hexafluoride; (b) a reaction system for conversion of bromine trifluoride to bromine pentafluoride; and (c) a sorption or distillation separation system for purifying the uranium hexafluoride from bromine compounds.

The use of bromine fluorides for nuclear fuel reprocessing had been studied previously but mainly for metallic uranium or alloy type fuels. From these efforts, data are available for many of the component propertiest, table II.

* Experimental studies are in progress at Argonne National Laboratory to verify this conclusion and provide kinetic data.

† Stoller, S. M., and Richards, B. B., editors, Keactor Handbook, Volume II, Fuel Reprocessing, Interscience Publishers, Inc., New York (1961). 
LOW BOILING

DWG. NO. G-65-348

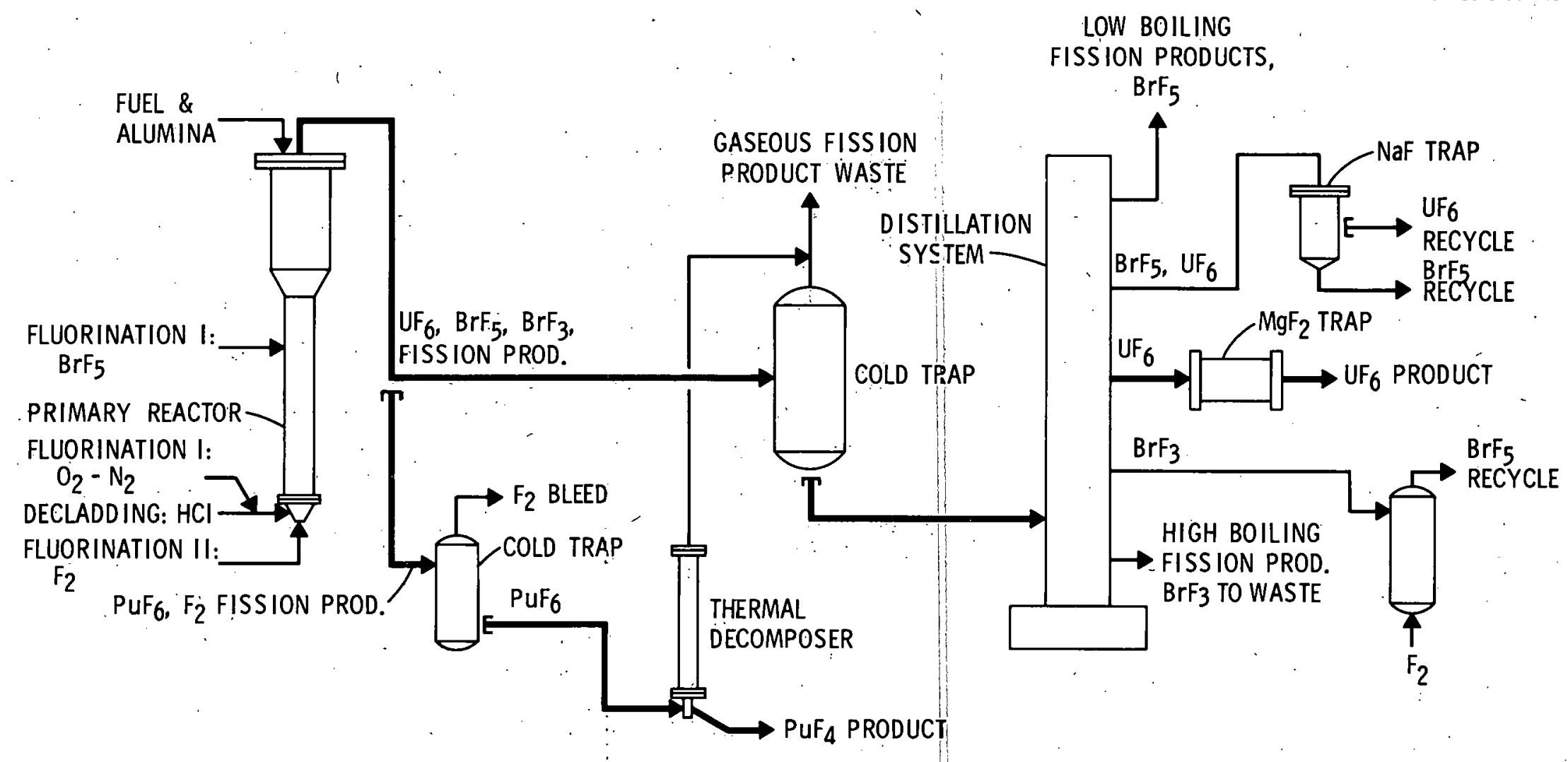

Figure 4

INTERHALOGEN REFERENCE FLOW SHEET 
TABLE II

PHYSICAL PROPERTIES OF

BROMINE PENTAFLUORIDE, BROMINE TRIFLUORIDE, AND URANIUM HEXAF LUORIDE

\begin{tabular}{|c|c|c|c|}
\hline Property & $\begin{array}{c}\text { Uranium } \\
\text { Hexafluoride }\end{array}$ & $\begin{array}{c}\text { Bromine } \\
\text { Pentafluoride }\end{array}$ & $\begin{array}{c}\text { Bromine } \\
\text { Trifluoride }\end{array}$ \\
\hline Molecular Weight & 352 & 174.92 & 136.92 \\
\hline Melting Point, ${ }^{\circ} \mathrm{C}$. & 64.02 & -60.5 & 8.77 \\
\hline Normal Boiling Point, ${ }^{\circ} \mathrm{C}$. & $56.54 *$ & 41.3 & 125.75 \\
\hline Triple Point Pressure, mm. H & 1137 & 1.7 & 2.4 \\
\hline $\begin{array}{l}\text { Critical Constant (estimated } \\
\text { Temperature, }{ }^{\circ} \mathrm{C} . \\
\text { Pressure, atmospheres }\end{array}$ & $\begin{array}{l}230 \\
45.5\end{array}$ & $\begin{array}{r}213 \\
47\end{array}$ & $\begin{array}{r}340 \\
70\end{array}$ \\
\hline Heat of Fusion, kcal./mole & 4.588 & 1.74 & 2.875 \\
\hline $\begin{array}{l}\text { Heat of Vaporization, } \\
\text { kcal./mole }\end{array}$ & 6.82 & 6.88 & 10.235 \\
\hline $\begin{array}{l}\text { Density, g./cc. } \\
\text { Solid } \\
\text { Liquid }\end{array}$ & $\begin{array}{l}5.06\left(25^{\circ} \mathrm{C} .\right. \\
3.67\left(64^{\circ} \mathrm{C} .\right.\end{array}$ & $\begin{array}{l}3.09\left(-61^{\circ} \mathrm{C} .\right) \\
2.4604\left(25^{\circ} \mathrm{C} .\right)\end{array}$ & $\begin{array}{l}3.23\left(8.8^{\circ} \mathrm{C} .\right. \\
2.803\left(25^{\circ} \mathrm{C} .\right.\end{array}$ \\
\hline $\begin{array}{l}\text { Solubility of Uranium } \\
\text { Hexafluoride in Bromine } \\
\text { Pentafluoride at }-40^{\circ} \mathrm{C} . \\
\text { g. UF } 6 / \mathrm{g} \cdot \mathrm{BrF}_{5}\end{array}$ & .0 .163 & - & - \\
\hline $\begin{array}{l}\text { Vapor Pressure of Pure } \\
\text { Component at }-40^{\circ} \mathrm{C} \text {, } \\
\mathrm{mm} \text {. Hgt }\end{array}$ & 0.3 & 8.5 & 0.05 \\
\hline \multicolumn{4}{|c|}{$\begin{array}{l}\text { * Uranium hexafluoride sublimes at normal atmospheric pressures. } \\
\text { t This should be about the same as partial pressure of solute above a } \\
\text { seturaled sulullun al lhis lemperdure. }\end{array}$} \\
\hline
\end{tabular}

Liquid-solid phase diagram information is available for the binary systems uran ium hexafluoride-bromine pentafiuoride and uranium hexatiuoridebromine trifluoride. Liquid-vapor equilibrium diagrams are available for the binary systems but not for low total pressures. Ternary phase equilibrium data have not been found in the literature. Based on the available data, the following comments can be made:

1. Cocurrent condensation of a liquid mixture of bromine pentafluoride, bromine trifluoride, and uranium hexafluoride with high recovery 
from a dilute gas stream requires that the bromine pentafluoride be in high concentration in the nix. For a reactor off-gas containing 3\% uranium hexafluoride, $10 \%$ bromine trifluoride, and $3 \%$ bromine pentafluoride, precipitation of uranium hexafluoride and bromine trifluoride would probably occur at temperatures not much below the uranium hexafluoride triple point; however, a mixture containing 90 mole percent bromine pentafluoride, 5 mole percent bromine trifluoride, and 5 mole percent uranium hexafluoride is expected to be a liquid at minus $30^{\circ} \mathrm{C}$, at which temperature, the total vapor pressure of the solution would be about $10 \mathrm{~mm}$. $\mathrm{Hg}$, and the uranium hexafluoride partial pressure would be about $1 \mathrm{~mm}$. $\mathrm{Hg}$. The freezing point of a liquid containing. $95 \%$ bromine pentafluoride and $5 \%$ uranium hexafluoride would, however, be about minus $53^{\circ} \mathrm{C}$, at which point, the uranium hexafluoride vapor pressure would be about $0.05 \mathrm{~mm}$. $\mathrm{Hg}$.

2. Continuous distillation of a bromine pentafluoride, bromine trifluoride, and uranium hexafluoride mix to produce purified uranium hexafluoride with high recovery would appear to require two columns, since the uranium hexafluoride is intermediate in volatility.

3. Obtaining a purified uranium hexafluoride product from the bromine pentafluoride-uranium hexáfluoride mix mà be relatively simple, since the relative volatility of bromine pentafluoride to uranium hexafluoride at the low bromine pentafluoride end exceeds two. Purifying the bromine pentafluoride from uranium hexafluoride by distillation will be more difficult but probably less important, since some recycle of uranium hexafluoride in this stream may be tolerated. British reports of an azeotrope at a significant uranium hexafluoride concentration are discounted by Argonne National Laboratory work*.

4. Stripping of the lower boiling bromine trifluoride from uranium hexafluoride to achieve concentrations of $1 \mathrm{ppm}$. brominet may require a considerable number of transfer units in a continuous distillation unit. Further data as to the activity coefficient of bromine trifluoride at the low bromine trifluoride concentration end may be need.ed.

5. Kinetics of conversion of bromine trifluoride to bromine pentafluoride by reaction in a gaseous state with fluorine are such that moderately high conversion efficiencies, i.e., 95 plus percent, may be obtained even from fairly dilute streams. Ultrahigh conversions, i.e., so that less than $1 \mathrm{ppm}$. bromine as bromine trifluoride (uranium basis) remains, may require a fairly large reactor or may even be prevented by equilibrium considerations. It appears that the best solution of the distillation problem would be to eliminate bromine

* Ellis, J. F., Johnson, K. D. B., J. Inorg. Nucl. Chem., 6, 194 (1958).

+ This is the present specification limit for return of uranium hexafluoride to the AEC. Recycle directly to fuel fabrication operations might allow a considerably higher specification limit and considerably ease the separation problem. 
trifluoride from the system by prior reaction possibly helped along by injection of some fluorine into the still reboiler to ensure reaction completion.

The selection of a process flow sheet depends not only on feasibility but also on economics. Accordingly, several flow sheet arrangements which are all thought to be technically feasible have been prepared for preliminary evaluation.

These flow sheets all presume hydrogen chloride decladding for removal of the zircaloy clad and then two-zone oxidation-fluorination, using bromine pentafluoride, for volatilization of the uranium. Plutonium would then be recovered by fluorination with elemental fluorine. The differences among the arrangements lie in the off-gas handling portion of the two-zone oxidation-fluorination step. The oxidation-fluorination operation in the main reactor would be essentially the same as before. except that bromine pentafluoride would be used, and thus no plutonium would be volatilized. The off-gas will be mostly oxygen and nitrogen with, on the average, about 3 mole percent uranium hexafluoride, 3 mole percent bromine pentafluoride, and 10 mole percent bromine trifluoride.

The variations are related to the location of the step for fluorination of bromine trifluoride to bromine pentafluoride in the process scheme, i.e., before and after separation of the cundensables from the head-end fluid-bed reactor off-gas, and to the selection of the major uranium hexafluoride purification process; i.e., sorption or distillation. An additional variant can be introduced depending on whether a flash coolercondenser requiring substantial amounts of bromine pentafluoride liquid recycle is employed to remove condensables from the gas stream at such high relative bromine pentafluoride concentrations that uranium hexafluoride and bromine trifluoride are dissolved. In some flow sheets, particularly if distillation is the purification method, this strategem would probably reduce the size of the necessary cold-trapping systems.

Work is in progress to complete the conceptual sizing of the equipment required for each of these flow sheets. Comparison of the equipment requirements will hopefully lead to elimination of some of the alternatives so that more detailed comparisons can be made, including the reference flow sheet using fluorine alone in this group.

Head-End Fluid-Bed Reactor

The fluid-bed halogenator is probably the key unit in the volatility process for power reactor fuels. It must serve satisfactorily in processing highly radioactive material through rigorous chemical treatment under conditions that are far from those usually considered ideal for fluidization. These conditions include the heterogeneous situation during decladding when the fuel bundle is immersed in the fluidized bed of alumina. Furthermore, for the zircaloy fuels, the oxidation of uranium dioxide takes place in a packed bed of fuel pellet fragments with the alumina grain fluidized in the interstices. 
In the first case noted above, the main question appears to be how freely the fluidized alumina bed and the gas move through the tube bundle. This circulation is necessary for both heat removal and reaction reasons. Test work to date has been limited and on a relatively small scale; i.e., nine tubes*. In the zircaloy-clad class, a single Dresden-type module has 36 tubes, and proposals are being made for still larger modules. Oyster Creek is scheduled to have 64 tubes per module. Stainless clad fuels have as many as 169 tubes per module. A production reprocessing batch charge for the zircaloy-clad fuels as presently contemplated would be on the order of 150 tubes. With nine tubes, the center tube has only one tube between it and the free bed. Thus, the dynamic and reaction situation of interior tubes located many rows from the free bed has probably not been achieved. The pellet oxidation studies have been mainly on a 3-inch diameter bed with some work on a 6-inch diameter unit.

As discussed in the component section that follows, a semiworks reactor intermediate in scale between the plant unit and the present test units has been proposed.

A two-diameter reactor is contemplated so that high gas velocities may be attained in the pellet oxidation zone while having a normal velocity in the upper portion of the bed. For example, the present conceptual plant reactor is 24 inches in diameter in the upper part of the bed which gives room for charging fuel elements side by side to a total of 500 to $1000 \mathrm{~kg}$. of uranium and allows operation with an outlet gas velocity less than $1 \mathrm{ft} . / \mathrm{sec}$. for the flow sheet gas quantities. At the same time, the lower portion of the reactor is only 1 foot in diameter which, after giving effect to pressure drop., still permits operation at 1.5 to 2.0 $\mathrm{ft.} / \mathrm{sec}$. gas velocity to aid in fines carryout from this zone. The smaller diameter also allows for a greater wall-area-to-bed-volume ratio for heat transfer.

Disadvantages of the two-zone approach that will have to be considered in the final optimization analyses are (a) an adverse effect from the greater overall reactor height on equipment and building expense, (b) the higher gas pressure drop that would be incurred, (c) possible compaction of the pellets at the bottom of the deep pellet bed, and (d) prevention of fines transfer from the deeper pellet bed to the upper fluid-bed zone by an impingement filtration action.

With regard to mechanical details, it appears that nickel is the leading and virtually only candidate material of construction on a corrosion resistance basis for a vessel in which hydrochlorination, oxidation, and fluorination are performed; i.e., where the single-vessel approach is used for the reactions in the fluid bed. If fluorination were carried out in a separate vessel, Inconel could probably be employed for the hydrochlorination and oxidation phases. The fluorinator would be a

* ANL experiments on a 25-tube bundle were scheduled as this report was in preparation. 
second fluid bed, and the process. would be called a two-vessel process. Either Inconel or nickel should have moderately good resistance to the hydrogen fluoride-oxygen gas mixture used for decladding stainless steelclad fuels.

For the single-vessel process, the present specification concept is that low carbon nickel will be used for surfaces in contact with the process. Welding will be performed using low carbon nickel rod and a modified Heliarc process. Except if needed for corrosion resistance, stress relief may not be required, particularly since the operating temperature will be near that used for stress relief. Inspection of welds will include dye penetrant and full X-ray. Pressure and leak testing will be required. The vessel design will be subjected to stress analyses per section III of the ASME code; however, stress values from section VIII will be employed.

\section{Radioactive Heat Generation}

Radioactive heat generation poses a problem in (a) fuel charging machinery, (b) the fluid bed in removal of heat from newly charged elements should fluidization cease in this area, and (c) the contaminated bed solids should fluidization fail for the whole bed.

Results of calculations covering. the centerline temperature rise rate for the settled alumina bed are given in table III. The 9-watt per liter case is valid for 1 to 2 bed cycles with fuel which has been cooled 130 . to 165 days after irradiation to 10,000 to 25,000 Mw.-day/metric ton of uranium. With the present shipping regulations, this much cooling time would probably be required for safety and economy. The 90-watt per liter. case was chosen to represent five bed recycles for processing the 30 -day cooled fuel. Since the bed material conductivity is not known, values of $0.25,0.5$, and $1.0 \mathrm{pcu} . / \mathrm{hr} .-\mathrm{ft} .{ }^{\circ} \mathrm{C}$. were used in the calculations. 
TABIE III

TEMPERATURE RISE IN A 20-INCH DIAMETER

SETTLED BED WITH VOLUME HEAT GENERATION

\begin{tabular}{|c|c|c|c|c|c|c|}
\hline \multirow{3}{*}{$\begin{array}{c}\text { Time, } \\
\text { hr. }\end{array}$} & \multicolumn{6}{|c|}{$\triangle \mathrm{T},{ }^{\circ} \mathrm{C}}$. \\
\hline & \multicolumn{3}{|c|}{$Q=9$} & \multicolumn{3}{|c|}{$Q=90$} \\
\hline & $\mathrm{k}=0.25$ & $k=0.50$ & $\mathrm{k}=\mathrm{I.0}$ & $\mathrm{k}=0.25$ & $\mathrm{k}=0.50$ & $\mathrm{k}=1.0$ \\
\hline 1 & 13.9 & 13.9 & 13.9 & 139 & 139 & 139 \\
\hline 2 & 27.8 & 27.8 & $27 \cdot 5$ & 278 & 278 & 275 \\
\hline 4 & 55.0 & 55.0 & 48.6 & 550 & 550 & 486 \\
\hline 8 & 113.9 & 97.2 & 70.5 & 1,139 & 972 & 705 \\
\hline 16 & 194.4 & 141.6 & 80.5 & 1,944 & 1,416 & 805 \\
\hline $\begin{array}{l}\text { Steady } \\
\text { State }\end{array}$ & 335.6 & 167.8 & 83.4 & 3,356 & 1,678 & 834 \\
\hline Notes: & $\begin{aligned} & \Delta \mathrm{T}=\text { Cen } \\
& \mathrm{k}=\text { The } \\
& \mathrm{Q}=\text { Hea } \\
& \text { Specific } \\
& \text { Density }\end{aligned}$ & $\begin{array}{l}\text { rline Tem } \\
\text { al Conduc } \\
\text { Generatio } \\
\text { eat used } \\
\text { ed was } 13\end{array}$ & $\begin{array}{l}\text { rature } R \\
\text { vity of } \\
\text { in Bed-, } \\
\text { s } 0.26 \text { p } \\
\text { lb./cf. }\end{array}$ & $\frac{{ }^{\circ} \mathrm{C} .}{1 / \mathrm{pcu} . / \mathrm{r}}$ & $-\mathrm{ft} .-^{\circ} \mathrm{C}$. & \\
\hline
\end{tabular}

For the first 4 hours, the centerline temperature rise is about that which could be calculated for adiabatic conditions. Accordingly, for this period of time for the centerline temperatures, the actual value of the thermal conductivity is not important so long as it is less than $1.0 \mathrm{pcu} . / \mathrm{hr}$.ft. $-{ }^{\circ} \mathrm{C}$, and it does not matter if the wall temperature is held constant; i.e., whether heat is removed at the wall or not. While it is not feasible to put an upper limit on allowable alumina temperature now because the èfect of solids residues (both radioactive and nonradioactive) on the caking tendency has not been established; it is reasonable that a temperature of perhaps $700^{\circ} \mathrm{C}$. would be limiting. If the charging commences with the bed initially at $400^{\circ} \mathrm{C}$., the numbers in table III indicate that the bed may be settled for 2 hours before centerline temperatures get too high, even with the higher power level alumina. It is also apparent that difficulties. with sintering and even alumina melting could occur under extreme circumstances with the lowest value assumed for thermal conductivity of the bed. Calculations were also made to determine the temperature rise rate for a module immersed in a settled bed. A machine program was written to compute rod temperatures for a fuel element having an even, square array with the element being immersed in a bed of greater diameter than the diagonal of the arráy.

Calculations were made for a pseudo-Westinghouse module, $14 \times 14$ rods in dimension. The module was considered to be immersed in a bed 16 inches in diameter; i.e., about 6 inches longer than the diagonal of the cluster. The bed was assumed to be initially at a uniform temperature of $350^{\circ} \mathrm{C}$. and to be cooled through the wall by a heat transfer media at a tempera- 
ture of $100^{\circ} \mathrm{C}$. with a heat transfer coefficient of $10 \mathrm{pcu} . / \mathrm{hr} .-$ sq.ft. $-{ }^{\circ} \mathrm{C}$. The bed conductivity was taken at $0.25 \mathrm{pcu} . / \mathrm{hr} .-\mathrm{ft} .{ }^{\circ} \mathrm{C}$. , and the density and specific heat again approximated those for alumina. Although the chosen model does not precisely duplicate the contemplated reactor sizing, i.e., a bed of about 2 feet in diameter containing two 173-rod clusters side by side, it is thought to be sufficiently close to provide usable information. The calculation results are given in table IV. The two cases simulate the 130- to 165-day cooled material in a bed recycled about two times and the 30-day cooled element in a bed recycled five times. Significantly, for both cases for the innermost rod, the temperature rise is essentially adiabatic for at least 6 hours. The adiabatic temperature rises per hour are about 78 and $228^{\circ} \mathrm{C}$. for case I and case II, respectively.

One conclusion from the calculations is that the temperature rise rates are large enough to impose significant problems, particularly with the shorter cooled, higher burnup material. Certainly the melting point of stainless steel, i.e., about $1400^{\circ} \mathrm{C}$., would be a circumstance resulting in unusual operating difficulty, and the sintering of bed material, perhaps $700^{\circ} \mathrm{C}$. or slightly higher, might be used as the restriction for more usual operating difficulty situations. A second conclusion is that calculation of adiabatic temperature rise rates is probably adequate for consideration of the problem; thus, much use of the machine program is not required. A few additional situations may be explored to determine the effect of use of a higher bed material conductivity, probably $k=$ 1 pcu. $/ \mathrm{hr}$. -ft. ${ }^{\circ} \mathrm{C}$, of smaller bed diameter, and of smaller modules. A memorandum has been prepared to cover in detail the radioactive heat generation calculations made to date.

Alumina Diluent and Bed Storage Costs for Power Reactor Fuel Processing

Calculations relating to the economics of bed recycling, including alumina cost, fuel cooling time before reprocessing, and waste storage investment using bin storage costs developed at the ICPP*, have been made. Some of the results are presented in table $V$. The $0.4 \mathrm{~kg}$. alumina per $\mathrm{kg}$. of uranium usage rate corresponds to about six bed recycles or, equivalently, a $16 \%$ drawoff after each cycle. 'l'he results in general indicate that, as might be expected, reduction of alumina usage is desirable from an economic standpoint. They also show that storage capital costs are of the same order of magnitude as the value of plutonium losses of $1 \%$, which is the presently envisioned process loss limit. For example, for a fuel containing $10 \mathrm{~kg}$. of plutonium per MTU, a high value for slightly enriched uranium fuels, a loss of $1 \%$ amounts to 100 grams per MTU, or about $\$ 1,000$ per MTU. Thus, the incentive for increasing alumina utilization may lie as much in reduction in waste storage costs as in further increases in plutonium' recovery efficiency.

* Stevens, J. I., An Economic Evaluation of Ultimate Disposal of-Liquid Radioactive Wastes by the Fluidized Bed Calcination Process, Phillips Petruleum Company, October 30, 1962 (IDO-14595). 


\section{TABLE IV}

ELEMENT TEMPERATURE TRANSTENTS IN SETTLED BED

FOR $14 \times 14$ PSEUDO-WESTINGHOUSE MODULE IN 16-INCH DIAMETER-BED*

\begin{tabular}{|c|c|c|c|c|}
\hline \multirow[b]{3}{*}{$\begin{array}{c}\text { Time, } \\
\text { hr. }\end{array}$} & \multicolumn{4}{|c|}{$\Delta \mathrm{T},{ }^{\circ} \mathrm{C}$. } \\
\hline & \multicolumn{2}{|c|}{ Case It } & \multicolumn{2}{|c|}{ Case IIf } \\
\hline & $\begin{array}{c}\text { Innermost } \\
\text { Rod } \\
\end{array}$ & $\begin{array}{l}\text { Outermost } \\
\text { Rod } \\
\end{array}$ & $\begin{array}{c}\text { Innermost } \\
\text { Rod } \\
\end{array}$ & $\begin{array}{l}\text { Outermost } \\
\text { Rod } \\
\end{array}$ \\
\hline 0 & 0 & 0 & - & 0 \\
\hline 0.5 & 40 & 36 & 115 & 109 \\
\hline 1.0 & 80 & 67 & 230 & 211 \\
\hline 2.0 & 160 & 117 & 460 & 401 \\
\hline 3.0 & 240 & 161 & 690 & 577 \\
\hline 4.0 & 320 & 202 & 920 & 745 \\
\hline 6.0 & 479 & 284 & 1,380 & 1,062 \\
\hline 8.0 & 638 & 366 & - & - \\
\hline 11.5 & 911 & 507 & - & - \\
\hline
\end{tabular}

* Rod diameter is 0.340 inch, and the rods are in a square pitch array with a center-to-center diatance of 0.452 inch. The actual element contains 173 rods with the same center-to-center spacing and rod diameter but with two offset rows accounting for the deviation. from a $13 \times 13$ array. The boundary condition employs a wall heat transfer coefficient of $10 \mathrm{pcu} . / \mathrm{hr}:-\mathrm{sq} . \mathrm{ft} . \mathrm{-}^{\circ} \mathrm{C}$. to a cooling media with a temperature of $100^{\circ} \mathrm{C}$. The starting condition is a uniform bed temperature: of $350^{\circ} \mathrm{C}$. The cooling was sufficient to reduce the wall temperature below $350^{\circ} \mathrm{C}$. in each case. The bed material is assumed to have a density of 135 pounds per cubic foot, a specific heat of 0.25 pcu./1b.${ }^{\circ} \mathrm{C}$. , and a thermal conductivity of $0.25 \mathrm{pcu} . / \mathrm{hr} .-\mathrm{ft} .{ }^{\circ} \mathrm{C}$.

t Heat generation in rods is equivalent to $1 \mathrm{kw}$. per $100 \mathrm{~kg}$. of uranium; heat generation in bed solids, 9 watts per liter. This may be considered to be the case for about two bed recycles for processing 130to 165-day cooled material.

* Heat generation in rods is equivalent to $2.81 \mathrm{kw}$. per $100 \mathrm{~kg}$. of uranium. Heat generation in bed solids is 90 watts per liter. This may be considered to be the case for perhaps five bed recycles for processing 30-day cooled material. 
TABLE V

ALUMINA USAGE ECONOMICS

\begin{tabular}{|c|c|c|c|c|c|c|}
\hline $\begin{array}{l}\text { Cooling } \\
\text { Time, } \\
\text { days } \\
\end{array}$ & $\begin{array}{c}\text { Heat } \\
\text { Release*, } \\
\text { Btu./hr.-MTU } \\
\end{array}$ & $\begin{array}{c}\mathrm{Al}_{2} \mathrm{O}_{3} \\
\text { Requirements, } \\
\mathrm{kg} \cdot / \mathrm{kg} \cdot \mathrm{U} \\
\end{array}$ & $\begin{array}{c}\text { Storage } \\
\text { Volume, } \\
\text { cu.ft./MTUt } \\
\end{array}$ & $\begin{array}{l}\text { Storage } \\
\text { Cost } \neq, \\
\$ / \mathrm{MTU} \\
\end{array}$ & $\begin{array}{l}\mathrm{Al}_{2} \mathrm{O}_{3} \\
\mathrm{Cost}, \\
\$ / \mathrm{MTU}\end{array}$ & $\begin{array}{l}\text { Total, } \\
\text { \$/MTU }\end{array}$ \\
\hline 30 & 87,000 & 0.4 & 8.5 & 1,037 & 160 & 1,197 \\
\hline 60 & 58,500 & 0.4 & 8.5 & 961 & 160 & 1,121 \\
\hline 90 & 45,000 & 0.4 & 8.5 & 893 & 160 & 1,053 \\
\hline 150 & 30,000 & 0.4 & 8.5 & 833 & 160 & 993 \\
\hline 30 & 87,000 & 1.0 & 19.1 & 1,967 & 400 & 2,367 \\
\hline 150 & 30,000 & 1.0 & 19.1 & 1,643 & 400 & 2,043 \\
\hline
\end{tabular}

* As estimated using PHORBE code for fuel with burnup of 10,000 Mw.days/MTU as a specific powder of $20 \mathrm{kw} . / \mathrm{kg}$. of uranium.

+ Based on 125 pounds of alumina per cubic ioot and 1.5 cubic feet of cladding fines per MTU.

\# Based on cost table in IDO-14595 and calculation of annular bin thickness assuming that $90 \%$ of fission product powder in feed goes to storage and that bed centerline-to-wall $\Delta T$ is $1000^{\circ} \mathrm{C}$. with a thermal conductivity of $0.3 \mathrm{Btu} . / \mathrm{hr} .-\mathrm{ft} .{ }^{\circ} \mathrm{F}$.

$\S$ Assuming cost of $\$ 0.40$ per $\mathrm{kg}$. of alumina.

It is also indicated that some storage cost saving may be made by processing longer cooled fuel; however, this saving apparently is not large enough to be economically controlling at the same waste volume. If processing of longer cooled fuel allowed reduction in waste volume, the economic significance would be much greater.

Finally, the cost of alumina is not a large factor for the $\$ 0.40$ per $\mathrm{kg}$. (or less) variety; however, one grade has been considered which would cost about $\$ 1.50$ per $\mathrm{kg}$. The cost differential for the more expensive alumina is certaint.y important at $1.0 \mathrm{~kg}$. of alumina per $\mathrm{kg}$. of uranium and is not insignificant at the 0.4 ratio. Nevertheless, use of the higher priced grade would well be justified if it can be employed through more recycles.

\section{CRITICALITY CALCUIATIONS}

High Enrichment Fuels

One advantage of a volatility process is that the critical mass for the poorly moderated systems is high relative to that for aqueous solution 
processing. Calculations were made for the purpose of estimating the critical mass for highly enriched uranium processing. The limiting case was considered to be the fully reflected sphere.

Accordingly, sizes and uranium masses for urano-uranic oxide spheres reflected with alumina or water were calculated for several values of $k$ ff from 0.9 to 1.0 . The uranium-235 density was taken as $3.0 \mathrm{~g} . / \mathrm{cc}$., which is felt to be the maximum conceivable value for the processes and fuels being considered. The DTK and DDK transport codes were used for the calculations. The results are given in table VI.

TABLE VI

CRITICAL SIZE OF URANO-URANIC OXIDE* SPHERES FOR DIFFERENT MULTIPLICATION FACTORS, $k_{\text {eff }}$

\begin{tabular}{|c|c|c|c|}
\hline $\mathrm{k}_{\text {eff }}$ & $\begin{array}{c}\text { Radius, } \\
\mathrm{cm} .\end{array}$ & $\begin{array}{l}\text { Uranium-235 } \\
\text { Mass, kg. }\end{array}$ & Reflector \\
\hline 1.00 & 24.58 & 186.6 & Water \\
\hline 0.95 & 22.68 & 146.6 & Water \\
\hline 1.00 & 21.08 & 117.7 & A-Iumina \\
\hline 0.98 & 20.58 & 109.5 & Alumina \\
\hline 0.95 & 19.80 & 97.55 & Alumina \\
\hline 0.90 & 18.60 & 80.86 & Alumina \\
\hline \multicolumn{4}{|c|}{$\begin{array}{l}\text { * Uranium is } 100 \% \text { uranium }-235 \text { at a density of } 3.0 \mathrm{~g} . / \mathrm{cc} \text {. } \\
\text { t The reflector thickness is } 30 \mathrm{~cm} . \text {, with water and alumina densities } \\
\text { of } 1.0 \text { and } 2.5 \mathrm{~g} . / \mathrm{cc} . \text {, respectively. }\end{array}$} \\
\hline
\end{tabular}

The reflected sphere at $3.0 \mathrm{~g} . / \mathrm{cc}$. uranium -235 density has been taken as the controlling case, since spheres or cylinders of lower uranium density have somewhat higher critical masses. The possibility of obtaining a sphere or sphere-like geometry with the assumed uranium density is thought to be very slim; accordingly, this assumption is probably quite conservative.

The results also indicate that, for the large reflector thicknesses used, spheres have somewhat lower masses for the same $k_{\text {ff }}$ for alumina reflection than for water reflection. Usually, the equivalent of the waterreflected situation might be expected to hold; however, pending analysis of possible effective reflection by furnace and vessel components, as well as alumina contained in the process vessels, the more restrictive aluminareflected cases are being used.

With the estimated potential calculation error of $2 \%$ in $k_{\text {ff }}$, the critical mass of uranium would appear to be greater than $109 \mathrm{~kg}$. As the uranium235 is diluted with uranium-238 to hold a uranium-235 density of $3.0 \mathrm{~g}$. $/ \mathrm{cc}$., the critical uranium mass will increase; however, the mass of uranium-235 required for criticality will decrease slightly. 
The calculations also indicate that, for either water or alumina reflection, the neutron spectrum is quite fast. For example, at $\mathrm{k}_{\mathrm{eff}}$ equal to 1 , $99 \%$ of the neutrons has an energy greater than $10 \mathrm{KEV}$.

Low Enrichment Fuels

During reprocessing of low enrichment nuclear reactor fuels by fluid-bed fluoride volatility methods, large quantities of uranium dioxide will be contained in the fluid-bed reactors proposed. Several calculations were made using the DTK transport code to determine nuclear properties of uranium dioxide systems for criticality control purposes*. In order to obtain mass limits, homogeneous mixtures of materials were assumed. The ultraconservative case where minimum critical masses result from optimum spacing of feed in a matrix arrangement was not employed. Such a condition is highly unlikely here, particularly considering the relatively small size of the fuel fragments and the random arrangement implied for dumped beds.

Since processing will take place in the dry state at elevated temperatures, assumption of water moderation is unnecessarily restrictive; therefore, neutron multiplication factors in infinite media, i.e., $\mathrm{k}_{\infty}$, are listed in table VII for mixtures containing alumina granules and pellets of uranium dioxide at 2 and 5\% uranium-235 enrichment.

TABLE VII

INFINITE MEDIUM NEUTRON MULTIPLICATION CONSTANTS FOR URANIUM DIOXIDE-ALUMINA MIXTURES

\begin{tabular}{ccc}
\hline $\begin{array}{c}\text { Uranium Concentration, } \\
\text { g./cc. bulk* }\end{array}$ & $\frac{k_{\infty}}{2 \% \text { Enrichment }}$ & 5\% Enrichment \\
\hline 8.814 & 0.551 & 0.843 \\
7.051 & 0.538 & 0.828 \\
5.289 & 0.552 & - \\
* The density of alumina was assumed to be $2.5 \mathrm{~g} . / \mathrm{cc}$. &
\end{tabular}

Since all the $k_{\infty}$ 's are less than 1 , a finite system containing any of the above mixtures presents no criticality problem according to the calculations.

* In the event that unirradiated or very short burnup fuels were processed, plutonium would be essentially absent; additional calculations for high burnup fuels are planned in which the largely compensatory effects of uranium-235 depletion and plutonium buildup are considered. 
As just noted, elevated temperatures and the sequence of processing steps, no water in liquid form should be present in the equipment. Nevertheless, computations were made in order to evaluate the "order-of-magnitude" of limits for uranium dioxide-water systems. Infinite multiplication factors were determined for uranium dioxide concentrations between 10 and 60 volume percent. In all cases involving 2 and $5 \%$ enrichment, $k_{\infty}$ was close to or greater than one.

The study was extended to include determinations of critical properties of geometric systems (cylinders and spheres) containing úranium dioxide pellets and water. The cylinder calculations assumed infinite length with $30 \mathrm{~cm}$. of water reflection. Critical radii are shown in table VIII.

TABL̀E VIII

$$
\begin{aligned}
& \text { CRITICAL RADII OF INFINITE CYLINDERS* } \\
& \text { CONTAINING URANIUM DIOXIDE-WATER MIXTURES }
\end{aligned}
$$

\begin{tabular}{ccccc}
\hline $\begin{array}{l}\text { Uranium Dioxide, } \\
\text { volume percent }\end{array}$ & $\begin{array}{c}\text { Uranium } \\
\text { Concentration, } \\
\text { g./cc. }\end{array}$ & 2\% Enrichment & 5\% Enrichment \\
\hline 60 & 5.765 & - & 29.80 \\
40 & 3.843 & 30.91 & 17.61 \\
30 & 2.882 & 25.67 & 15.28 \\
20 & 1.992 & 26.59 & 14.11 \\
10 & 0.9608 & - & 15.37 \\
* Reflected with $30 \mathrm{~cm}$. of water. & & & - \\
\hline
\end{tabular}

Table IX gives the critical masses and critical radii of several spheres containing uranium dioxide-water mixtures, assuming $30 \mathrm{~cm}$. of water reflection. The minimum critical masses appear to be about $370 \mathrm{~kg}$. of $2 \%$ enriched uranium at 21 volume percent uranium dioxide in water and $37 \mathrm{~kg}$. of $5 \%$ enriched uranium at 9.4 volume percent uranium dioxide in water. 
TABIE IX

CRITICAL SPHERES* OF URANIUM DIOXIDE-WATER MIXTURES

\begin{tabular}{|c|c|c|c|c|}
\hline $\begin{array}{l}\text { Uranium Dioxide, } \\
\text { volume percent }\end{array}$ & $\begin{array}{l}\text { Uranium } \\
\text { Enrichment, } \\
\text { Percent } \\
\text { Uranium-235 } \\
\end{array}$ & $\begin{array}{l}\text { Uranium } \\
\text { Concentration, } \\
\text { g./cc. } \\
\end{array}$ & $\begin{array}{c}\text { Critical } \\
\text { Radius, } \\
\mathrm{cm} . \\
\end{array}$ & $\begin{array}{c}\text { Critical } \\
\text { Mass, } \\
\mathrm{kg} \text {. of } \mathrm{U}\end{array}$ \\
\hline 25 & 2 & 2.402 & 33.93 & 393.02 \\
\hline 20 & 2 & 1.992 & 36.04 & 376.89 \\
\hline 15 & 2 & 1.441 & 41.65 & 436.1 \\
\hline 13 & 2 & 1.249 & 49.41 & 631.1 \\
\hline 15.5 & 5 & 1.489 & 19.68 & 47.54 \\
\hline 12 & 5 & 1.153 & 20.37 & 40.82 \\
\hline 8 & 5 & $0.768 \%$ & 22.81 & 38.20 \\
\hline 6 & 5 & 0.5764 & 26.72 & 46.06 \\
\hline
\end{tabular}

* Reflected with $30 \mathrm{~cm}$. of water.

When a $\mathrm{k}_{\text {eff }}$ of 0.90 is employed for mixtures of uranium dioxide pellets in water, computations indicate that a sphere containing 21 volume percent uranium dioxide at $2 \%$ enrichment should be limited to a radius of $25.88 \mathrm{~cm}$. The mass limit for the above set of conditions is thus $146 \mathrm{~kg}$. of uranium; i.e., the amount of uranium contained in such a sphere at the optimum hydrogen-to-uranium ratio. Likewise, a sphere with 9.4 volume percent uranium dioxide at $5 \%$ enrichment should have a radius of $17.60 \mathrm{~cm}$. and a mas's of $20.62 \mathrm{~kg}$. of uranium.

Since these critical quantities for liquid water-uranium dioxide mixtures are less than the conceptual design 'point batch charge of' about $500 \mathrm{~kg}$. of uranium, the contemplated precautions in design and the use of operating interlocks which will, to a satisfactory degree, prevent liquid water inter,jection appear to be mandatory. These precultions include use of air cooling for.the reactor and auxiliaries, and provision of sensor activated interlocks to prevent operation at temperatures which would allow liquid hydrogeneous material accumulation.

\section{Plutoniun}

Four critical mass calculations have been made for spherical plutonium salt assemblies reflected with alumina. The resultant numbers provide some orientation for critical mass problems involved in power reactor fuel processing. Table $X$ gives the results of these computations. At a reflector thickness of $50 \mathrm{cc}$. and a plutonium density of $4.6 \mathrm{~g} . / \mathrm{cc}$., the critical radius was $10.79 \mathrm{~cm}$, and the critical mass was $24.2 \mathrm{~kg}$. of plutonium. The total diameter of the core reflector assembly was about $123 \mathrm{~cm}$. The critical mass for the high density spheres of plutonium 
dioxide is about 20\% of that found for spheres of urano-uranic oxide with 3.0 grams of uranium per cubic centimeter.

TABLE X

CRITICAL MASS OF PLUTONIUM DIOXIDE SPHERES REF LECTED WITH ALUMINA

\begin{tabular}{lccc}
\hline $\begin{array}{l}\text { Plutonium } \\
\begin{array}{c}\text { Density* } \\
\text { g./cc. }\end{array}\end{array}$ & $\begin{array}{c}\text { Reflector } \\
\text { Thicknesst, } \\
\text { in. }\end{array}$ & $\begin{array}{c}\text { Critical } \\
\text { Radius, } \\
\mathrm{cm} .\end{array}$ & $\begin{array}{c}\text { Critical Mass } \\
\text { of Plutonium, } \\
\mathrm{kg} .\end{array}$ \\
\cline { 2 - 3 } 3.0 & 12.8 & $\frac{15.14}{43.6}$ & $\frac{109.8}{4.6}$ \\
4.6 & 12.8 & 17.86 & 27.1 \\
4.6 & 20.0 & 11.20 & 24.2
\end{tabular}

* The plutonium densities of 3.0 and $4.6 \mathrm{~g} . / \mathrm{cc}$. are based on 30 and $45 \%$ of the theoretical crystal density of plutonium dioxide, respectively. + The density of alumina reflector was taken as $2.5 \mathrm{~g} . / \mathrm{cc}$.

It should be realized that the assumed plutonium densities and reflector thicknesses may be unnecessarily restrictive. Additionally, it should be recognized that plutonium-239 was used for the calculation rather than the probably less reactive mixture of the 239, 240, 241, and 242 isotopes present in the irradiated low assay enriched uranium dioxide power reactor fuels.

\section{COLD TRAPS}

Final collection of uranium hexafluoride in any of the volatility processing methods will be accomplished by desublimation in a refrigerated heat exchanger; i.e., cold trap. Batch desublimers have been generally used for condensation of uranium hexafluoride as a solid since the inception of the uranium isotope separation program in the early $1940^{\prime} \mathrm{s}$. A design procedure* was worked out at that time which, in essence, is still being used. This procedure utilized the basic heat and mass transfer equations which were interrelated by the application of the Chilton-Colburm j-factor equations. One of the biggest difficulties was prediction of the holding capacity of a trap, since the point accumulation rates for the empty exchanger were assumed to hold to plugging without correction for the effects of the deposit or the increase in gas velocities. Experimental work on several sizes of traps of similar geometry, however, allowed formulation of empirical correction factors.

* Thompson, W. I., "Theory of Heat and Mass Transfer in Batch Condensation of Solids", Engineering Developments in the Gaseous Diffusion Process, U.S.A.E.C., Technical Information Service Extension, Oak Ridge, Tennessee, 1949 (NNES-II-16). 
Because of the emerging requirements for new cold trap designs for the uranium hexafluoride and plutonium hexafluoride in volatility programs, coupled with the ready availability of high speed data processing equipment, improvements to this historic procedure are now both justified and possible. Accordingly, a desublimer design digital computer program is being developed.

A series of checks of the computer program is being made for a 10-inch diameter, "egg-crate" type trap design*. This trap is employed in the facility used for reprocessing uranium scrap returns at ORGDP. The theoretical uranium hexafluoride capacity is being calculated for various inlet concentrations of uranium hexafluoride, noncondensable flow rates, and inlet temperatures. In the future, such investigations will be of importance in the design of cold traps, not only for uranium hexafluoride, but for other desublimable materials. Availability of ready calculation techniques will potentially allow study of the basic characteristics of desublimer designs at a much lower cost than pilot plant testi.ng.

Before such computer simulation studies can be accepted and given credence, it must, of course, be shown that the results are consistent with those observed on operating systems. Accordingly, comparison of available data from both experimental testing and production operation of various traps with corresponding calculated results is planned.

Preliminary results of calculations are shown in table XI. The estimated operating conditions for this size trap in the ORGDP scrap reprocessing area are inlet temperature, about $60^{\circ} \mathrm{C}$; flow rate, about 0.4 pound per mole inert per hour; and inlet concentration of uranium hexafluoride, about 15 mole percent. The calculated capacity for these conditions is lower than the reported operational experience of approximately 270 pounds of uranium hexafluoride, although it can be seen that calculations for somewhat lower uranium hexafluoride concentrations and somewhat higher noncondensable flow rates tend toward this figure. As with any other batch desublimation problem, assumptions made as to the thermal conductivity and, particularly, density of the deposit are relatively crucial in estimating batch capacity. Unfortunately, accurate information as to the values of these deposit characteristics for various conditions of deposition appears to he scarre.

* Such a trap is depicted in the following reference: Smiley, S. H., Brater, D. C., Littlefield, C. C., and Pashley, J. H., "Quantitative Recovery of Uranium Hexafluoride from a Process Gas Stream", Ind. Eng. Chem., 51, 191-196 (1959). 
TABLE XI

CALCULATED URANIUM HFXXFLUORIDE CAPACITY

FOR 10-INCH DIAMETER, "EGG-CRATE" TYPE COLD TRAP

\begin{tabular}{cccc}
$\begin{array}{l}\text { Inlet Uranium } \\
\text { Hexafluoride, } \\
\text { mole percent }\end{array}$ & $\begin{array}{c}\text { Inert } \\
\text { Flow Rate, } \\
\text { Ib. mole/hr. }\end{array}$ & $\begin{array}{c}\text { Inlet Gas } \\
\text { Temperature, } \\
{ }^{\circ} \mathrm{C} .\end{array}$ & $\begin{array}{c}\text { Uranium Hexafluoride } \\
\text { Holding Capacity* } \\
\text { pounds }\end{array}$ \\
\hline 15 & 0.4 & 60 & 218 \\
15 & 0.6 & 60 & 246 \\
15 & 0.4 & 40 & 233 \\
15 & 0.4 & 90 & 253 \\
30 & 0.4 & 60 & 211 \\
5 & 0.4 & 60 & 259
\end{tabular}

* Calculated using a nitrogen inert, trap cooling temperature of minus $48^{\circ} \mathrm{C}$., desublimed solid thermal conductivity of 0.1 pcu./hr. $-\mathrm{ft} .{ }^{\circ} \mathrm{C}$. , and bulk density of 135 . pounds per cubic foot.

More exact plant trap performance data will be obtained when the reprocessing system is next operated. Additionally, improvements are being made to the program which should increase calculation accuracy. 
PROTOTYPE TESTING AND EVALUATION

D. C. Brater, L. W. Anderson, P. S. Cates,

B. I. Geldmeier, H. L. Kaufman, V. H. Kiplinger

MATERIALS OF CONSTRUCTION - CORROSION TESTING AND RELATED STUDIES

For a commercial reprocessing facility, it may be desirable to use a single fluid-bed reactor for all types of low and high enrichment fuels. Thus, the reactor must be able to withstand the conditions for (a) the hydrogen chloride-fluorine procedure for high enrichment zircaloy and aluminum alloy fuels, (b) the hydrogen chloride-oxygen-fluorine process for low enrichment zircaloy-clad ceramic fuels, and (c) the hydrogen. fluoride plus oxygen-fluorine system for stainless steel and zircaloyclad ceramic fuels. Because of the high temperatures during oxidation, a separate system would be required for graphite-type fuels.

To evaluate various materials, tests are being conducted in a bench-scale controlled-atmosphere loop. Samples are sealed in an electrically heated vessel, and gas of the desired composition is passed through the system at a low rate. To minimize the possibility of inleakage, an all-welded system is used. Additional data are belng accumulated in conjunction with filter performance evaluation in a fluid-bed system. The results of the studies completed to date are presented in table XII. For convenience, the tests are divided into two groups, i.e., filter materials and flange and reactor materials, and will not necessarily be discussed in the numerical order shown in the table. Conditions expected for the high enrichment zircaloy and the low enrichment stainless steel-clad fuels have been studied to date. Tests with alternating hydrochlorination, oxidation, and fluorination atmospheres have been started to obtain data for the low enrichment zircaloy-clad fuel recovery process.

\section{Filter Matcrials}

In run 1 , samples of porous nickel and Monel filter materials and a porous alumina dịsc were subjected to cyclic expusures at $315^{\circ} \mathrm{C}$. to a mixture of zirconium tetrachloride, stannous chloride, hydrogen chloride, and hydrogen, and then to a fluorination atmosphere of uranium hexafluoride, fluorine, and nitrogen. These conditions are expected when high enrichment zircaloy fuels are reprocessed. Twenty-two cycles of alternating 16-hour hydrochlorinations and 4-hour fluorinations were made. As was anticipated, no apparent attack of the alumina was noted, while the Monel samples deteriorated extensively. Microscopic examination of the nickel sample indicated that it withstood the exposure well, as there was no evidence of cracking. Flow tests sliowed that the permeability was acceptable for filtering purposes.

Run 2 was made to investigate further the corrosion effects of hydrogen chloride and fluorine on sintered nickel filter material. Two samples cut from a Micrometallic type-G nickel bayonet filter tube were exposed 
TABLE XII

RESUTTS OF CORROSION TTESTS

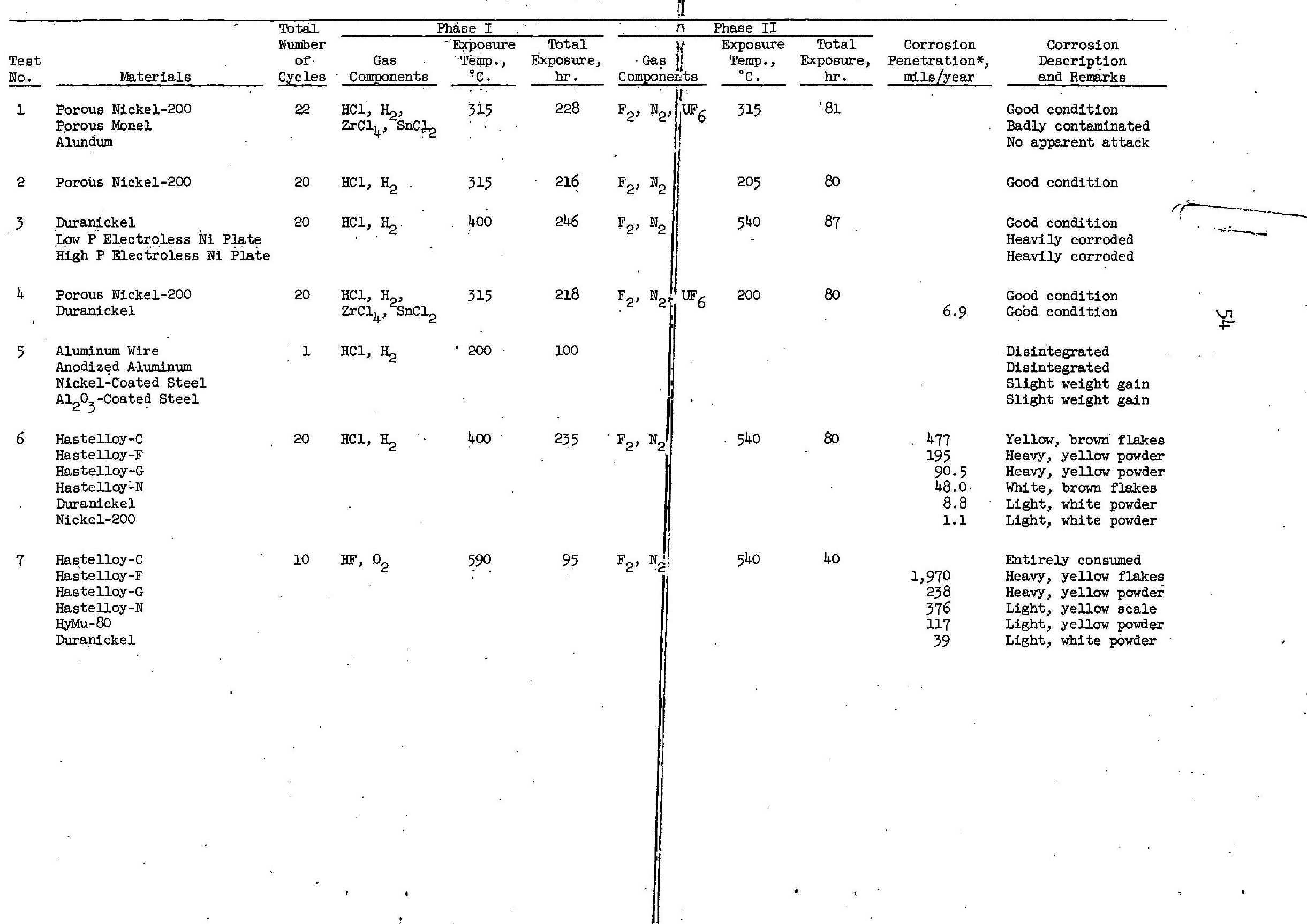


TABLE XII (Contd.)

RESULTS OF CORROSION TESTS

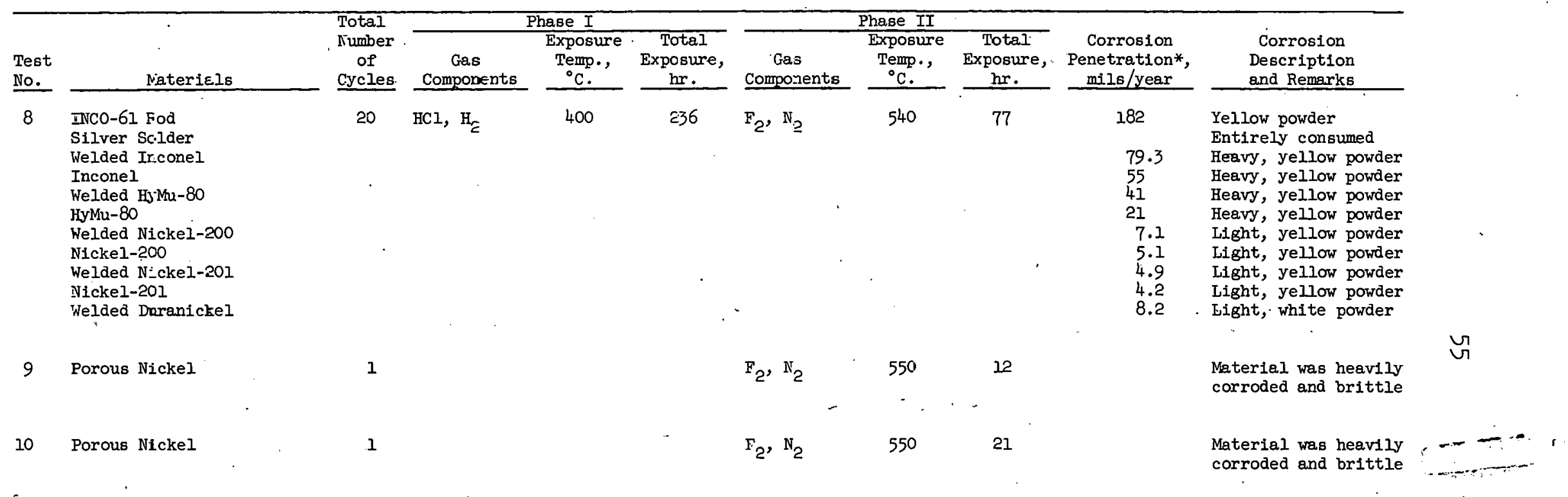

* Based on weight change and sample surface area. 
alternately to hydrogen chloride in hydrogen at $315^{\circ} \mathrm{C}$. and to dilute fluorine at $205^{\circ} \mathrm{C}$. for twenty cycles involving 80 hours of fluorination and 216 hours of hydrochlorination. The experiment was started with a fluorination cycle and was concluded after a hydrochlorination cycle. One of the porous nickel samples was subsequently fluorinated for 4 hours before analyses were made.

Visual inspection showed that both samples had darkened in color with a thin, reddish deposit on the bayonet weld area. Laboratory analysis of the sintered nickel showed $81 \mathrm{ppm}$. fluoride and $398 \mathrm{ppm}$. "chloride after hydrochlorination and $1,170 \mathrm{ppm}$. fluoride and $130 \mathrm{ppm}$. chloride after fluorination. These low fluoride and chloride values were considered acceptable for fluoride volatility applications. Flow measurements indicated a $20 \%$ plug of the material caused by the exposure treatment, but this loss is not considered serious. Figure 5 shows the grain structures of the exposed and unexposed samples involved in this test.

A qualitative spectrographic analysis of the reddish deposit on the areas and also of the weld material itself showed unexpectedly high concentrations of iron and manganese. Modification of vendor welding procedures may be necessary if this type filter is to be used.

Another study of the Micrometallic type-G porous nickel material was made in test 4 wherein samples were subjected to twenty cycles of exposures to hydrogen chloride, hydrogen, and zirconium tetrachloride at $315^{\circ} \mathrm{C}$. and to fluorine, uranium hexafluoride, and nitrogen at $200^{\circ} \mathrm{C}$. Small weight gains of less than $1 \%$ were experienced during this test, and again the sample appeared undamaged.

It was thought originally that, in a low enrichment fuel reprocessing facility, treatment of the fluoride volatility equipment periodically with fluorine at $550^{\circ} \mathrm{C}$. might be necessary to convert any reduced plutonium tetrafluoride in the system back to plutonium hexafluoride. One of the concerns of such a procedure was the effect of the treatment on the porous nickel filters. In test $9^{\circ}$, two samples of Micrometallic porous nickel were exposed to fluorine at $550^{\circ} \mathrm{C}$, one for 12 hours and one for 21 hours. Examination of the exposed materials, figure 6, showed that both samples were heavily corroded, had become very brittle, and were not acceptable as filter material. The present opinion of Argonne National Laboratory personnel is that the plutonium cleanup will be satisfactory at $350^{\circ} \mathrm{C}$. ; therefore, the test is to be repeated at that temperature level.

A problem which might be encountered in fluorinating a filter is that uranium deposits could react rapidly resulting in high localized temperatures and filter failure. Prediction of the magnitude of such a problem is difficult; however, it should be noted that, in a low enrichment zircaloy-clad fuel system using simultaneous oxidation and fluorination, uranium dusts should not reach the filter. Uranium accumulation on the filter would be expected with the present flow sheets for high enrichment alloy fuels and low enrichment stainless steel-clad fuels. Temperature measurements on the filter may be necessary to evaluate this 


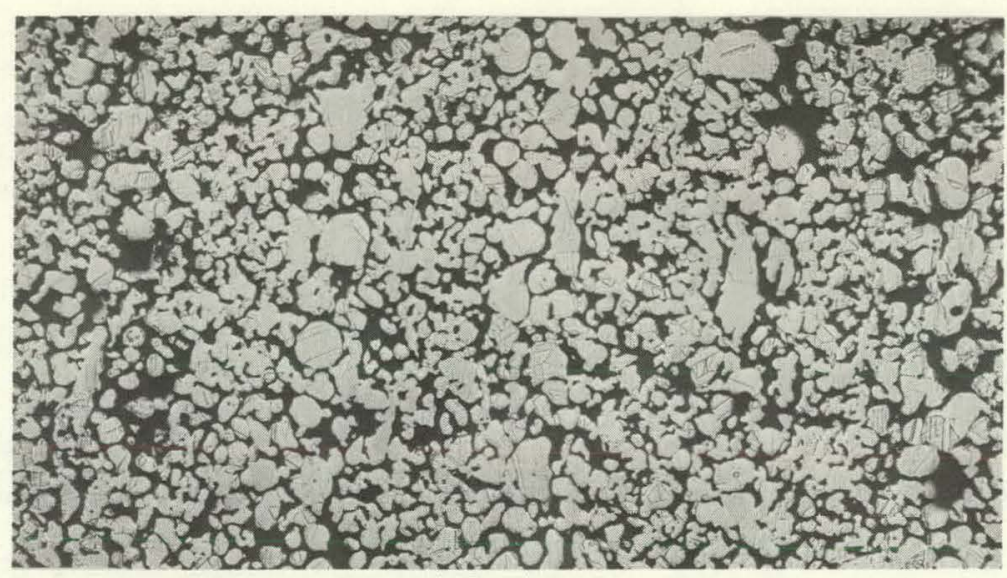

Unexposed

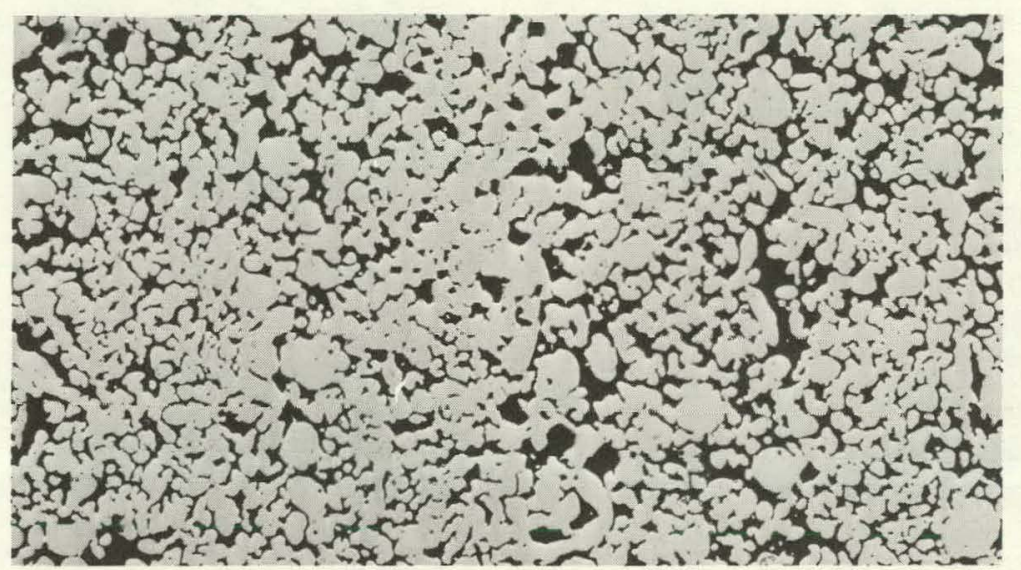

After Final $\mathrm{HCl}$ Treatment

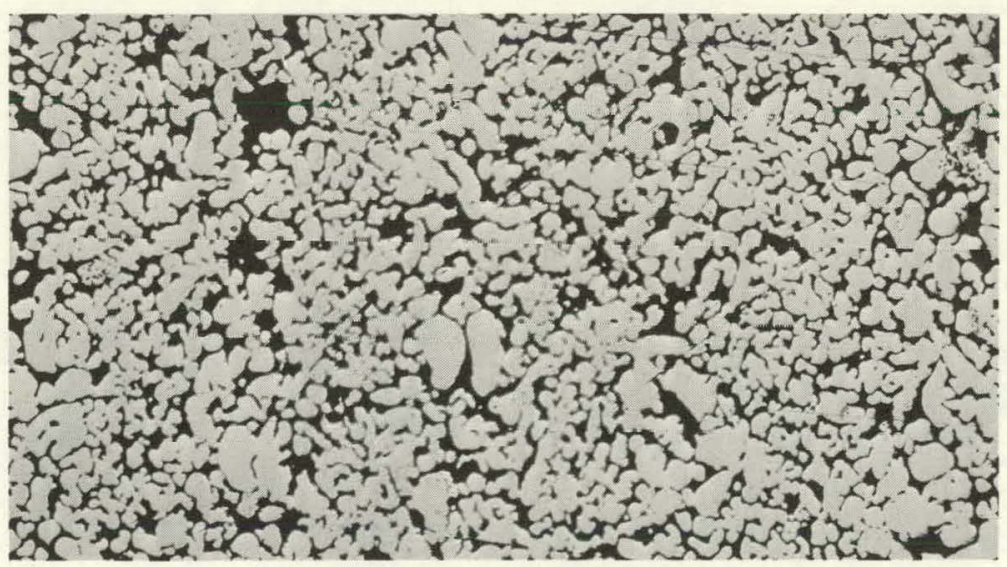

After Final $F_{2}$ Treatment

Figure 5

CORROSION OF POROUS NICKEL 
21 Hours

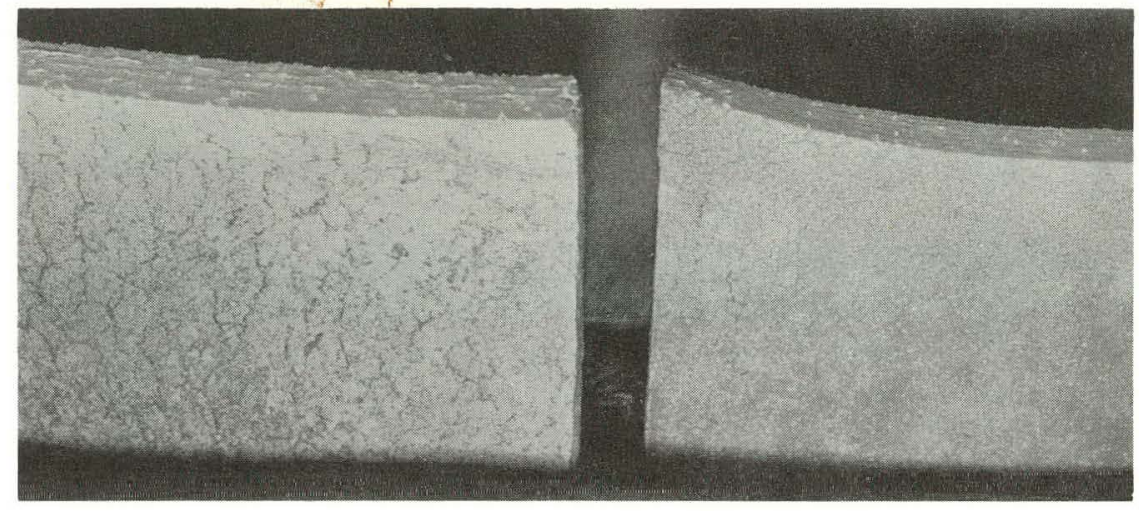

12 Hours

Exposure

Exposure

$1-1 / 4 \times$ Magnification

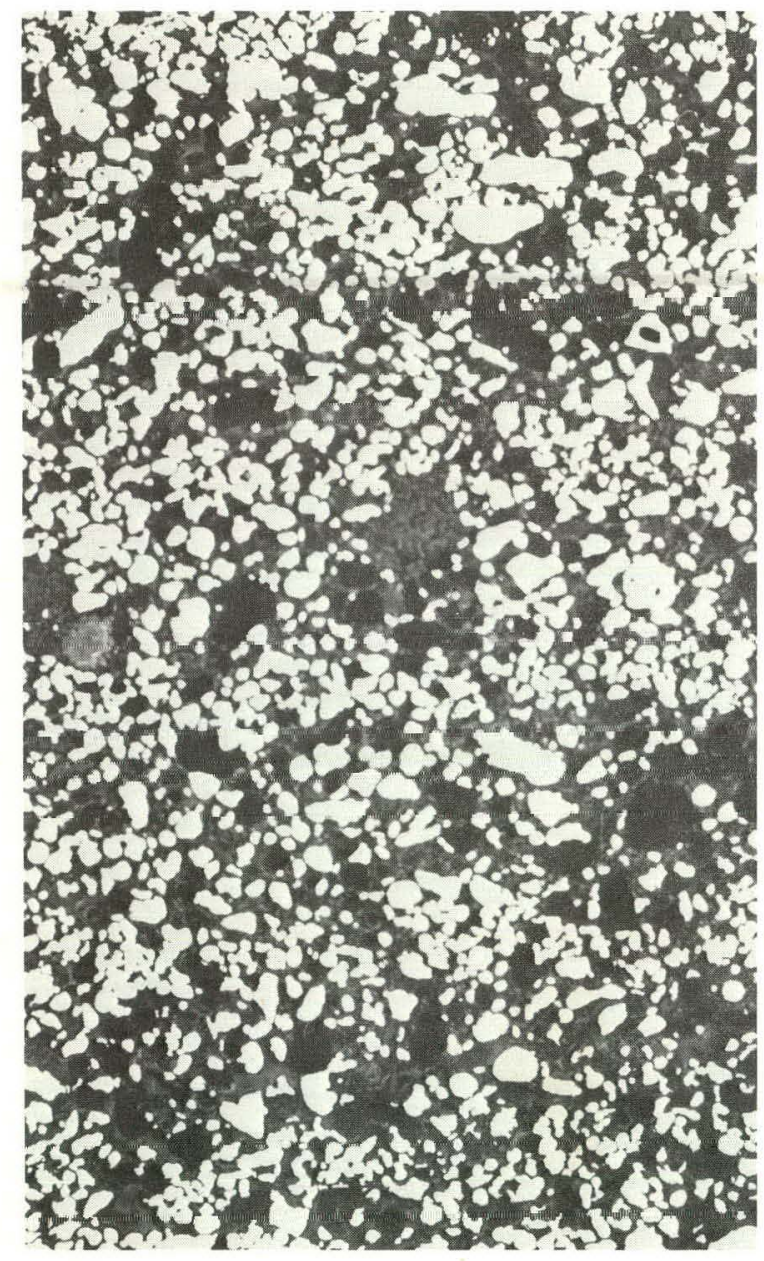

12 Hours Exposure

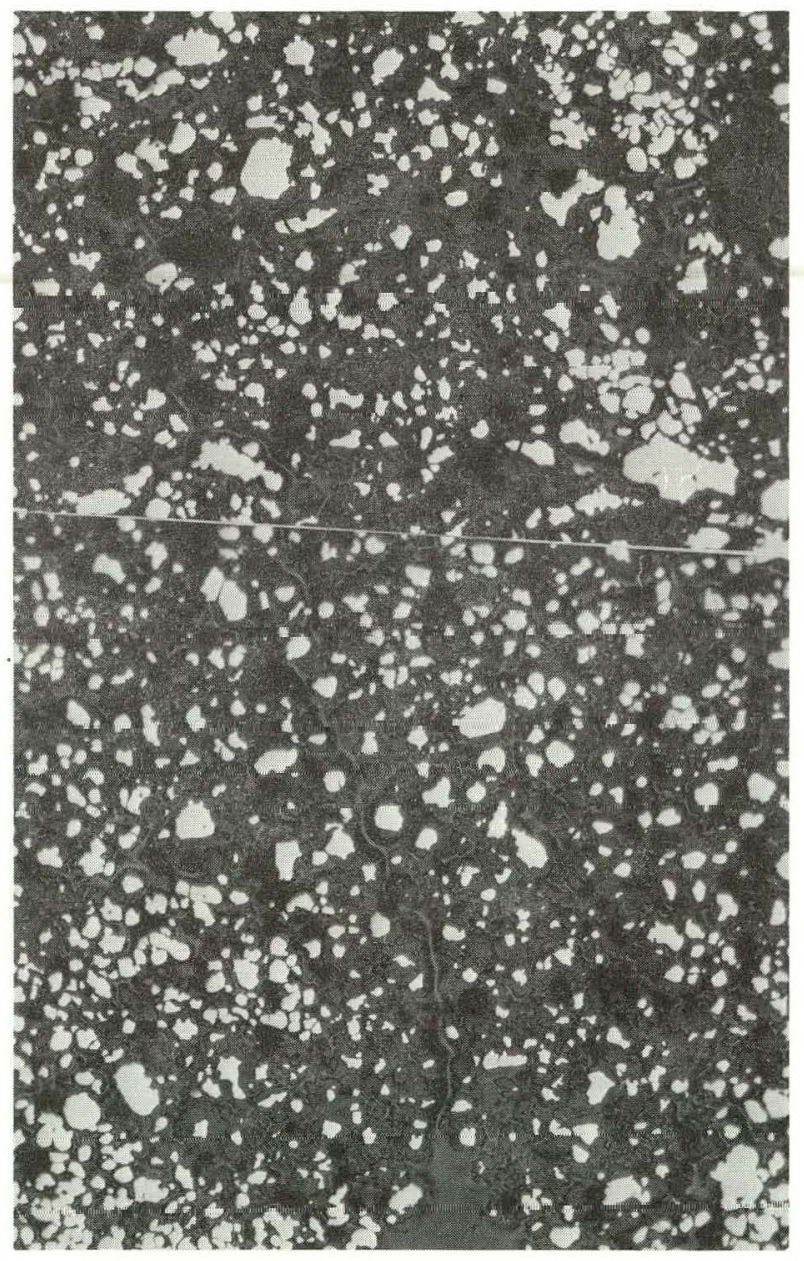

21 Hours Exposure

$50 \times$ Magnification

Figure 6

POROUS NICKEL EXPOSED TO FLUORINE AT $550^{\circ} \mathrm{C}$. 
problem.

One test was also made early in the program (not shown in table XII) to investigate the suitability of various filter materials for alternating oxygen-fluorine exposures, both at $315^{\circ} \mathrm{C}$. These atmospheres would be encountered in a volatility system for reprocessing graphite-type fuels. Sintered nickel, porous alumina, fine nickel wire, and nickel wool all appeared satisfactory.

Flange and Reactor Materials

The search for a hard surface for gasket compression in connector design for the process was the reason for test 3. Samples of Duranickel (a nickel alloy containing about 4-1/2\% aluminum), low phosphorus electroless nickel plate, and high phosphorus electroless nickel plate were subjected to cyclic exposures of hydrogen chloride in hydrogen at $400^{\circ} \mathrm{C}$. and dilute fluorine at $540^{\circ} \mathrm{C}$. Twenty cycles were completed involving 246 hours of hydrochlorination and 87 hours of fluorination.

Both of the electroless nickel plate samples became heavily corroded; thick, powdery deposits formed on the surfaces. Microphotographs, figure 7 , revealed that, while a considerable amount of the electroless plate remained after the exposure treatment, there was corrosion penetration into the plate.

The Duranickel sample withstood the corrosion attack well. A very light, white, powdery film was visible on the surface after exposure, and microphotographs, figure 8, showed a slight surface attack but no intergranular attack. These results were supported in subsequent tests, 4, 6, and 8, which indicate a corrosion rate of less than 10 mils per year under similar exposure conditions.

In test 5, parts of a proposed canned rotor pump having possible application for gas recycle during fuel reprocessing was subjected to a flow of hydrogen chloride in hydrogen at $200^{\circ} \mathrm{C}$. for 100 hours. As expected, samples of aluminum and anodized aluminum disintegrated. Steel and electroless nickel-plated steel parts darkened in color, but very little weight change was noted. Electroless nickel-plated steel plasma-coated with aluminum oxide appeared unaffected.

Tests 6 and 8 were made to evaluate possible materials of construction for the head-end fluid-bed reactor where high strength at elevated temperatures is required in addition to corrosion resistance. In test 6, samplcc of Hastelloy-C, Hastelloy-F, Hastelloy-G, Hastelloy-N, Duranickel, and nickel-200 were exposed to cyclic hydrochlorination at $400^{\circ} \mathrm{C}$. and fluorination at $540^{\circ} \mathrm{C}$. The corrosion penetration of the Hastelloys was found to be high compared with Duranickel and nickel-200 under the conditions of the test.

In test 8, samples of silver solder, INCO-61 welding rod, welded and unwelded Inconel, HyMu-80 ( $80 \%$ nickel, $4 \%$ molybdenum, and 16\% iron), nickel-200, and nickel-201 were subjected to twenty cycles of alternating 


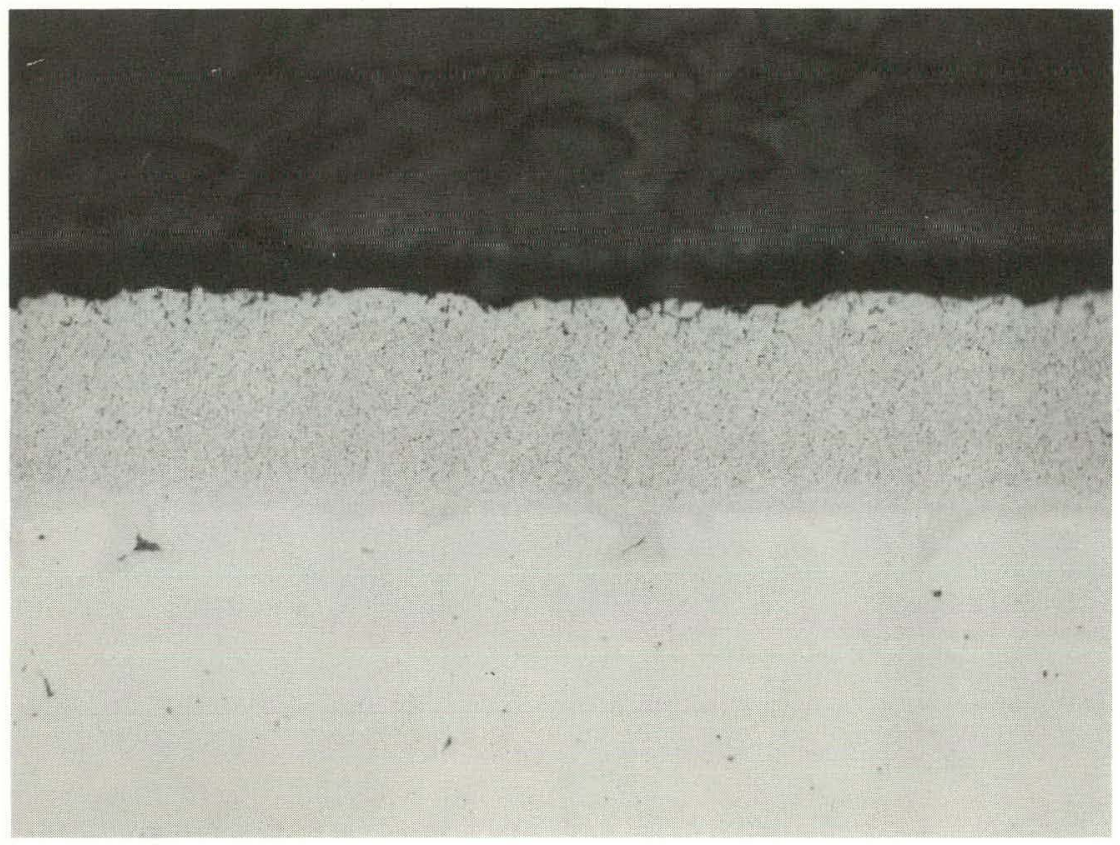

Plastic

Corrosion Product

Nickel Plate

Substrate

Magnification $500 \mathrm{X}$

High Phosphorus

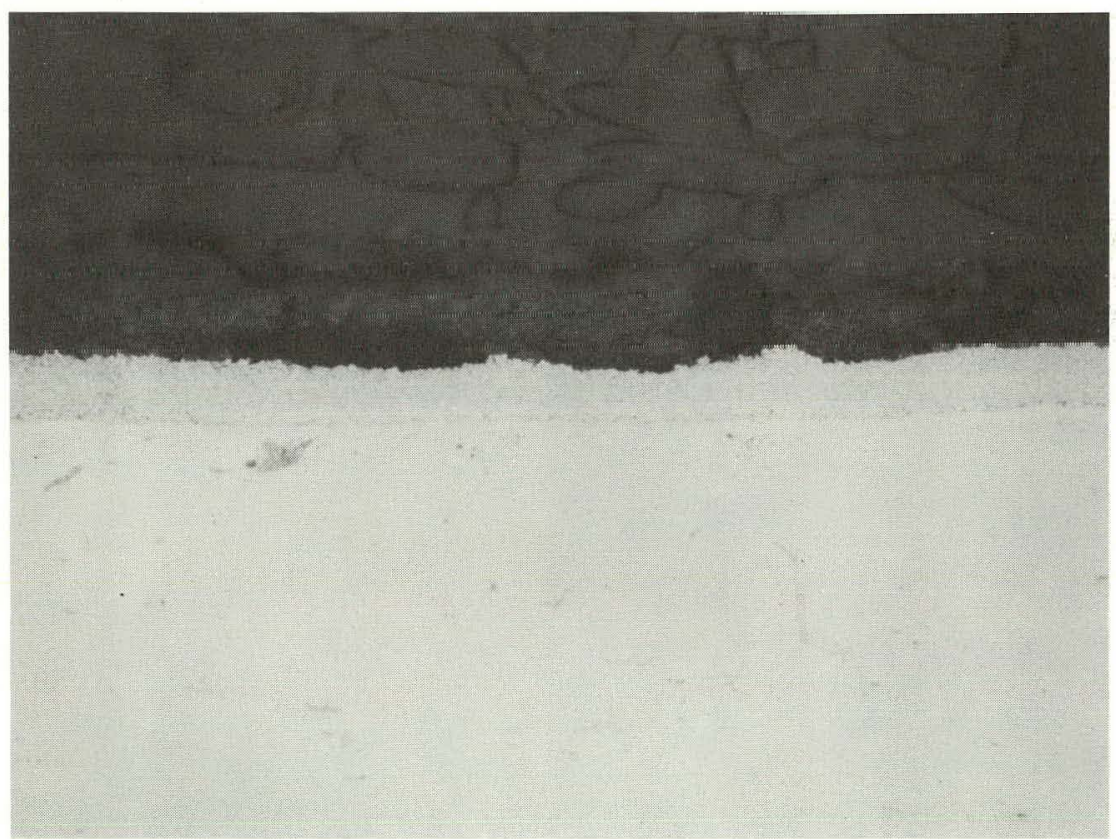

Plastir

Corrosiun Product

Nickel Plate

Substrate

Low Phosphorus

Magnification $500 \mathrm{X}$

Figure 7

ELECTROLESS NICKEL PLATE CORROSION ATTACK 


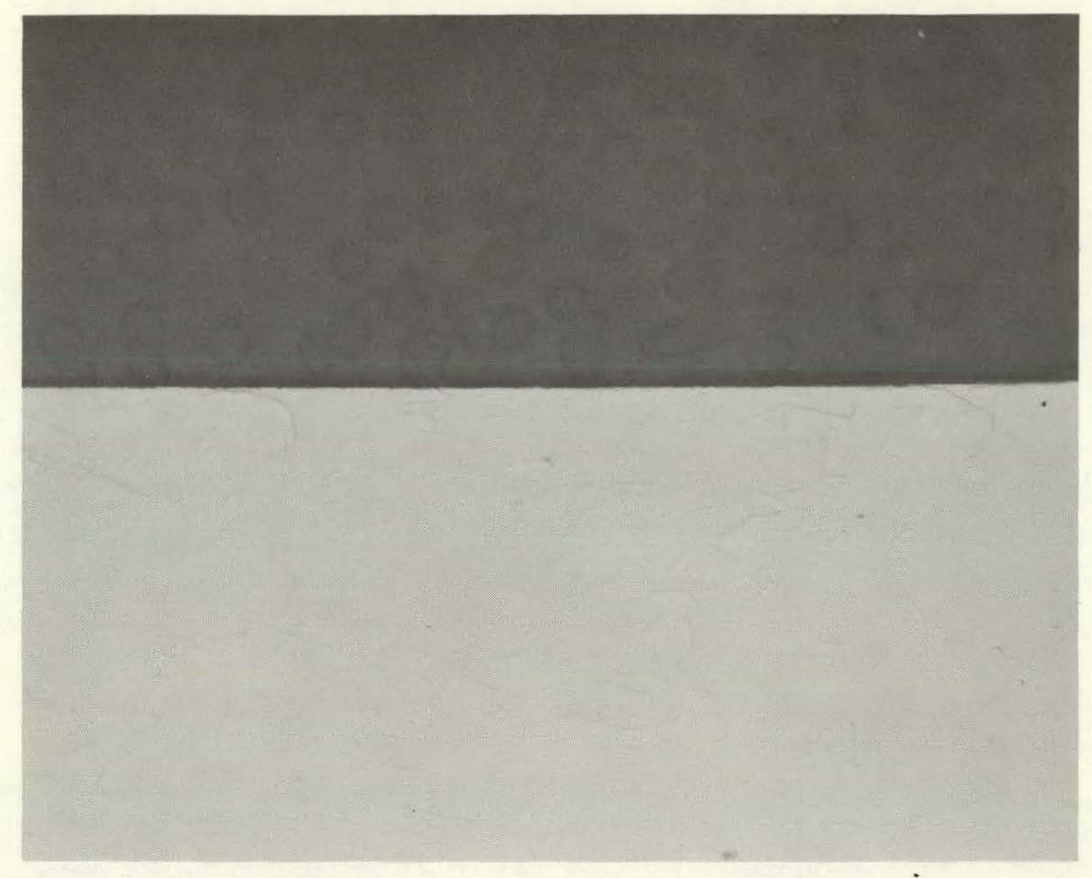

Plastic

Duranickel

Magnification $500 \mathrm{X}$

Unexposed

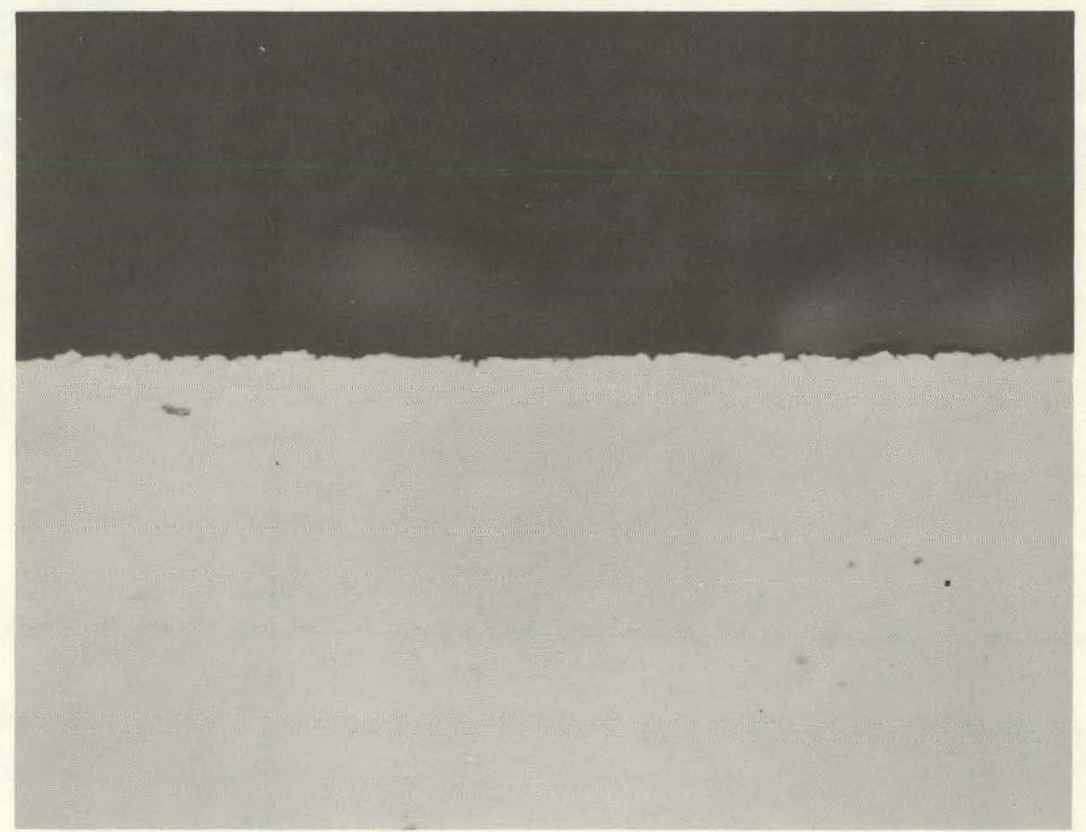

Plastic

Magnification $500 \mathrm{X}$ Exposed

Figure 8

DURANICKEL CORROSION ATTACK 
exposures to hydrogen chloride and hydrogen at $400^{\circ} \mathrm{C}$. and to dilute fluorine at $540^{\circ} \mathrm{C}$. All nickel welds were made with INCO-6I rod, while the Inconel and HyMu-80 samples were welded with INCO-82T rod. Nickel again exhibited the best corrosion resistance. The weight losses for the welded samples were greater than those for unwelded samples of the same materials, and microscopic inspection showed the corrosion penetration of the weld material to be several times that of the base metal. Some of the samples after exposure are illustrated in figures 9 and 10 .

Stainless steel-clad fuel elements require decladding in a hydrogen fluoride-oxygen atmosphere; therefore, in test 7, samples of Hastelloy-C, Hastelloy-G, Hastelloy-N, HyMu-80, and Duranickel were suspended in the filter loop fluid-bed reactor above the powder bed and were subjected to ten cycles of alternate exposures to hydrogen fluoride and oxygen at $590^{\circ} \mathrm{C}$. and to dilute fluorine at $540^{\circ} \mathrm{C}$. Again, the Hastelloys exhibited poor resistance to the exposure conditions. The Hastelloy-C sample corroded to the extent that it fell from its support into the fluid bed. during the sixth cycle and was assumed to be consumed during the test. Microphotographs of the HyMu-80 and Hastelloy-N samples, figure 1l, show the attack on these materials. While Duranickel exhibited fair resistance to corrosion, based on penetration data, some intergranular attack was prcscnt, as shown in figure 12 .

In summary, it is apparent that nickel-200, nickel-201, and Duranickel are the most corrosion-resistant materials tested to date. As new alloys become available, they will be exposed to similar conditions; e.g., samples of an alloy called Berylco Nickel-440 are being prepared for testing. This metal contains small quantities of beryllium and titanium and has age hardening properties which might be useful in flange face application.

\section{PROCESS AND REACTOR STUDIES}

Extension of studies made at the National Laboratories will be necessary to prove the volatility processes on a larger scale and to obtain good engineering design data for a production facility. The major uncertainty in basing plant design on the present small-scale work arises from the fact that good fluidization and bed homogeneity are probably not achieved during the decladding and pellet oxidation steps for recovery of low enrichment zircaloy or stainless steel-clad fuels. Predictions of heat transfer and gas contact problems, therefore, are difficult if not impossible. To obtain the required design information, process work on a larger scale is planned. The initial tests will be made in a 10inch diameter head end reactor. Still larger equipment will be used if necessary. In addition, the decladding and fluorination reactions will be observed in the filter test loop in conjunction with that test program. Inert gas fluidization will also be studied in transparent columns to evaluate proposed reactor sizing and configuration. 


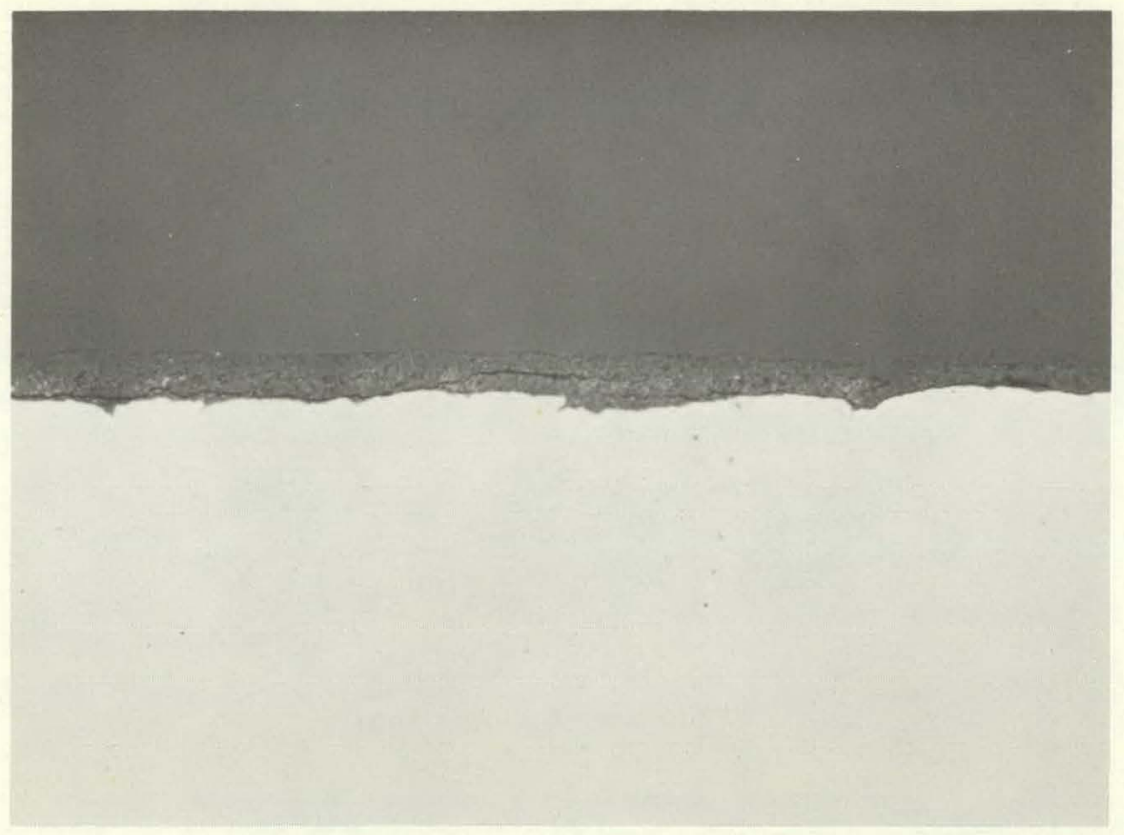

Plastic

Corrosion

Hy $\mathrm{Mu}-80$

Hy $\mathrm{Mu}-80$

Magnification $500 \times$

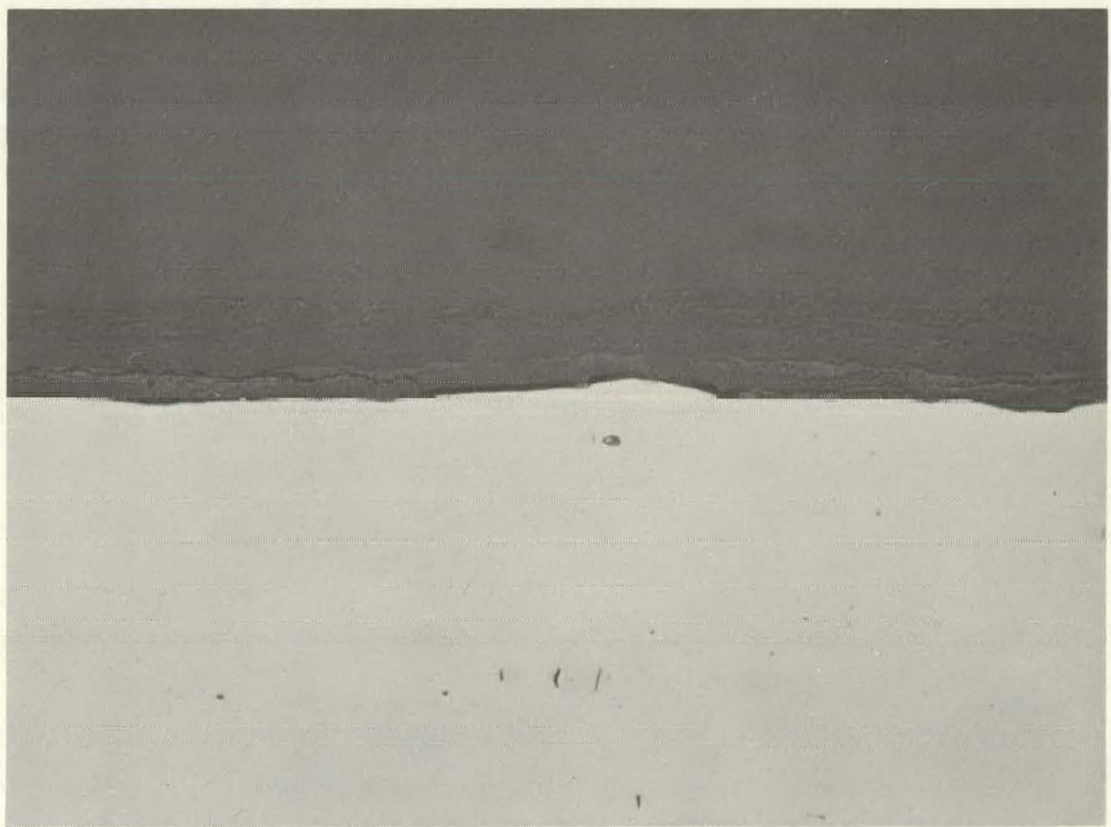

Plastic

Corrosion

Magnification $500 \times$

Hastelloy $N$

Figure 9

CORROSION RESULTS (TEST \#8) 


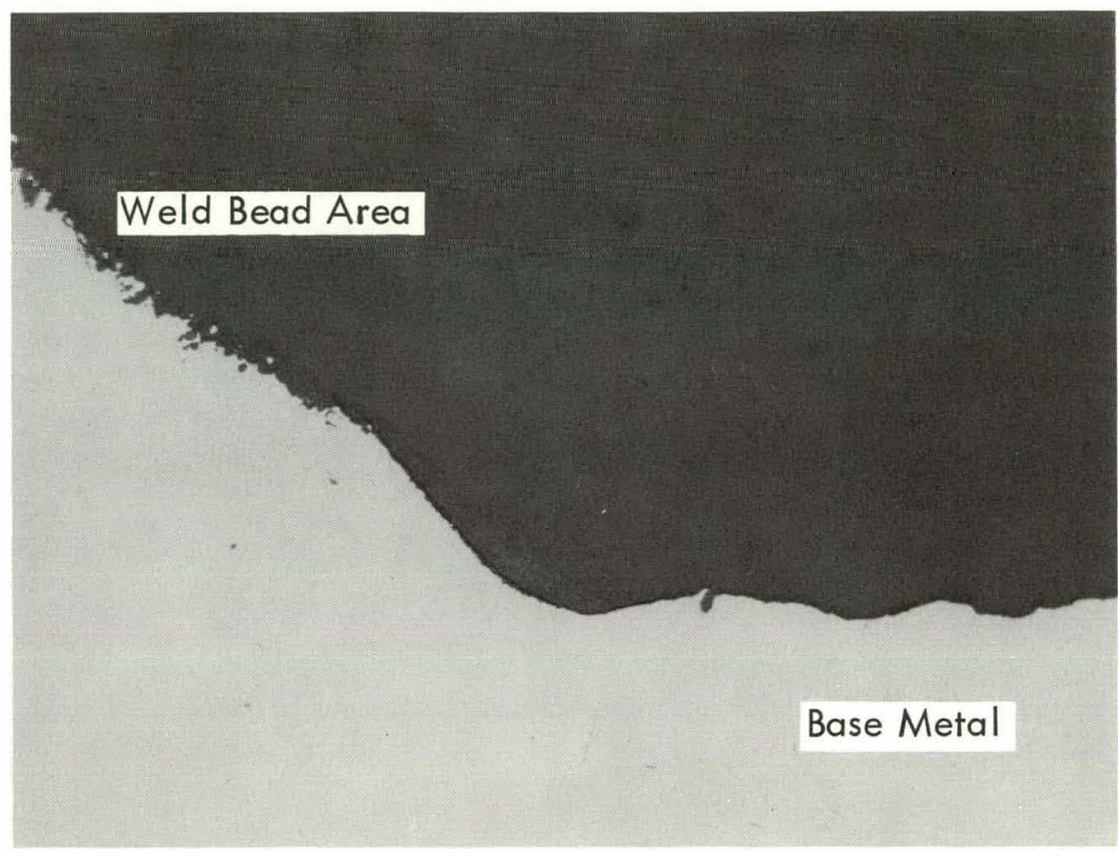

Magnification $250 X$

$\mathrm{Ni}-200$

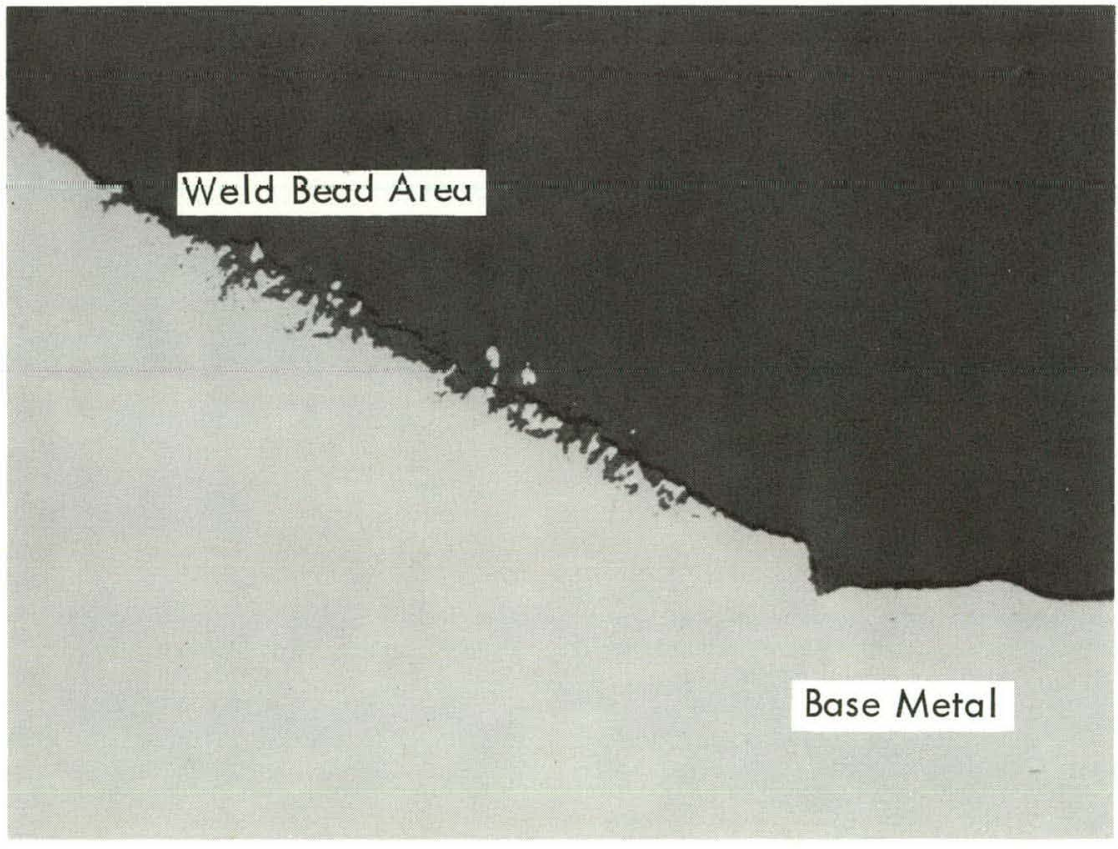

$\mathrm{Ni}-201$

Magnification $250 \mathrm{X}$

Figure 10

CORROSION RESULTS (TEST \#8) 


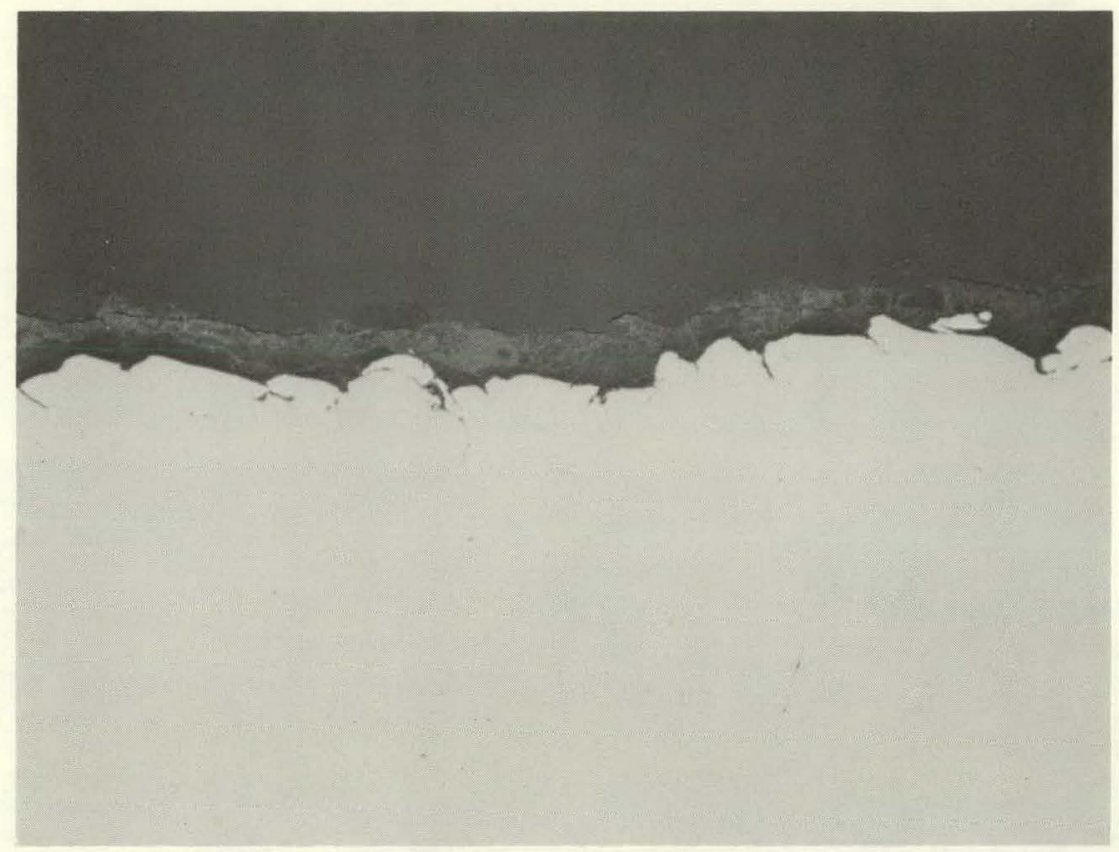

Plastic

Corrosion

Hy $\mathrm{Mu}-80$

Hy $\mathrm{Mu}-80$

Magnification $500 \times$

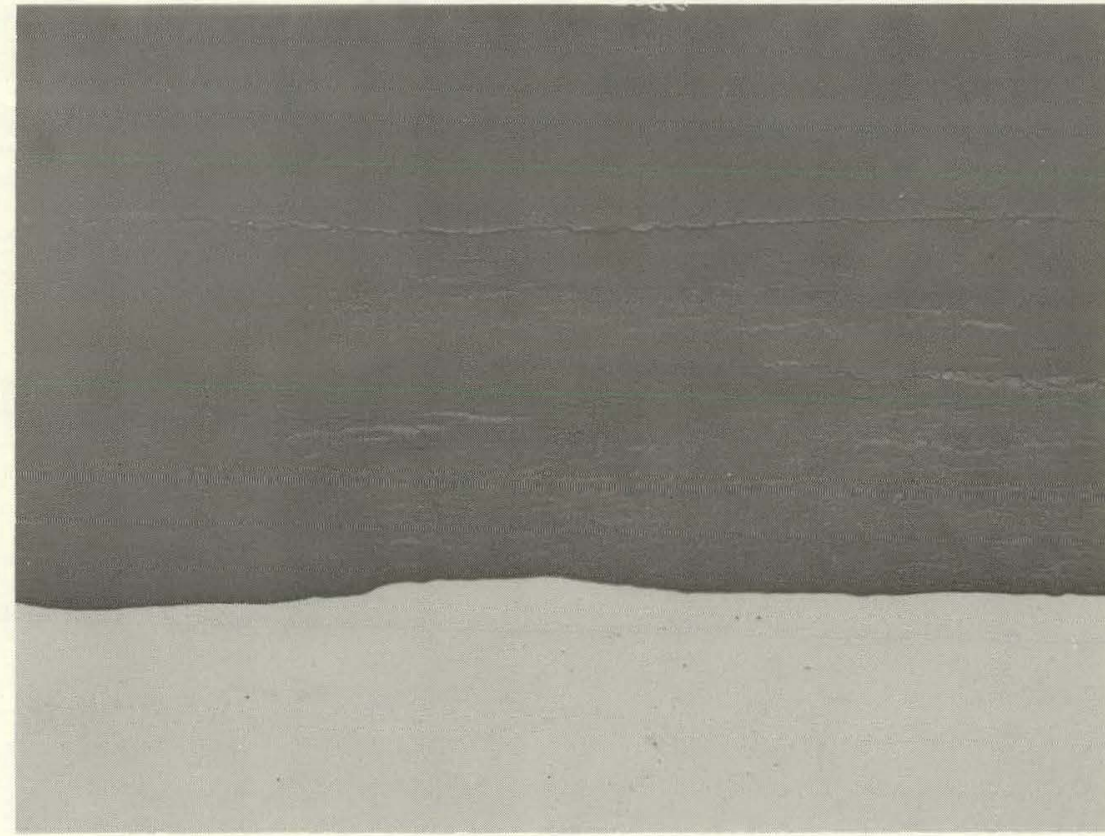

Plastic

Corrosion

Magnification $500 \times$

Hastelloy $\mathrm{N}$

Figure 11

CORROSION RESULTS (TEST \#7)

Hastelloy $N$ 


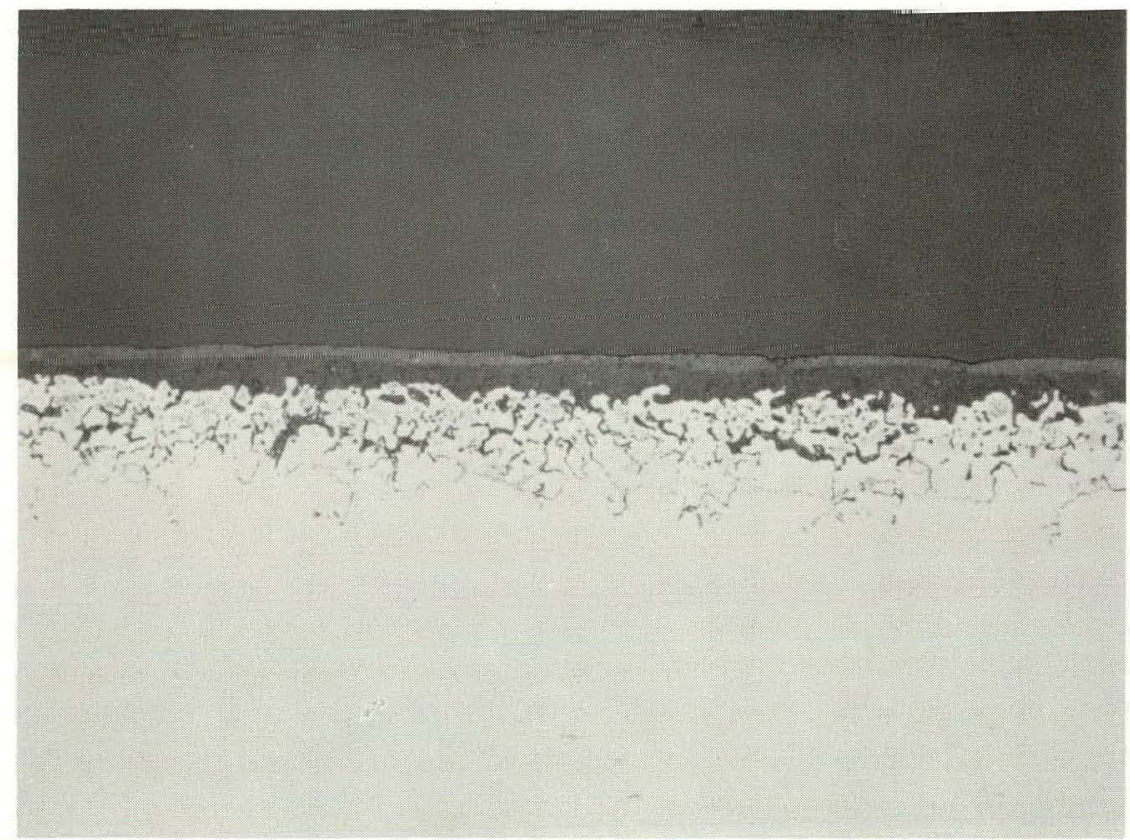

Plastic

Corrosion Products

Intergranular Attack

Duranickel

Magnification $500 \times$

Duranickel

Figure 12

CORROSION RESULTS (TEST \#7) 
Decladding and Fluorination Studies

Some studies related to the hydrogen chloride reaction with high enrichment zirconium alloy fuels have been made in conjunction with filter tests which are described later. In these studies, where expected conditions at the filter must be simulated as nearly as possible, information on the performance of the fluid-bed reactor for the various process steps is generated at little or no additional cost. Uranium metal was added to the fluid bed before halogenation to simulate more nearly conditions which might increase filter loading, either from volatile uranium tetrachloride or from fine uranium trichloride particulates. Inspection following hydrochlorination showed that the bed was black instead of the green uranium chloride color expected. Analyses of the bed material detected the presence of uranium dioxide.

Although the formation of uranium dioxide was unexpected, it is known that uranium will react readily with oxygen and even preferentially in basically chloride systems; therefore, a series of test runs was conducted to determine the oxygen source. The tests included (a) substituting magnesium fluoride as a fluid-bed media instead of alumina, (b) drying the hydrogen with Molecular Sieves, (c) drying the hydrogen chloride with refrigerated silica gel, and (d) substituting argon for the nitrogen diluent. In all cases, oxidation of the uranium still occurred, thus indicating that the oxygen contents of the nitrogen and argon diluents were higher than could be tolerated. This assumption was verified when a test run made with undiluted hydroger and hydrogen chlorlde gave a green reaction product in the bed.

During the testing of sintered Monel filters in the hydrogen fluorideoxygen system proposed for decladding stainless steel-clad uranium dioxide fuel elements, a number of observations relating to performance of the fluid bed were made. Several test decladding runs were made usling stainless steel 347 and 304L tubing. Hydrogen fluoride concentrations were varied from 15 to $80 \%$, and reaction temperatures covered a wide range of 540 to $620^{\circ} \mathrm{C}$. In general, the observations reported by ANL and BNL were verified. A hydrogen fluoride concentration of $40 \%$ and a bed temperature of $590^{\circ} \mathrm{C}$. appeared to be the optimum. In all cases, the decladding reaction produced a hard, coarse oxide scale that was slightly magnetic and insoluble in hydrochloric acid. Fluorination treatment broke the scale into fine particles.

Presently, studies of pulverizing uranium dioxide pellets by oxidation and of fluorinating the resulting urano-uranic oxide to uranium hexafluoride are being made in conjunction with Purolater filter unit tests.

Inert Gas Fluidizaliun

Two brief investigations were made with fluid beds utilizing glass columns for visual observation. The first of these was carried out to determine the possibility of simplifying low enrichment stainless steel clad fuel reprocessing by 'separating. the stainless steel oxide scale from the alumina bed by elutriation. The bench-scale unit consisted of 
a 2-inch diameter glass column mounted below a 5-inch diameter glass column. Air for fluidizing and elutriation entered at the bottom of the 2-inch column. The columns were filled with minus 100-mesh tabular alumina to a height of about 6 inches in the 5-inch column, and 500 grams of coarse stainless steel oxide scale was inserted on the top of this bed.

When an air flow was established, the stainless scale moved downward through the two glass sections and collected in the 2-inch portion; however, complete separation could not be accomplished with gas velocities as great as 10 feet per second. A velocity of 20 feet per second in the 2-inch column elutriated both the alumina and the scale.

In a second test, the 5-inch glass column was used to observe fluidization in a simulated bed of uranium dioxide pellets. The conical bottom was filled with $1 / 2$ - and $1 / 4$-inch steel balls. Minus 60-mesh tabular alumina was then added to the columir to a depth of 1 foot. This bed fluidized nicely at a gas velocity of 0.2 to 0.6 foot per second, and some elutriation was evident at about 1 foot per second. Stainless steel pellets, $1 / 2$ inch in diameter by 1 inch long (simulating oxide fuel pellets), were then inserted on top of the alumina bed to a depth of 4 to 5 inches. The pellets moved downward through the bed during fluidization to the ball bearing base; however, movement around the pellets was essentially nil even with gas velocities as high as 3 feet per second. Some evidence of gas channeling through the pellets was observed.

The test was repeated using 60- to 100-mesh Norton RR Alundum. Although - a higher fluidization velocity was required ( 0.75 t. 1.0 foot per oecond), the resulls were essentially the same as with tabular alumina.

An 8-inch transparent plastic column is being fabricated to study fluidization and gas flows in beds containing simulated reactor fuel modules.

\section{Semiworks Reactor}

The design of the planned semiworks head-end reactor is shown in figure 13. The 10-inch diameter reactor will. be provided with a j-l/2-toot long, 5 -inch diameter lower section for the initial tests. The reduction in diameter at the bottom of the reactor will increase the gas velocity through the portion of the bed which will contain the nonfluidizable chunks of stainless steel oxides and/or uranium dioxide pellets. Improved heat transfer and gas contact should result. If the two-diameter concept proves to be undesirable, this lower section can be removed easily. Furthermore, bottom sections of different dimensions can be fabricated and evaluated if program results indicate the expediency of such an approach.

The reactor dimensions are almost half those estimated for a production unit capable of processing about $500 \mathrm{~kg}$. of uranium dioxide per batch. A charge of 65 to $85 \mathrm{~kg}$. of uranium dioxide will be used. Studies of both the hydrogen chloride and hydrogen fluoride-oxygen decladding methods will be possible, and fluorine introduction will be provided at several 


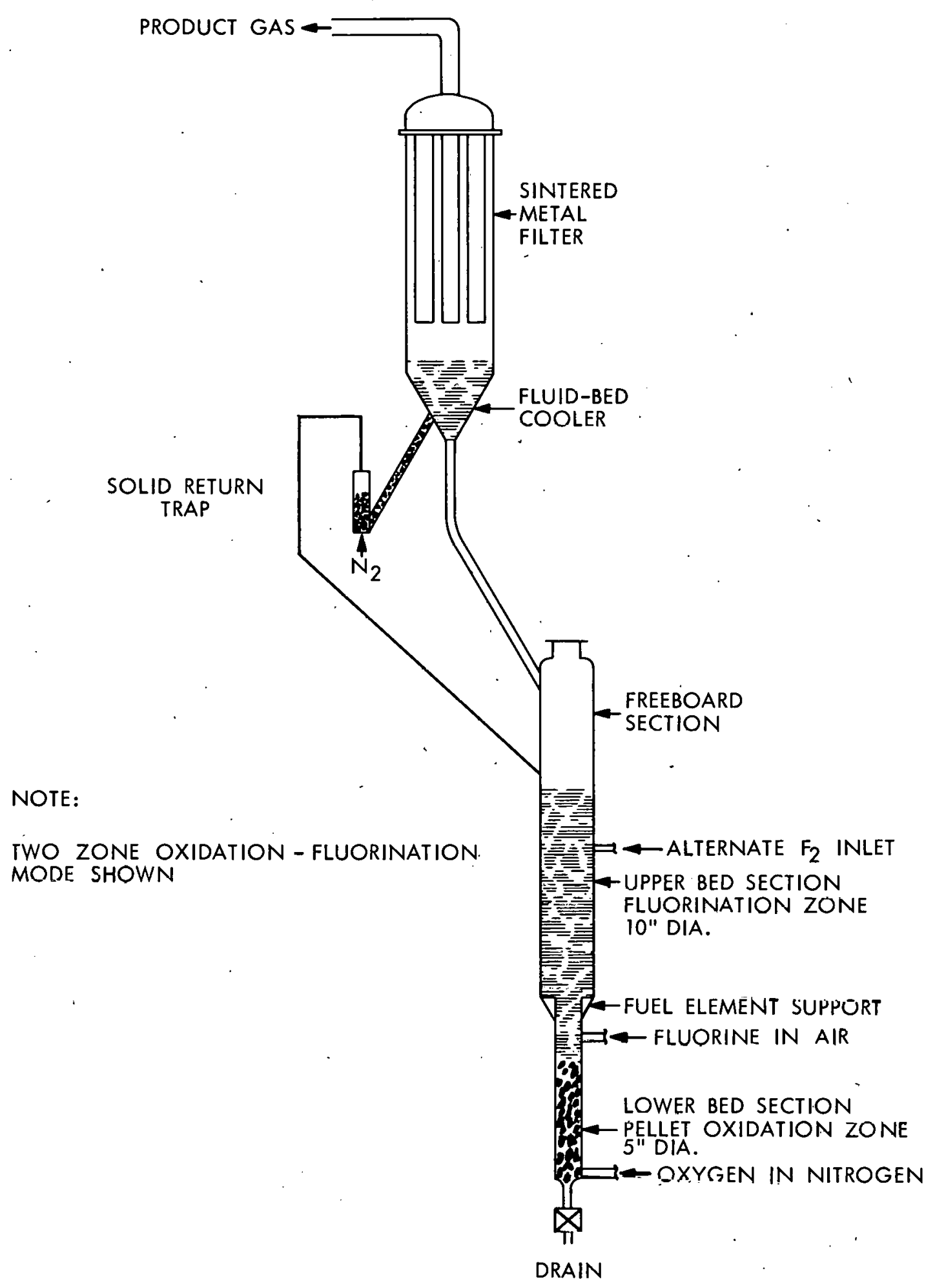

Figure 13

SEMI-WORKS FLUID-BED REACTOR 
points so that simultaneous oxidation and fluorination can be evaluated. The system could also be modified to test the bromine pentafluoride fluorination flow sheet.

Based on an anticipated specific reaction rate of $34 \mathrm{~kg}$. of uranium hexafluoride per hour per square foot of cross-sectional area, about $20 \mathrm{~kg}$. of uranium hexafluoride will be produced per hour in the 10-inch diameter bed with a heat generation of about 50,000 Btu./hr. Setting the bed depth at 5 feet, the heat flux at the inside wall is about 3,800 Btu./hr.-sq.ft. which should be removed easily, since the high temperatures of the operation, 400 to $500^{\circ} \mathrm{C}$, allow a correspondingly high temperature differential between reactor and coolant.

The rate of oxidation of the uranium dioxide is expected to be stoichiometrically equivalent to the rate at which urano-uranic oxide is fluorinated; therefore, the oxidation rate of the uranium dioxide pellets will be about 34 pounds of urano-uranic oxide reacted per hour with an associated heat generation of $5,600 \mathrm{Btu} . / \mathrm{hr}$. Using a 3-foot packed bed depth in the oxidation section, the average heat flux at the inside wall is about 1,400 Btu./hr.-sq.ft. The point heat release rate is expected to be somewhat greater owing to the difficulty of achieving good fluidization and corrcaponding evening of temperatures in the pellet zone. Despite this factor, the high temperature differential attainable, coupled with the ability to vary the oxygen content of the feed gas, hopefully will allow reasonable control.

Off-gases from the reactor will be cooled to $100^{\circ} \mathrm{C}$, probably in a fluidbed cooler, and will be filtered through sintered nickel filter tubes. Cooling to $100^{\circ} \mathrm{C}$. is specifled, since in the end application, such a temperature limit is expected to minimize thermal decomposition of the plutonium hexafluoride. From a filter life standpoint, cooling to $200^{\circ} \mathrm{C}$. should be ample. The product uranium hexafluoride will be collected in cold traps for accountability purposes.

For stainless steel-clad fuels, the declad procedure of present choice is hydrogen fluoride-oxygen treatment at about $600^{\circ} \mathrm{C}$. Although this treatment breaks up the uranium dioxide itself into fine powder, it leaves much of the clad in the form of relatively coarse, i.e., greater than 20 mesh, shards which tend to sink to the bottom of the fluid bed. The ability to use a high gas velocity and to control reagent concentrations in the smaller diameter section of the semiworks bed should be of advantage in minimizing hot spots by control of the reaction of these pieces.

\section{OUTLET GAS FILTER STUDIES}

Commercially available sintered metal filters are being evaluated in the test loop shown in figure 14. The loop includes a 4-inch diameter fluid bed, an inlet gas preheater, an internally finned outlet gas cooler, and a filter section. The purpose of this work is to determine if sintered metal filters mounted directly above the fluid bed will give satisfactory service in the proposed volatility processes. Packed bed filters scaled 
DWG. NO. G-65-361

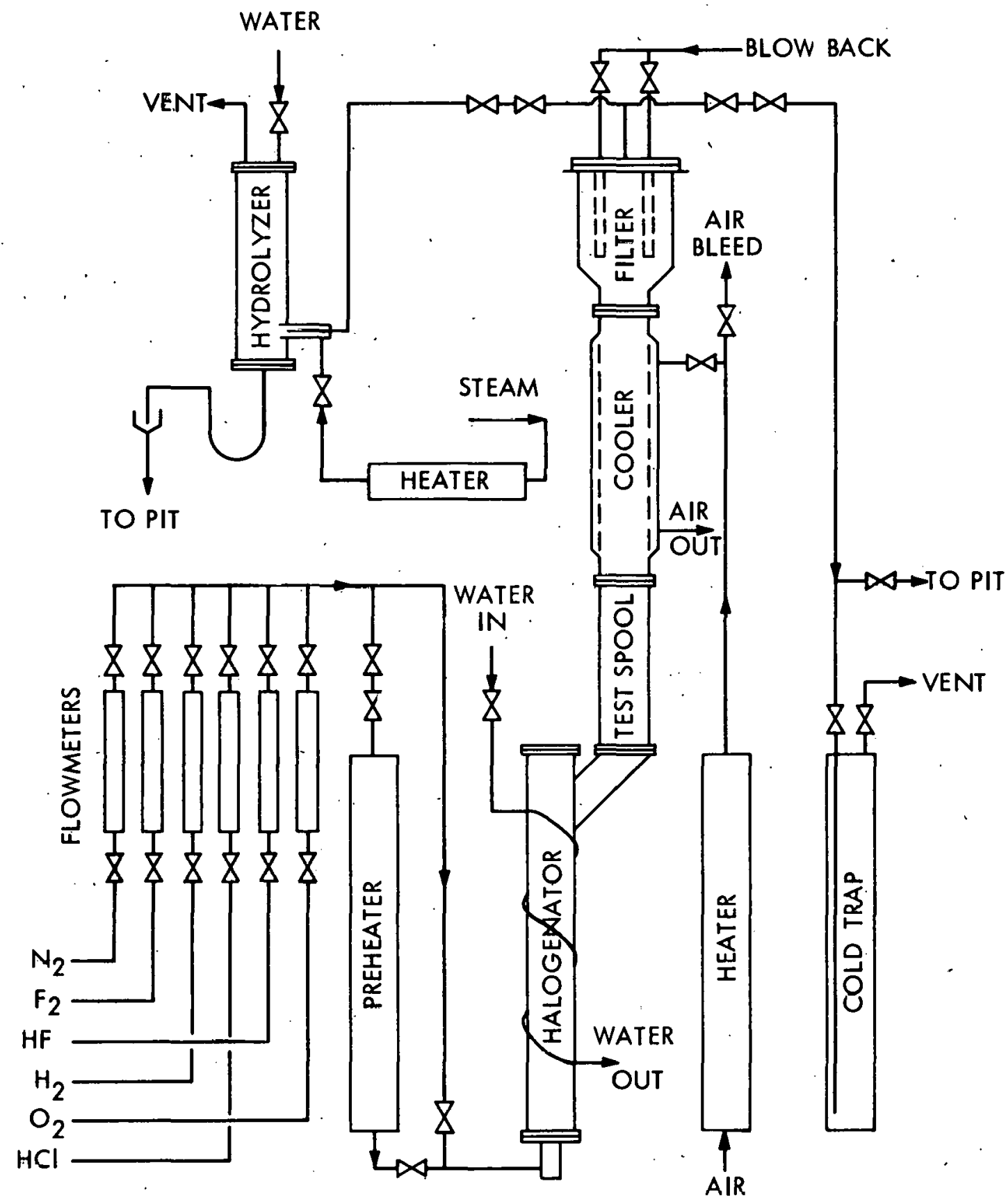

Figure 14

FILTER TEST LOOP 
from laboratory studies would be quite large in a plant system and would increase the possibility of uranium and/or plutonium holdup and loss. Also, since a considerable amount of uranium dust would probably be transported to the filter during decladding and/or pellet oxidation, generation of heat at the filter during fluorination could present difficulties.

The first series of tests was made with type-G Micrometallic nickel bayonet filter tubes. During hydrofluorination, an operating temperature of $315^{\circ} \mathrm{C}$. at the filter was selected because this is the minimum safe temperature necessary to prevent condensation of stannous chloride. At. the flow sheet fluorination conditions, condensation will not be a problem provided the temperature is above $100^{\circ} \mathrm{C}$. 'Based on past ORGDP experience, a maximum filter temperature of $200^{\circ} \mathrm{C}$. was chosen for the fluorination step:

Two 3-inch wide by 3-foot long filter tubes were subjected to fourteen cycles in which first dilute hydrogen chloride-hydrogen and then fluorinenitrogen mixtures were passed through a bed of Alcoa T-6I tabular alumina and through the filters. Fluidizing velocities were varied from 0.5 to 2.0 feet per second, and fluid-bed temperatures were $400^{\circ} \mathrm{C}$. for the hydrochlorination step and $540^{\circ} \mathrm{C}$. during fluorination. Filter temperatures were maintained a.t the levele noted earlier.

During the 183 hours of hydrochlorination and 56 hours of fluorination, the performance of the filters appeared normal. The pressure drop across the tubes increased rapidly and then leveled out at an acceptable value requiring only infrequent blowback. Inspection of the tubes after the runs showed a coating of fine powder which was primarily alumina containing some aluminum-f1.unxide and nickel rluorlde. Measurements on the two tubes showed air flows of 7.6 and 6.6 std. cfm., with a pressure differential of 1 psi., as compared with a flow of 28.5 std. cfm. for a new tube. Such initial plugging was anticipated. Similar results were obtained in a second series of tests during. which 157 hours of hydrochlorination and 23 hours of fluorination were accumulated. In the latter test, uranium metal turnings were added to the bed before each cycle to provide uranium hexafluoride in the gas passing through the filter during fluorination.

Slight cracking at the welds of the bayonet tubes was noted after the tests just described, and the next evaluations were made with Micrometall1c cylindrical tubes of the same material. After 150 hours of hydrochlorination and 20 hours of fluorination, the cylindrical tubes were inspected and were found to be badly cracked on each side of the longitudinal weld, figure 15. Analyses of the weld material showed some titanium, about 1\%, indicating that INCO nickel-61 welding rod had been used.

In view of the weld cracking problems, molded (seamless) nickel filter tubes manufactured by the Purolator Corporation were obtained and are being evaluated. In these tests, an oxygen exposure has been added after hydrochlorination to simulate more nearly the process for low enrichment fuels. The exposure treatment consists of hydrogen chloride and hydrogen 


$$
11
$$


for 5 hours at $315^{\circ} \mathrm{C}$, oxygen for 10 hours at $100^{\circ} \mathrm{C}$, and fluorine for 10 hours at $100^{\circ} \mathrm{C}$. At the recommendation of Argonne National Laboratory, the filter temperature during fluorination was lowered from 200 to $100^{\circ} \mathrm{C}$., the temperature necessary to lower plutonium decomposition to an acceptable value during actual processing. The bed in the reactor consists of minus 60-mesh tabular alumina. After four cycles, the tubes were inspected and were found to be in excellent condition. Testing is continuing.

One series of tests was made to determine the suitability of cylindrical Micrometallic Monel tubes for the alternating hydrogen fluoride-oxygen and fluorine atmospheres encountered when stainless steel-clad fuels are reprocessed. As would be expected from production experience in uranium hexafluoride manufacturing plants developed and operated by Union Carbide Corporation, these tubes were in excellent condition following 10 cycles of exposure involving about 50 hours with each gas. The filter temperature was held at $200^{\circ} \mathrm{C}$. Stainless steel tubing was charged to the bed before each cycle to simulate chemical conditions during decladding. Monel tubes were not tested for the hydrochlorination-fluorination system because bench-scale corrosion tests showed rapid deterioration of the Monel.

Following the tests currently in progress, use of Inconel tubes will be studied. At the lower filter temperature of $100^{\circ} \mathrm{C}$. during fluorination, Inconel may be equal to, or even better than, nickel for the combined service.

\section{PRODUCT PURIFICATION, SORPTION-DESORPTION SYSTEM}

In the flow sheets for the proposed volatility processes, there are several applications for solid sorbent traps. With high enricnment fuels where the plutonium content is negligible, fluorination off-gases are passed through high temperature $\left(400^{\circ} \mathrm{C}\right.$.) sodium fluoride pellet traps to remove some fission products. The partially purified uranium hexafluoride is then collected on low temperature $\left(120^{\circ} \mathrm{C}.\right)$ sodium fluoride pellets allowing other impurities, such as molybdenum, to pass through. Similar uranium hexafluoride purification in the low enrichment cases might also be possible following plutonium removal.

Studies are being made in three different systems. Investigation of operating conditions and testing of various types of sodium fluoride pellets are proceeding in a simple cylindrical trap. Trap design is being evaluated by testing a prototype annular unit; and finally, a continuous uranium hexafluoride collection system involving a fluidized bed of sodium fluoride powder and a screw regenerator is being considered. A pilot-scale unit of this latter type is available from other programs.

\section{Cylindrical Pellet Trap}

The test loop, figure 16, constructed to study pellet characteristics and effects of operating conditions consists of a vertical length of 4-inch nickel pipe providing a 7-foot deep bed of pellets. The trap is electrically heated and water-cooled and is installed with a gas metering station, cold traps, and an outlet gas uranium hexafluoride detection unit. 


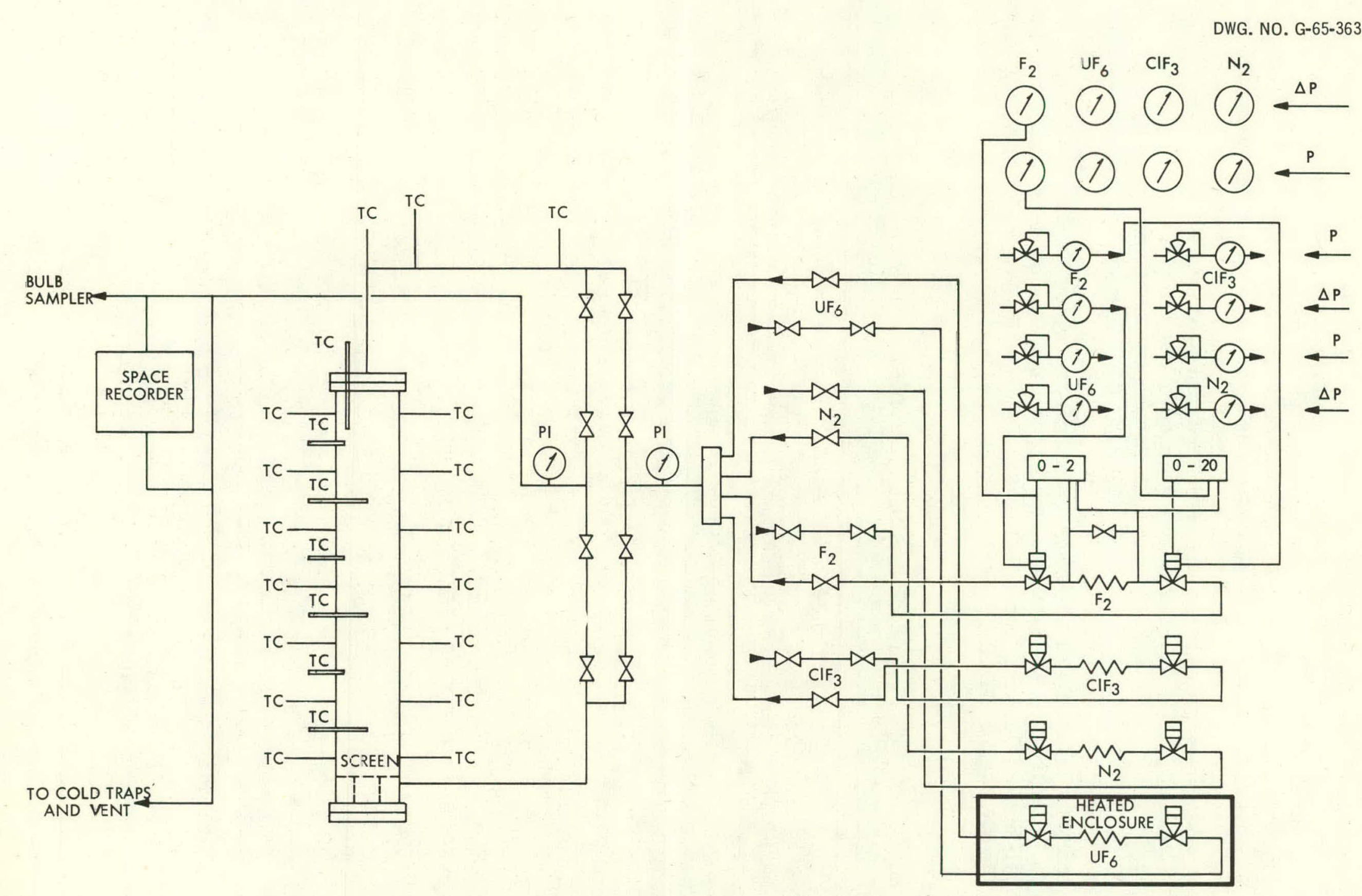

Figure 16

4" SORBER LOOP 
The first series of tests, runs 1 through 24 in table XIII, was made to study the effects of various gas compositions on uranium hexafluoride sorption capability. Effects of uranium hexafluoride, fluorine, and chlorine trifluoride concentrations were determined; chlorine trifluoride will be encountered in the high enrichment process when chlorides are converted to fluorides. The sodium fluoride used was prepared from commercially available*, I/8-inch, cylindrical pellets of sodium bifluoride by heating at $540^{\circ} \mathrm{C}$. for 5 hours in an inert atmosphere. Operation was carried out using a sorption temperature of $120^{\circ} \mathrm{C}$., a gas retention time of 80 seconds (assuming 100\% voids), and a desorption temperature of $400^{\circ} \mathrm{C}$. During the sorption cycle, the gas flows were maintained constant with the gas entering the top and leaving the bottom of the bed until uranium hexafluoride breakthrough was indicated by the detection unit in the trap outlet line. Concentrations in excess of $1 \mathrm{ppm}$. of uranium hexafluoride were considered breakthrough.

TABLE XIII

RESULTS OF 4-INCH DIAMETER SODIUM FLUORIDE TRAP SORPTION TESTS

\begin{tabular}{|c|c|c|c|c|c|c|c|c|}
\hline Run Number & $\begin{array}{l}\text { Total } \\
\text { Flow, } \\
\text { sta.cfm. }\end{array}$ & \multicolumn{4}{|c|}{$\begin{array}{c}\text { Inlet Gas } \\
\text { Concentration, } \\
\%\end{array}$} & $\begin{array}{l}\text { Average } \\
\text { Snrntion } \\
\text { Time, } \\
\text { hr. } \\
\end{array}$ & $\begin{array}{l}\text { Desorption } \\
\text { Time, } \\
\text { hr. } \\
\end{array}$ & \begin{tabular}{l}
\multicolumn{1}{c}{ Avcragc } \\
Sorption Ratio, \\
lb. UF / $/ \mathrm{lb}$. NaF
\end{tabular} \\
\hline 1 & 0.3 & 10 & 15 & 30 & 45 & $27 \cdot 7$ & 12 & 0.49 \\
\hline 2 thru 14 & 0.3 & 10 & 15 & 30 & 45 & 6.3 & 12 & 0.28 \\
\hline 15 thru 18 & 0.3 & 10 & 15 & 60 & 15 & 5.1 & 11 & 0.28 \\
\hline 19 thru 23 & 0.3 & 10 & 15 & 0 & 75 & 8.3 & 14 & 0.47 \\
\hline 24 & 0.3 & 10 & 15 & 30 & 45 & 5.0 & 14 & 0.25 \\
\hline$A-1$ & 0.3 & 10 & 15 & 30 & 4.5 & 8.2 & 14 & 0.45 \\
\hline A-2 thru A-6 & 0.3 & 10 & 15 & 30 & 45 & 5.2 & 14 & 0.26 \\
\hline A-7 thru $A-10$ & 0.3 & 10 & 15 & 0 & 75 & 3.9 & 14 & 0.21 \\
\hline B-I thru B-6 & 0.3 & 10 & 15 & 30 & 45 & 2.9 & 14 & 0.10 \\
\hline B-7 thru B-15 & 0.3 & 10 & 15 & 0 & 75 & 3.0 & 14 & 0.11 \\
\hline C-I thru C-5 & 0.3 & 10 & 0 & 0 & 90 & 3.9 & 14 & 0.13 \\
\hline D-I thru D-5 & 0.3 & 10 & 15 & 0 & 75 & 12.1 & 14 & 0.67 \\
\hline
\end{tabular}

On completion of the sorption cycle, the trap was purged, valved to reverse the gas flow through the bed, and heated to $400^{\circ} \mathrm{C}$. A small flow of fluorine was used to sweep the desorbed uranium hexafluoride and to convert any uranium pentafluoride to uranium hexafluoride.

* Harshaw Chemical Company, Technical Grade No. Na-0101T-1/8. 
As can be seen from the data, the sorptive capability of fresh pellets was approximately twice that of used material. The average capacity for used pellets in the first fifteen runs was about 0.28 pound of uranium hexafluoride per pound of sodium fluoride. Runs 15 through 18 show that increasing the chlorine trifluoride concentration from 30 to $60 \%$ had little effect on sorption. When the chlorine trifluoride flow was stopped in runs 19 through 23, the sorptive capacity almost doubled; resumption of the chlorine trifluoride flow in run 24 decreased the sorption to the earlier values. This phenomenon did not occur in the A and B series of test runs with different pellets. Run 25 was made to obtain breakthrough data for use in trap sizing and configuration. After the uranium hexafluoride detector showed a trace amount in the outlet gas, bulb samples were withdrawn periodically and were analyzed for uranium hexafluoride. Outlet uranium hexafluoride analyses were 0.3 mole percent 1 hour after breakthrough, 0.7 mole percent after $1-2 / 3$ hours, and 5.5 mole percent after 2-1/2 hours. Data of this type should allow prediction of the performance of traps of various lengths.

The pellets were removed and inspected after run 25. The top 6 inches of the bed was found to be a powder, and the remainder of the bed was a mixture of powder and pellets. Inspection of individual pellets revealed that, while the pellets were quite hard, they were considerably smaller than when charged. In search of a material that would be more resistant to surface degradation, sodium fluoride pellets were heat treated for 5 hours at different temperatures. The properties of these pellets are summarized in table XIV.

TABLE XIV

EFFECT OF PREPARATION TEMPERATURE ON SODIUM FLUORIDE PELLET CHARACTERISTICS

\begin{tabular}{cccc}
\hline $\begin{array}{c}\text { Treatment } \\
\begin{array}{c}\text { Temperature, } \\
{ }^{\circ} \mathrm{C} .\end{array}\end{array}$ & $\begin{array}{c}\text { Surface } \\
\text { Arca, } \\
\text { sq.m./g. }\end{array}$ & $\begin{array}{c}\text { Void } \\
\text { Fraction }\end{array}$ & $\begin{array}{c}\text { Stokes } \\
\text { Hardness, } \\
\text { div.* }\end{array}$ \\
\hline 540 & 2.149 & 0.406 & 1.0 \\
590 & 0.118 & 0.120 & 5.5 \\
650 & 0.061 & 0.104 & 6.5 \\
700 & 0.031 & 0.038 & 8.0 \\
760 & 0.060 & 0.097 & 8.0 \\
* Comparative scale. & & &
\end{tabular}

In the $B$ and $C$ series of tests, pellets were used that had been prepared by heating Harshaw sodium fluoride pellets to $650^{\circ} \mathrm{C}$. for 5 hours. These pellets had a surface area of $0.110 \mathrm{sq} . \mathrm{m} . / \mathrm{g}$. and a void fraction of 0.136 . Temperatures and gas flows were similar to those in the original series of tcoto. It is apparent from the data that the sorptive capacity of 
the $650^{\circ} \mathrm{C}$. pellets was approximately one-half that of pellets treated at $540^{\circ} \mathrm{C}$.

When the trap was emptied and the pellets were inspected, surface degradation was evident, although not so severe as with pellets treated at $540^{\circ} \mathrm{C}$. There appeared to be some bonding between pellets; however, the clumps were easily broken apart, and no hard caking was observed. The small decrease in pellet degradation was probably more than offset by the loss in sorptive capacity.

A special sorbent pellet prepared at the Paducah Gaseous Diffusion Plant by pelletizing sodium bifluoride and furnacing at $760^{\circ} \mathrm{C}$. was used in the D series of test runs. Gas flows and trap temperatures were again the same as those used previously. The data indicate that the sorptive capacity of this material is nearly three times that of the Harshaw type pellet used in all other runs; however, the fresh Paducah pellets sorbed less than used pellets which is contrary to experience with Harshaw pellets. When the trap contents were inspected on completion of the tests, severe pellet degradation was evident. The upper two-thirds of the trap was nearly 50\% powder, and those pellets remaining were easily crumbled. Photographs of the two types of pellets before and after use are shown in figure 17 .

After the Paducah pellet material was removed, the trap was filled with Harshaw sodium fluoride pellets which had been heat treated at $540^{\circ} \mathrm{C}$. The bed was then subjected to temperature cycling in a nitrogen almosphere to determine the effect of thermal shock on the pellet. An average cycle consisted of (a) maintaining a temperature of $120^{\circ} \mathrm{C}$. for 2 hours, (b) heating to $400^{\circ} \mathrm{C}$. in about 3 hours, (c) maintaining a temperature of $400^{\circ} \mathrm{C}$. for 4 hours, and (d) cooling to $120^{\circ} \mathrm{C}$. in approximately $1-1 / 2$ hours. After seventeen cycles, the trap was opened, and the bed was inspected. No abnormal dusting was evident, and a Stokes pellet test showed no apparent change in hardness. Not surprisingly, these data and inspections of pellets used previously in the 4-inch trap support the belief that pellet degradation is chiefly, if not completely, a function of the amount of sodium fluoride-uranium hexafluoride complex made and decomposed each cycle.

The above pellets were then exposed to a flow of 0.3 std.cfm. of gas consisting of 10\% uranium hexafluoride, $15 \%$ fluorine, and $75 \%$ nitrogen at varying sorption temperatures. Under these conditions, the sorption ratios, pound of uranium hexafluoride per pound of sodium fluoride, at temperatures of 85,120 , and $175^{\circ} \mathrm{C}$. averaged $0.32,0.37$, and 0.10 , respectively.

It is apparent from the above tests that occasional changeout of trap charges will be necessary if sodium fluoride pellets are used for uranium hexafluoride sorption. The effective trap operating time will be influenced by the type of pellet used and the uranium hexafluoride loading. When there is no uranium hexafluoride sorption, as in the high temperature fission product removal trap, no pellet deterioration problems would be expected. 


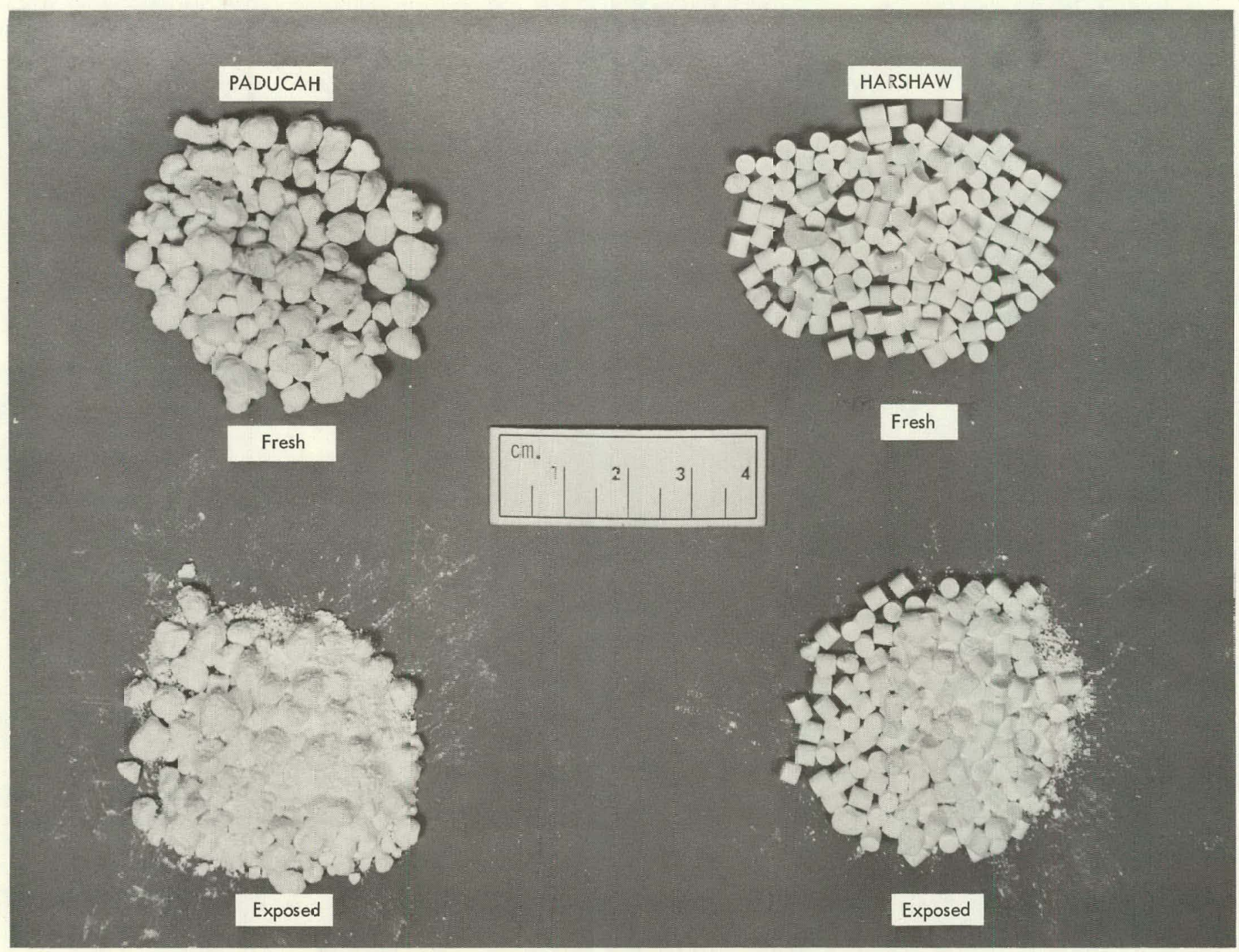

Figure 17

SODIUM FLUORICE PELLETS 
Trapping studies will be continued with different type pellets. Some tests are planned with pellets of mixed compositions.

Annular Pellet Trap

The primary problem encountered in designing large pellet traps for production use is one of heat transfer and resultant long desorption cycles. At this time, it is judged that large traps should be of annular design to minimize the distance from the center of the bed to the wall. A prototype unit consisting of concentric 5- and 12-inch diameter Monel pipes having a 60-inch bed height has been constructed. The annulus is baffled so that both the inlet and outlet pipes can be located at the top of the trap, and the bottom is coned to a central discharge port to facilitate removal of the pellets. The unit is heated electrically and is air cooled with the heating and cooling applied to the outside surface of the 12-inch pipe and to the inside surface of the 5-inch pipe. The trap and a flow diagram of the sorber loop are shown in figures 18 and 19.

The results of the annular trap sorption tests are shown in table XV. A total of 184.5 pounds of $540^{\circ} \mathrm{C}$. treated sodium fluoride pellets was used as a charge for the first series of runs. In all runs, a sorption temperature of $120^{\circ} \mathrm{C}$. and a desorption temperature of $400^{\circ} \mathrm{C}$. were used. As was expected, the fresh pellets sorbed more uranium hexafluoride per pound of sodium fluoride than did the used pellets; however, the average sorption ratio amounted to only 0.17 pound of uranium hexafluoride per pound of sodium fluoride. Since this ratio was somewhat lower than expected, the pellets have been put in storage. At a later date, 4-inch trap tests will determine whether the low value is associated with pellet properties or with trap design.

To investigate the possibility of gas channeling in the upflow section, the annular trap was modified for the B series of runs to allow a separate parallel downflow of gases through each side of the annulus and a rejoined flow outlet at the bottom of the trap. Flows through each half were not measured and were dependent on the pressure drops through each of the pellet beds. The sorption ratios for a third charge of pellets were slightly lower than those obtained with the trap used as designed originally. Modifications to the trap and operating conditions are being formulated in an attempt to improve the performance capability.

Fluidized Bed

Pilot-plant studies are being made of a continuous system, figure 20, for the sorption of uranium hexafluoride from a process gas stream. Uranium hexafluoride diluted with nitrogen is first passed through sodium fluoride powder in a 6-inch diameter, 30-inch deep stirred fluid bed held at $120^{\circ} \mathrm{C}$. Sodium fluoride is fed continuously, and the overflow powder is transported by the outlet gases to a filter mounted above the feed hopper for a ribbon flight screw desorber. The uranium hexafluoride-laden powder is fed from this hopper to the 6-inch diameter, 8-foot long screw, where it is heated to $400^{\circ} \mathrm{C}$. to drive off the uranium hexafluoride. A small flow of fluorine is maintained through the screw to prevent formation of 
DWG. NO. G-65-440

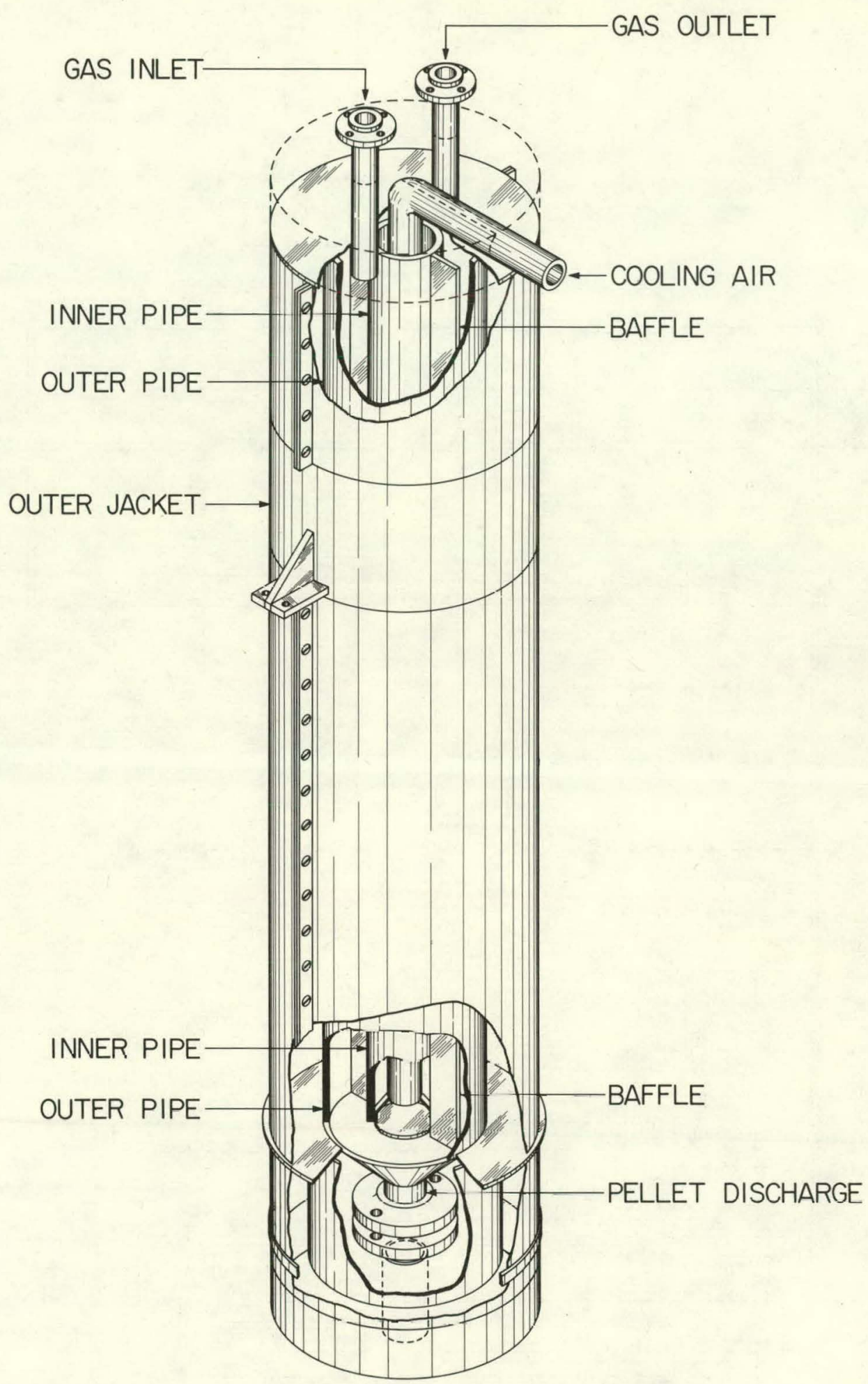

Figure 18

ANNULAR TRAP 
DWG. NO. G-65-364
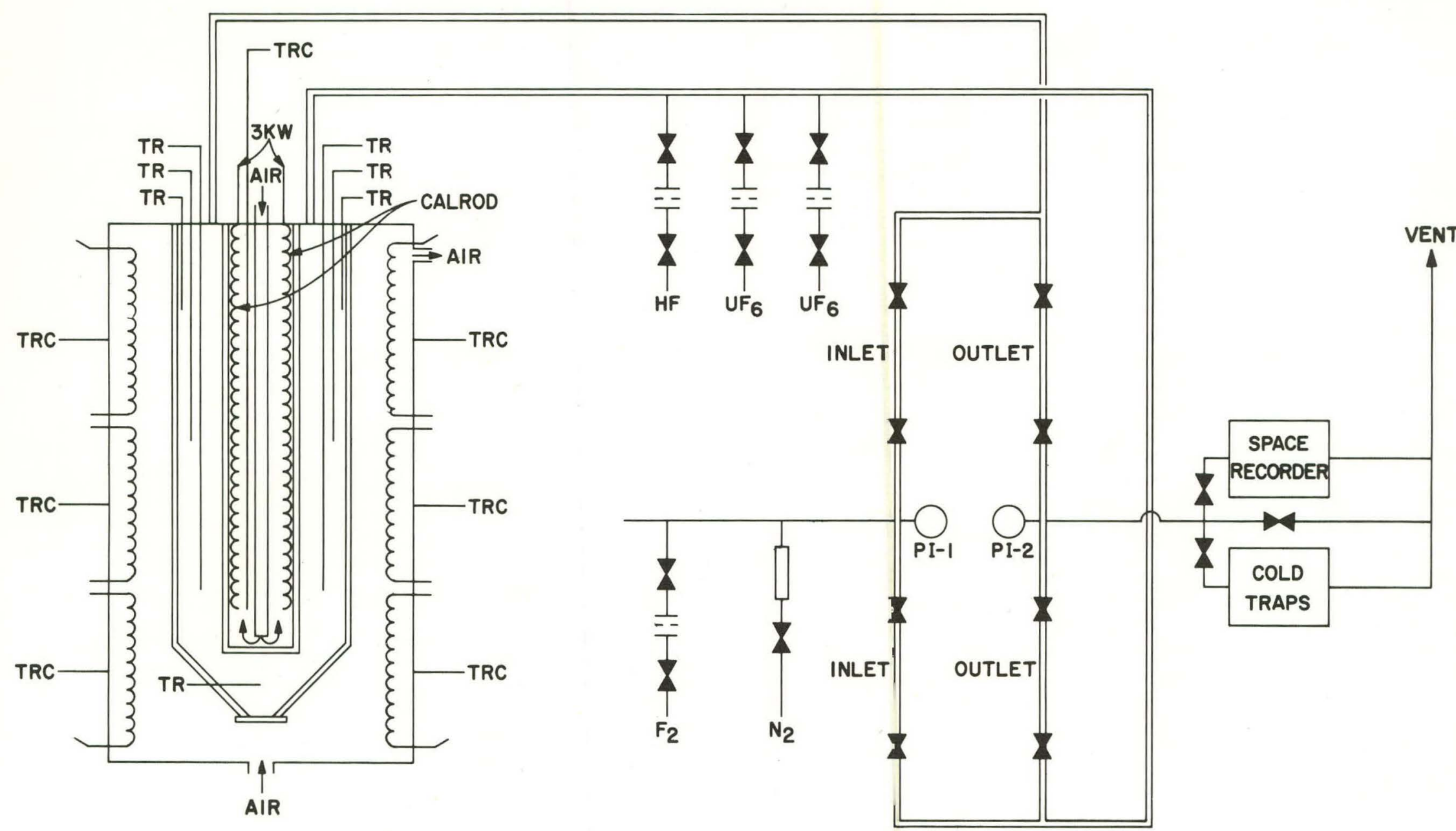

Figure 19

ANNULAR TRAP LOOP 
DWG. NO. G-65-359

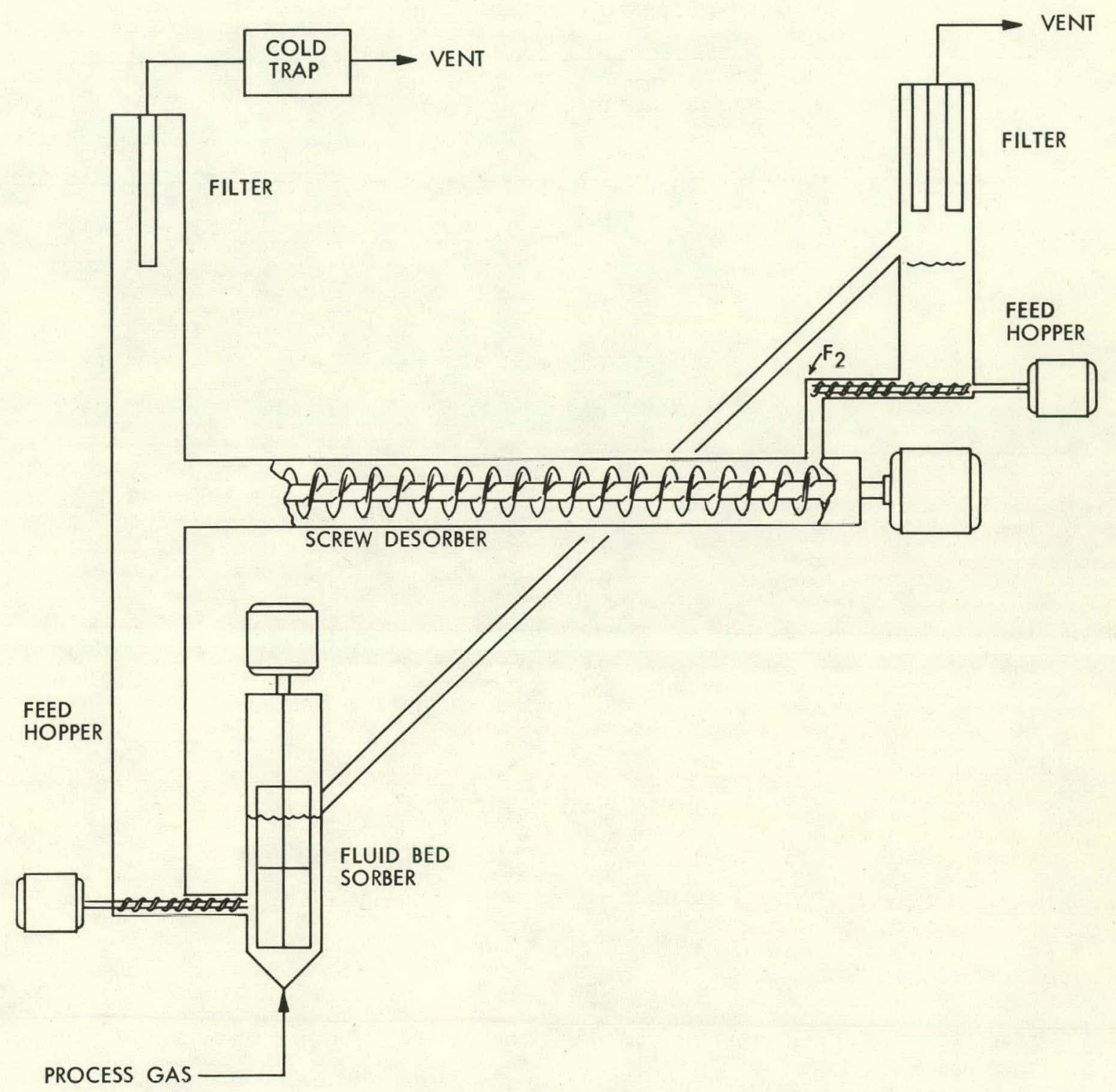

Figure 20

CONTINUOUS UF 6 SORPTION SYSTEM 
uranium compounds other than the hexafluoride. The regenerated sodium fluoride falls into the fluid-bed hopper to complete the cycle. The total sodium fluoride inventory in the system is about 200 pounds.

TABLE XV

RESULTS OF ANNULAR TRAP SORPTION TESTS

\begin{tabular}{|c|c|c|c|c|c|c|c|}
\hline \multirow{2}{*}{$\begin{array}{c}\text { Run } \\
\text { Number } \\
\end{array}$} & \multirow{2}{*}{$\begin{array}{l}\text { Total } \\
\text { Gas Flow, } \\
\text { std.cfm. } \\
\end{array}$} & \multicolumn{3}{|c|}{$\begin{array}{c}\text { Inlet Gas } \\
\text { Concentration, } \\
\% \\
\end{array}$} & \multirow{2}{*}{$\begin{array}{l}\text { Sorption } \\
\text { Time, } \\
\text { hr. } \\
\end{array}$} & \multirow{2}{*}{$\begin{array}{c}\text { Desorption } \\
\text { Time, } \\
\text { hr. } \\
\end{array}$} & \multirow{2}{*}{$\begin{array}{l}\text { Sorption Ratio, } \\
\text { Ib. UF / lb. NaF }\end{array}$} \\
\hline & & $\mathrm{UF}_{6}$ & $\underline{F}_{2}$ & $\underline{N}_{2}$ & & & \\
\hline 1 & 2.6 & 10 & 15 & 75 & 5.2 & 14 & 0.41 \\
\hline 2 & 2.6 & 10 & 15 & 75 & 3.0 & 14 & 0.24 \\
\hline 3 & 2.6 & 10 & 15 & 75 & 2.5 & 14 & 0.21 \\
\hline 4 & 2.6 & 10 & 15 & 75 & 2.0 & 14 & 0.16 \\
\hline 5 & 2.6 & 10 & 15 & 75 & 3.2 & 14 & 0.23 \\
\hline 6 & 4.0 & 10 & 15 & 75 & 1.2 & 14 & 0.11 \\
\hline 1 & 4.0 & 10 & 15 & 75 & 1.5 & 14 & 0.17 \\
\hline 8 & 4.0 & 10 & 15 & 75 & 2.2 & 14 & 0.24 \\
\hline 9 & 5.0 & 2 & 5 & 93 & 3.0 & 14 & 0.11 \\
\hline 10 & 5.0 & 2 & 5 & 93 & 5.0 & 14 & 0.13 \\
\hline 11 & 5.0 & 2 & 5 & 93 & 4.0 & 14 & 0.75 \\
\hline 12 & 5.0 & 2 & 5 & 93 & 4.0 & & $0.15 *$ \\
\hline B-I & 2.6 & 10 & 15 & 75 & 3.7 & 14 & 0.32 \\
\hline B-2 & 2.6 & 10 & 15 & 75 & 2.1 & 14 & 0.18 \\
\hline$B-3$ & 2.6 & 10 & 15 & 75 & 2.2 & 14 & 0.15 \\
\hline B-4 & 2.6 & 10 & 15 & 75 & 2.0 & 14 & 0.12 \\
\hline$B-5$ & 2.6 & 10 & 15 & 75 & 2.0 & 11 & 0.16 \\
\hline B-6 & 2.6 & 10 & 15 & 75 & 1.8 & 14 & 0.15 \\
\hline
\end{tabular}

* From flow measurements only. Not confirmed by cold trap weight on desorption.

Performance of the system has been very good for the range of conditions studied to date. The fluid bed has been operated with gas velocities of 0.15 to 0.70 foot per second, inlet gas uranium hexafluoride concentrations of 1 to $4 \%$, and a bed temperature of $120^{\circ} \mathrm{C}$. No problems have been noted with stirrer speeds as low as $20 \mathrm{rpm}$., and the average uranium hexafluoride concentration in the outlet gas has been consistently below 50 ppm. Essentially complete desorption of the uranium hexafluoride has been accomplished in the screw reactor at $400^{\circ} \mathrm{C}$. with only a small flow 
of buffering gas. Screw outlet gases containing as high as $40 \%$ uranium hexafluoride have been obtained. The rotational speed of the screw flight is 1 to $2 \mathrm{rpm}$.

The sodium fluoride used in the tests just described was prepared by heating sodium bifluoride cyrstals (100\% through 20 mesh, 5\% through 325 mesh) to $815^{\circ} \mathrm{C}$. for 2 hours. The resulting crystals meet essentially the same particle size specifications as the starting material, have bulk and packed densities of 1.3 and $1.6 \mathrm{~g} . / \mathrm{cc}$. , respectively, and have a surface area of 0.2 to $0.3 \mathrm{sq} . \mathrm{m} . / \mathrm{g}$. In the studies to date, only a small decrease in particle size to 10 to $15 \%$ through 325 mesh has been noted, and no effect on fluidization has been observed. If the powder is heated to only $535^{\circ} \mathrm{C}$, however, rapid attrition occurs.

Continued operation of the pilot-plant system is planned. Studies will be made to determine the maximum capability of the unit and to investigate the effects of operating variables and of fission product accumulation. Since, for reprocessing use, the system must be essentially maintenance free, extended operation of the pilot plant at the expected conditions is necessary.

\section{CONNECTORS}

Since remote maintenance will be a requirement at many points in the proposed fuel reprocessing facilities, custom designed connectors must be used to facilitate removal of equipment. Service conditions for connectors at some points in the system will be quite rigorous because of the high temperatures and the corrosive gas atmospheres, particularly in view of the large size of some of the connectors, possibly up to 36 inches in diameter.

The first approach to the connector problem was to contact possible commercial suppliers. Several manufacturers of couplings were found who could deliver what appeared to be satisfactory products for electrical, instrument, and small process line use; however, only the Marman Conoseal clamp made by Aeroquip Corporation showed promise for application in the larger process lines. To broaden the possibilities for success, design work on adapting standard flat-faced flange closures for the required service was initiated. Results of the studies on the two types of connectors are described below. For both types, it was thought that double gaskets should be used so that the pressure between the seals could be monitored to detect leaks.

\section{Marman Conoseal}

A standard cingle gasket Marman Conoseal connector is shown in figure 2l; a double seal unit is shown in figure 22. The initial problem faced in adapting the Marman connector for the intended service was selection of suitable materials for the flange and the gasket. Use of nickel for both parts was undesirable from the standpoint of galling. Duranickel which can be age hardened appeared to be the logical flange material based on corrosion data given in an earlier section of the report. Gaskets would 


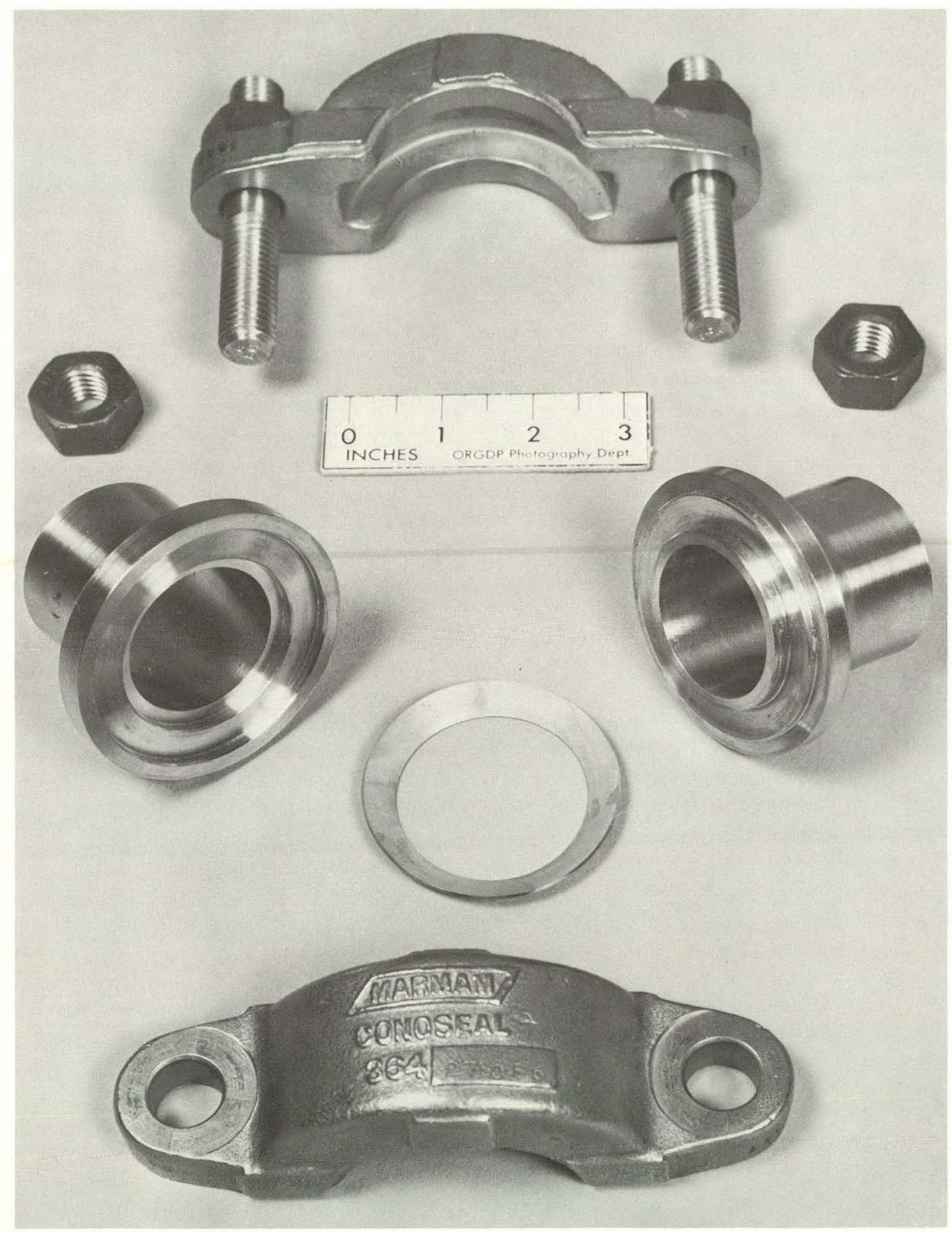

Figure 21

MARMAN CONOSEAL SINGLE SEAL 
PHOTO NO. PH-65-715

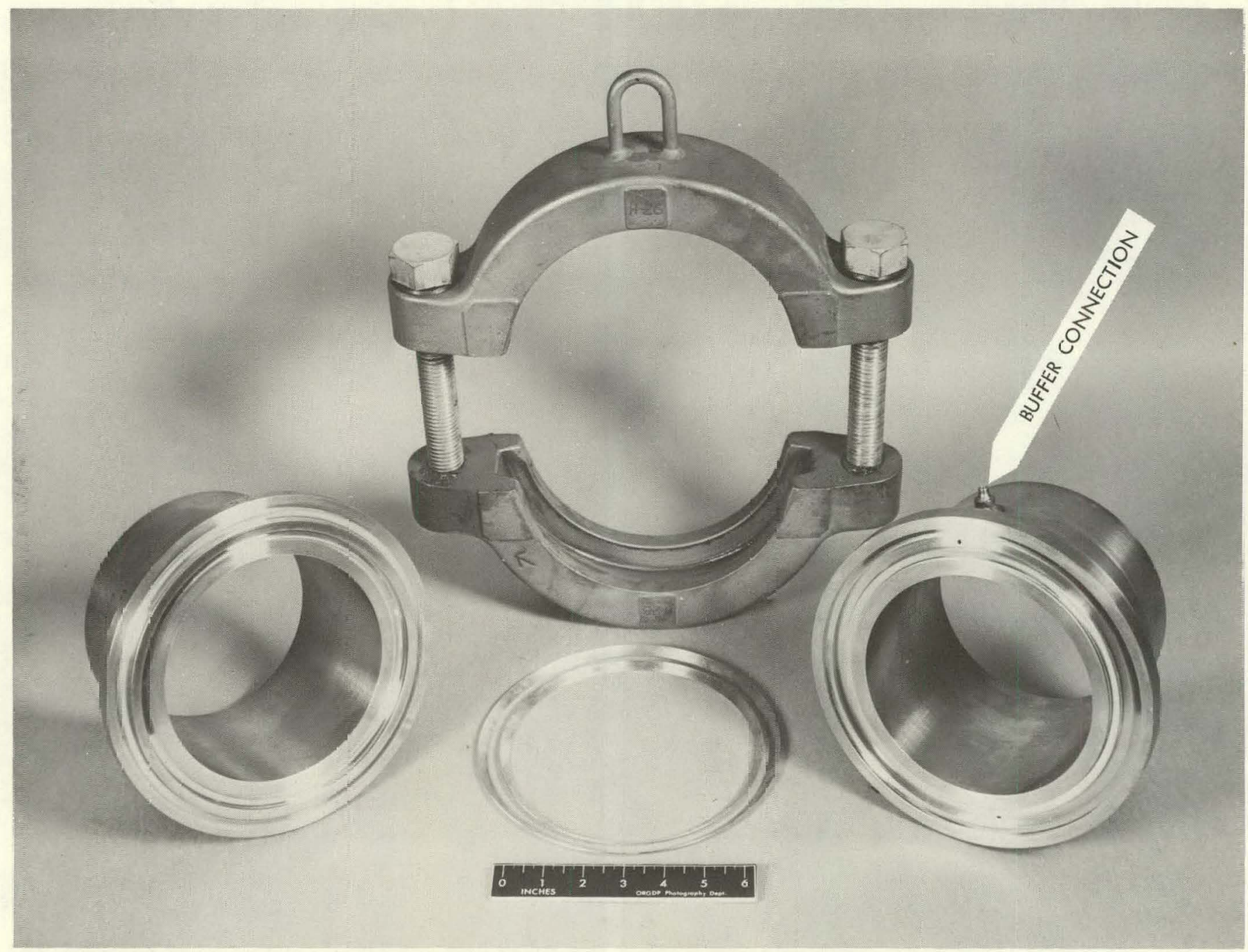

Figure 22

MARMAN CONOSEAL DOUBLE SEAL 
then be made of the softer nickel. Another possibility was plating of a hard flange material with nickel, either by electroless or electrolytic means. Accordingly, 1-l/2-inch Marman couplings made of nickel, Duranickel, and stainless steel were ordered for testing. Larger units were not obtained because of the high price quoted for single custom-built units.

Good sealing was obtained with an electroless nickel-plated flange if a soft aluminum gasket was used. With a stainless steel gasket, however, spalling of the plate occurred. Electrolytic plating was not attempted because it was felt that deposition of an even coating on the contemplated flange face was improbable. The decision to omit the electrolytic plating possibility from the program was further strengthened by good results with the Duranickel flange.

A-nickel and Duranickel 1-I/2-inch Conoseal joints were checked for seating at room temperature using nickel gaskets. The as-received hardness of the components were Rockwell B-75, B-95, and B-54 for the A-nickel flanges, the Duranickel flanges, and the gasket, respectively. The Duranickel flanges were subsequently heat treated to a hardness of Rockwell C-40 before testing.

Both joints sealed effectively at a bolt torque loading of 20 foot-pounds. Each joint was opened and closed six times using the same gasket and resealed satisfactorily each time. It was somewhat difficult to join the two flanges with the provided clamps due to the bevel angle of the gasket. Considerable prying was also necessary to open the clamps to inspect the joint after each test.

The two Conoseals were then subjected to a heat cycling procedure. Both joints were torqued to a bolt loading of 30 foot-pounds, pressured internally to approximately 10 psig., and then placed in a muffle wherein the temperature was cycled between 95 and $540^{\circ} \mathrm{C}$. and held at the maximum and minimum temperatures for 1 hour. After the sixth cycle, the A-nickel joint developed a leak and was subsequently retorqued to a bolt loading of 85 foot-pounds. Both connectors sealed for the remaining of the twenty-nine cycles of the test.

It was very difficult to open the joints at the conclusion of the experiment. The clamps on both assemblies required hammer force to separate them from the joint flanges. The A-nickel Conoseal appeared to have fused together at the gasket surfaces; however, the Duranickel flanges separated readily after the clamps were removed. Material hardness checks of the components gave a Rockwell B-58 for the A-nickel and Rockwell C-39 for the Duranickel flanges. This indicates that annealing of the A-nickel occurred, while the Duranickel hardness remained constant.

Results of the tests on their units have been discussed with Marman Conoseal representatives. It is their opinion that the clamp problem will probably be eliminated when the final design incorporates remote operator features and the use of dissimilar metals. The galling and fusing of the inner flanges and gaskets, resulting from the tests 
described, figure 23, however, are not so readily explainable, and the Marman engineers are reviewing their design for possible modifications.

\section{Flat-Faced Flange Connectors}

Four typical flange arrangements were chosen for the test program. Basically, these units consist of two standard 150-pound, 4-inch flanges machined and drilled for buffer connections to accommodate the various style gaskets. The joint arrangements include (a) a double wire ring gasket made of 1/16-inch nickel wire, figure 24; (b) a serrated type nickel gasket, figure 25; (c) a multiple touchpoint style nickel gasket, figure 26; and (d) a flat nickel gasket with a double ring serration milled into the flange, figure 27.

Compression tests showed that nickel was an unsatisfactory flange material with nickel gaskets. Severe scoring of flanges was noted under pressures required to give good sealing. Scoring was even observed with soft copper gaskets which had been nickel plated.

Efforts were then concentrated on the use of Duranickel for the flat-faced flanges. The first flanges made of this material were welded to nickel stubs and were age hardened by the following procedure:

1. Heat to $595^{\circ} \mathrm{C}$. in hydrogen atmospheres and maintain at that temperature for 16 hours.

2. Slow $\operatorname{cool}$ at $5^{\circ} \mathrm{C}$. per hour to $480^{\circ} \mathrm{C}$.

3. Cool at furnace cooling rate to room temperature.

Inspection of the flanges after hardening showed severe cracking, figure 28. At the recommendation of the International Nickel Company, the assembly was annealed by heating to $815^{\circ} \mathrm{C}$. under hydrogen and then waterquenching before hardening. Use of this procedure has eliminated the cracking.

The flange assemblies described earlier have been fabricatcd from Duranickel, and testing is in progress.

COMPRESSORS

In the volatility flow sheets, recycle of process gas will be required in the fluorination steps and probably during hydrogen chloride decladding. The only commercially available pump application for these services is the diaphragm type unit. Accordingly, bids from various vendors of such units were requested, and a Corblin compressor was purchased through the American Instrument Company, Inc. The lack of choice of commercial compressors, coupled with the inherent low capacity of the diaphragm machines, made it desirable to consider utilization of ORGDP compressor development experience to fill the process needs. Accordingly, work was started at the ORGDP in designing a peripheral type compressor, a unit that has many potential advantages over lhe diaphragm type machine. 
PHOTO NO. PH-64-475

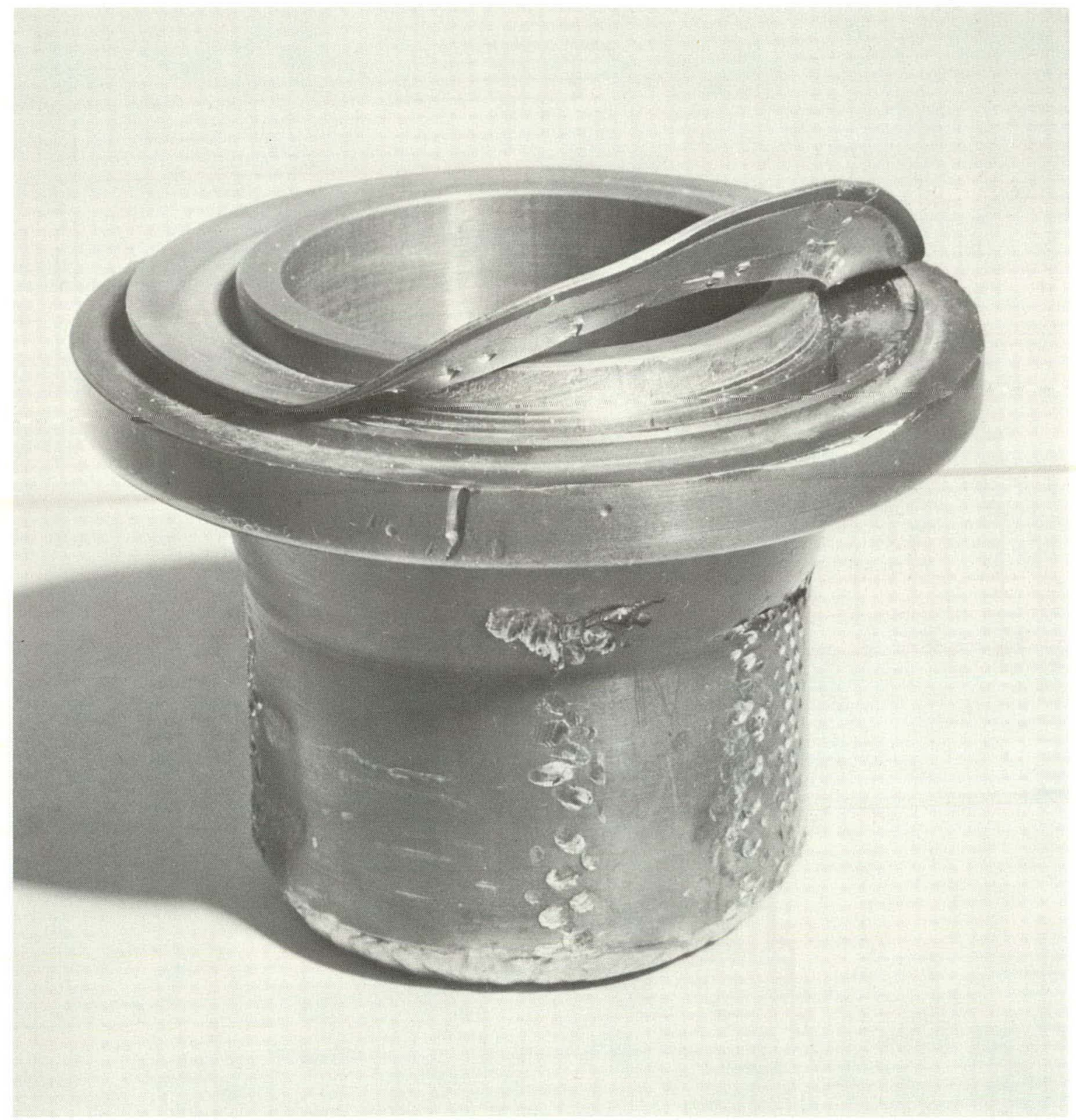

Figure 23

NICKEL MARMAN CONOSEAL AFTER HEAT CYCLING 


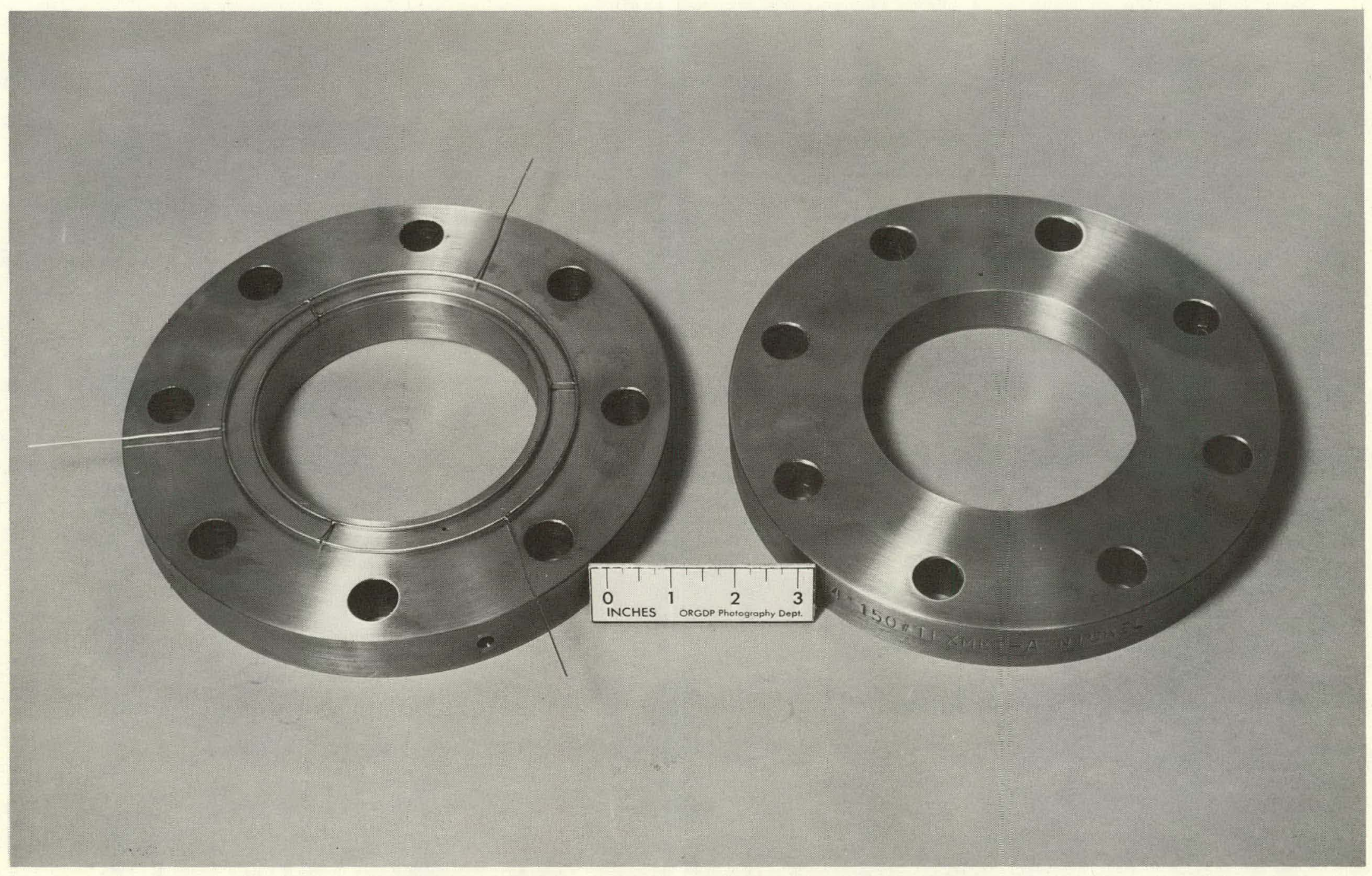

Figure 24

DOUBLE RING GASKET 


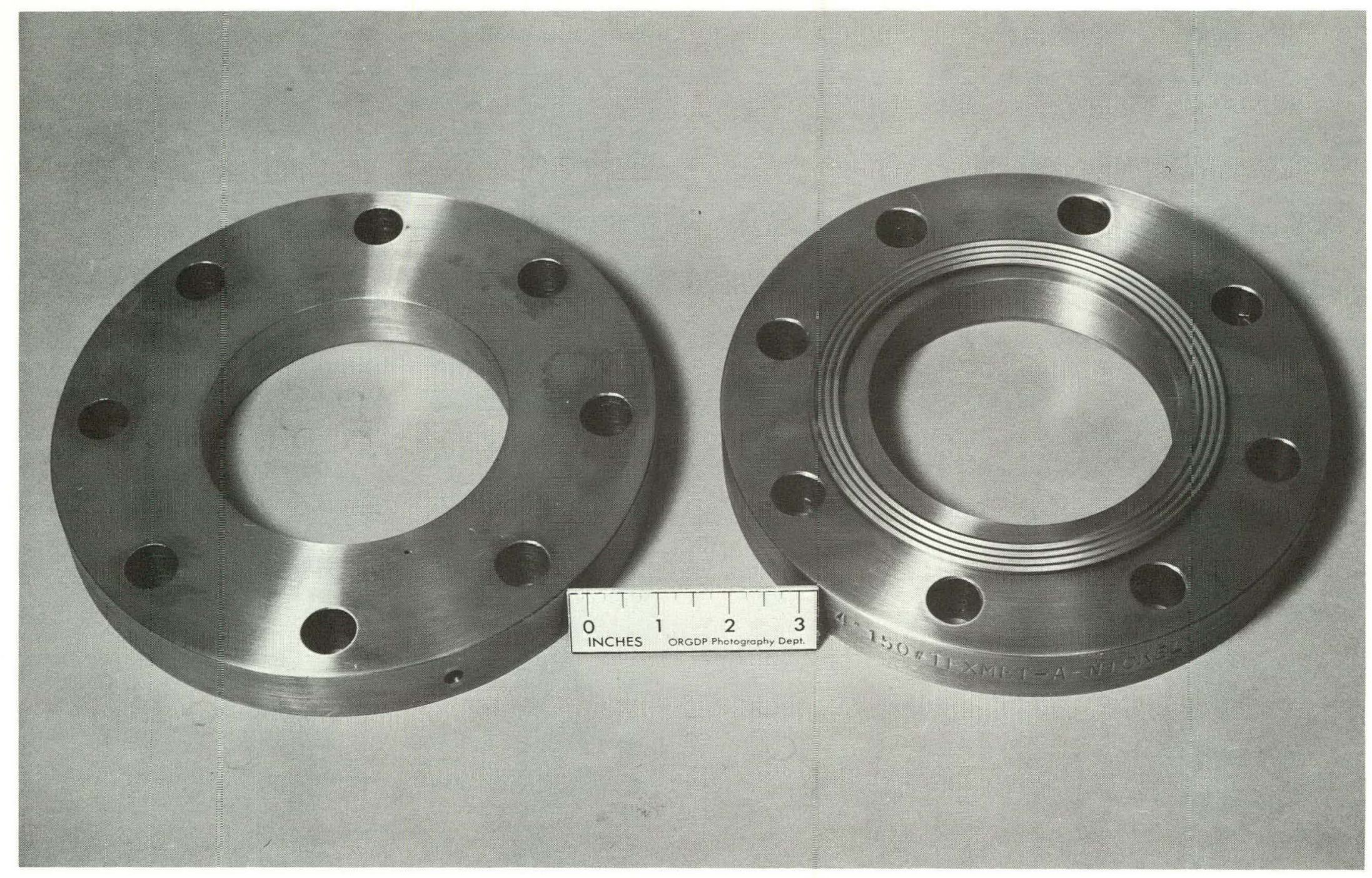

Figure 25

SERRATED GASKET 


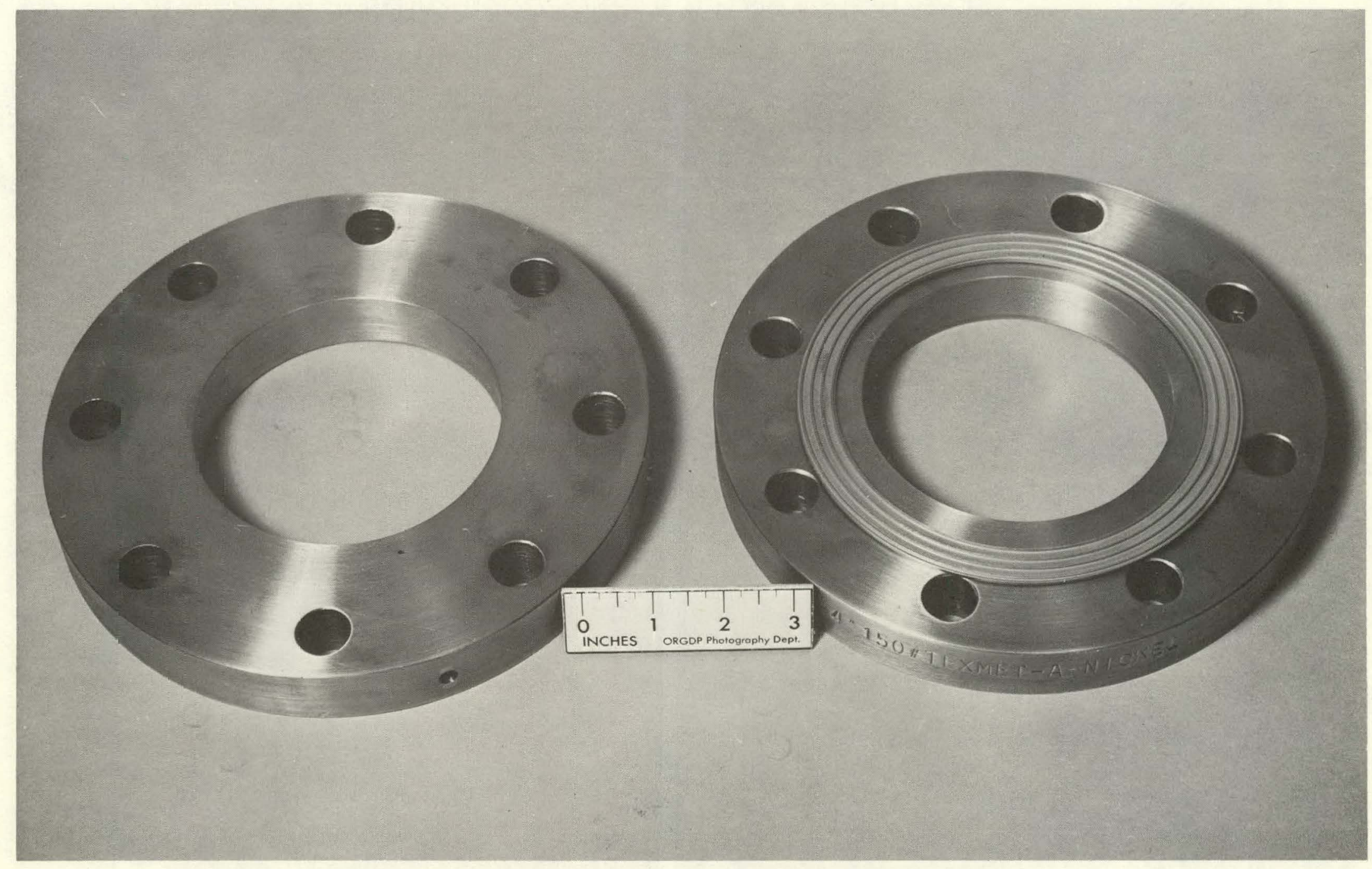

Figure 26

MILLED MULTIPLE TOUCHPOINT GASKET 


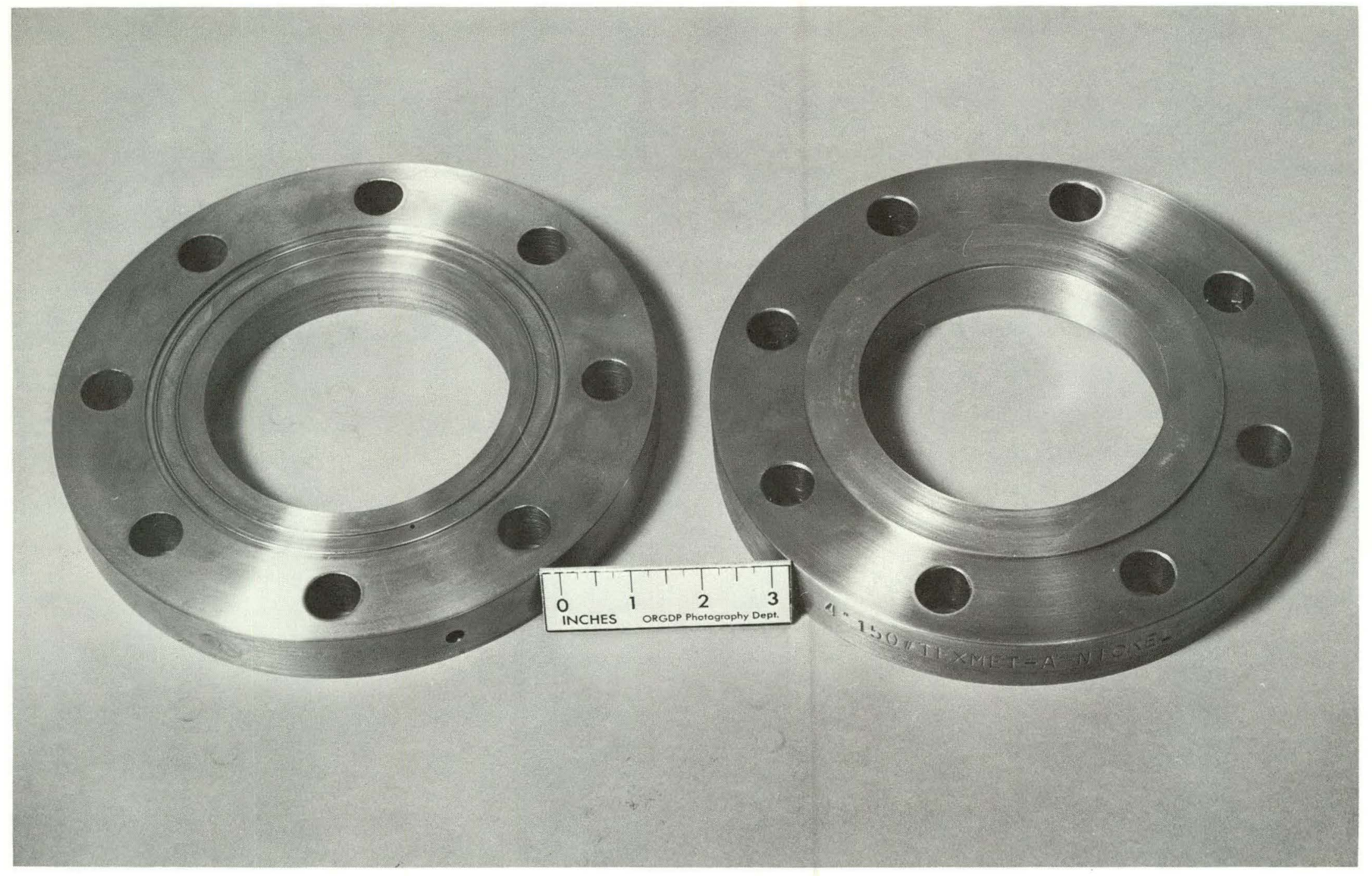

Figure 27

MULTIPLE TOUCHPOINTS ON FLANGE - FLAT GASKET 


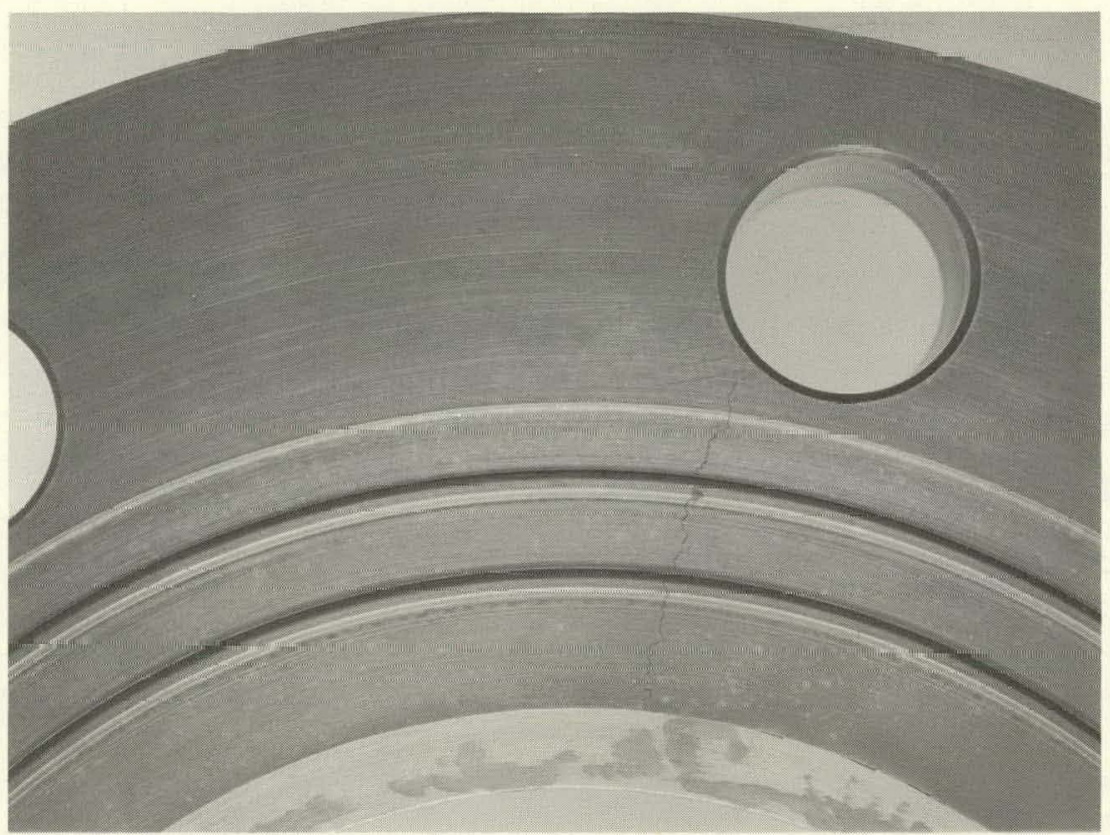

Magnification $1 X$

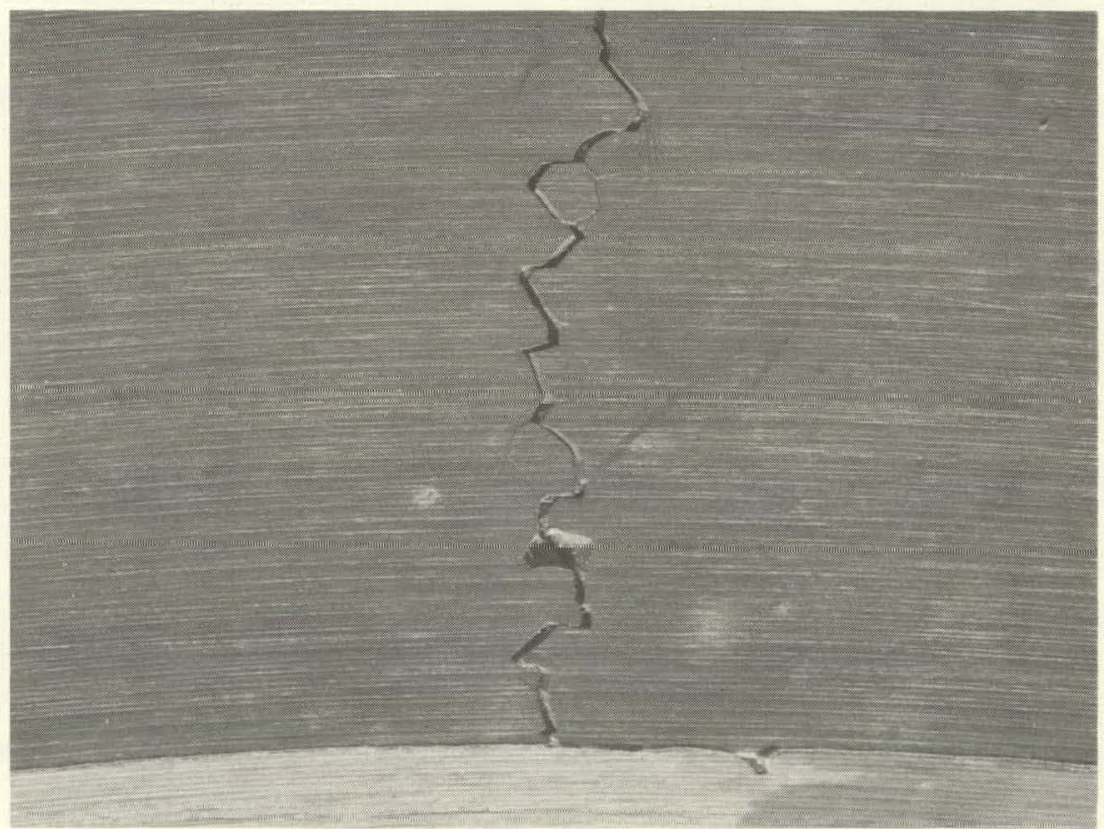

Magnification $10 \mathrm{X}$

Figure 28

DURANICKEL FRACTURES 


\section{Peripheral Compressor}

Compressor requirements for a l-tonne of uranium per day production line are summarized in table XVI. Studies at the ORGDP on the peripheral compressor indicated that it had attractive possibilities for meeting these requirements and would also operate reliably with satisfactorily low maintenance. A photograph of an experimental single-stage peripheral (sometimes called drag or regenerative) compressor is shown in figure 29. Positive displacement compressors, such as the reciprocating piston, the rotary lobe, and the diaphragm, are generally inferior because of problems associated with lubrication, wear, sealing, diaphragm life, and vibration. Compared with the centrifugal compressor, the peripheral type has simpler construction, operates stably throughout its flow range, and develops higher heads or pressure ratios for a given impeller speed and size.

TABLE XVI

DESIGN CRITERIA FOR

FLUID-BED VOLATILITY IOOP COMPRESSORS

I Tonne of Uranium Per Day Line

\begin{tabular}{|c|c|c|}
\hline & Compressor No. I & Compressor No. 2 \\
\hline Suction Pressure, psia. & 14.7 & 14.7 \\
\hline Pressure Ratio & $2: 1$ & $2: 1$ \\
\hline Volume Flow, std.cfm. & 50 to 150 & 25 to 50 \\
\hline Suction Temperature, ${ }^{\circ} \mathrm{C}$. & -40 to +25 & 95 \\
\hline Process Gas Constituents & $\mathrm{HCl}, \mathrm{H}_{2}, \mathrm{~N}_{2}$ & $\mathrm{~F}_{2}, \mathrm{~N}_{2}, \mathrm{UF}_{6}, \mathrm{ClF}_{3}$ \\
\hline $\begin{array}{l}\text { Approximate Range of } \\
\text { Molecular Weights }\end{array}$ & 18 to 35 & 28 to 61 \\
\hline Maximum Inleakage, sta.cfm. & 0.2 & 0.2 \\
\hline
\end{tabular}

In addition to selection of compressor type, it was necessary to choose the type of drive, bearing, and seal system. Two methods considered were (a) use of conventional bearings and motor with a shaft seal for protection from the process gas, and (b) use of process gas lubricated bearings with the motor operating in the process gas. Although the latter method has the advantage of a totally enclosed system with no inleakage, the technology, especially with regard to materials and motor protection, was considered insufficiently advanced to ensure a satisfactory compressor in the desired time.

The project therefore consisted of (a) development of the compressor aerodynamics; (b) development of a shaft seal design; and (c) combination of the aerodynamic, seal, shaft, bearing, and motor designs into a reliable, complete compressor. The goal was to evaluate the component and integrated designs and to construct a prototype compressor by July 1, 1965. 


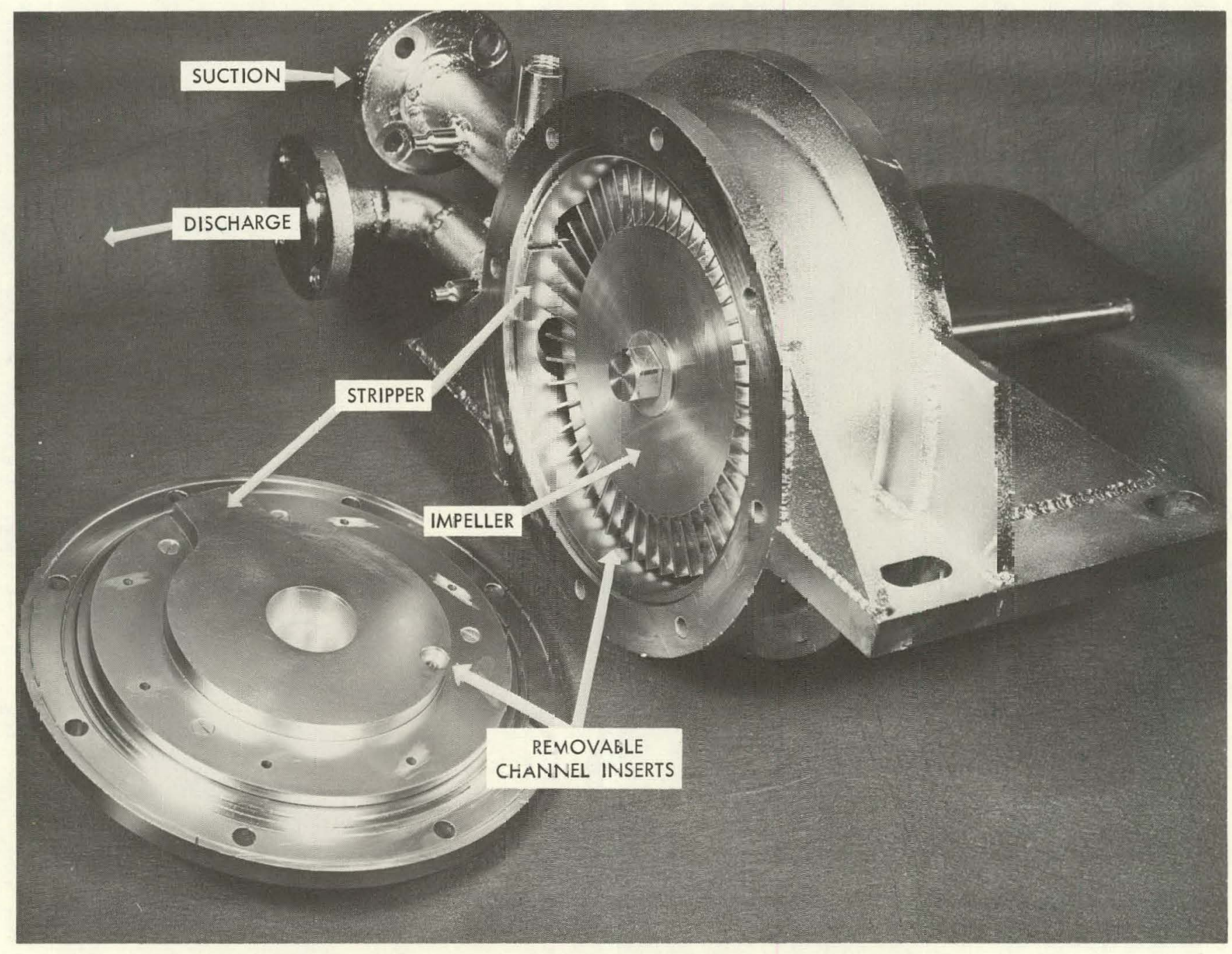

Figure 29

SINGLE STAGE PERIPHERAL COMPRESSOR 
The component development and testing, the integrated design evaluation, and the design of a prototype compressor have been completed. Construction of the prototype is in progress and is scheduled for completion by June 30, 1965. The compressor, shown in figure 30, will have two stages on a single impeller, and an interstage cooler will be used to remove the heat of compression from the first stage. Through the use of removable inserts to change the channel dimensions, one basic compressor design will meet the requirements of both compressors operating at 11,000 rpm. The design consists of the impeller and motor rotor mounted on a single shaft supported in precision ball bearings. A nitrogen-buffered bushing seal will seal the process gas with a small amount of nitrogen inleakage. Motor and bearing cooling will be accomplished by a water jacket around the motor stator and an air thermal barrier between the compressor passages and the bearing housing. The expected compressor performance curves based on results of tests conducted in air are shown in figures 31 and 32. Descriptions of the work involved in arriving at the design of the compressor follow.

Seal Development. For the relatively high shaft speed necessary for these compressors, a positive clearance seal was considered more feasible than a contact seal. Three seal types studied in the program were (a) labyrinth, (b) screw, and (c) bushing. A stand for conducting the seal tests were constructed, and several designs of each type were evaluated using a 1.9375-inch diameter shaft size. Figure 33 is a photograph showing each seal type studied. All tests were made in air at speeds of 0 , 8,600 , or $11,000 \mathrm{rpm}$. Capacitance-type clearance probes were used at monitor shaft position during various operating conditions. Radial clearances of 0.002 inch and 0.003 inch were tested; other geometric variables included length of seal, eccentricity of hub to sleeve, number and shape of labyrinth teeth, and design of screw seal grooving.

Designs of all three seal types which would meet the inleakage requirements were tested, and the best was the bushing seal. Table XVII summarizes the performance of the bushing seal. The flows reported are actual cfm. at 1 psi. differential pressure. The effect of eccentricity was studied to predict the result of any misalignment upon assembly or operation. As may be seen in the table, even with a 3.2-mil radial clearance and a 0.5 eccentricity, a 2 -inch long seal is adequate. The shorter length and larger clearance increase the freedom from assembly and operating difficulties. With precision ball bearings, a 3 -mil radial clearance is considered quite practical. Also, the pressure differential of 1 psi. is considered adequate to prevent any back diffusion of the process gas outward through the seal past the buffer gas (nitrogen).

Compressor Aerodynamics. Part of the ORGDP peripheral compressor program included studies of channel and impeller geometries. Of the impellers tested, one with 0.500 -inch deep blading was judged best. Stationary flow channel dimensions were systematically varied and tested with this impeller. Figure 34 summarizes the results obtained on nine channels which were closest to those required. Pressure ratio is plotted as a function of a dimensionless flow parameter which accounts for different fluid properties. Assuming two-stage operation, the approximate design points 
DWG. NO. G-65-382

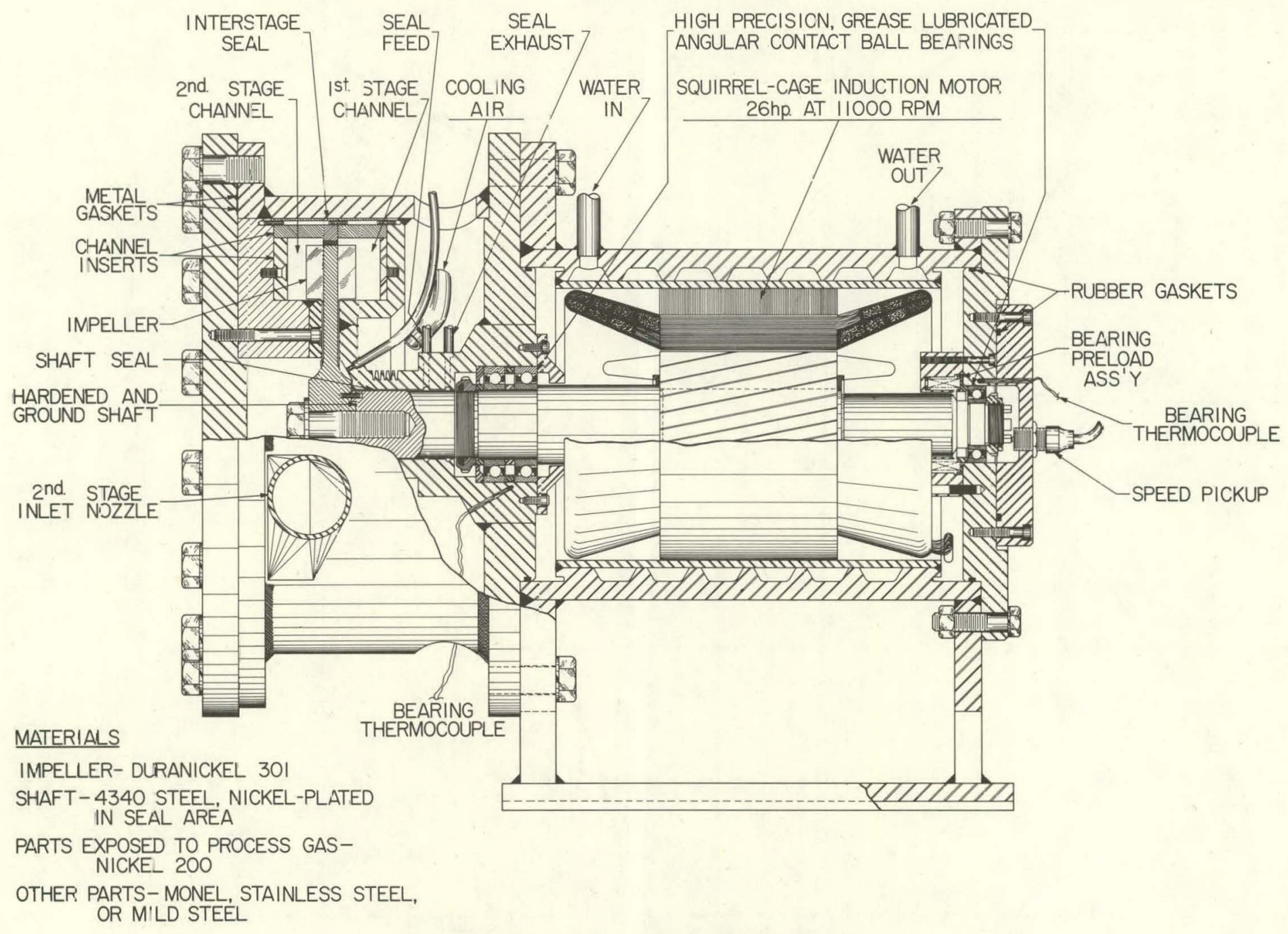

Figure 30

TWO-STAGE PERIPHERAL COMPRESSOR 


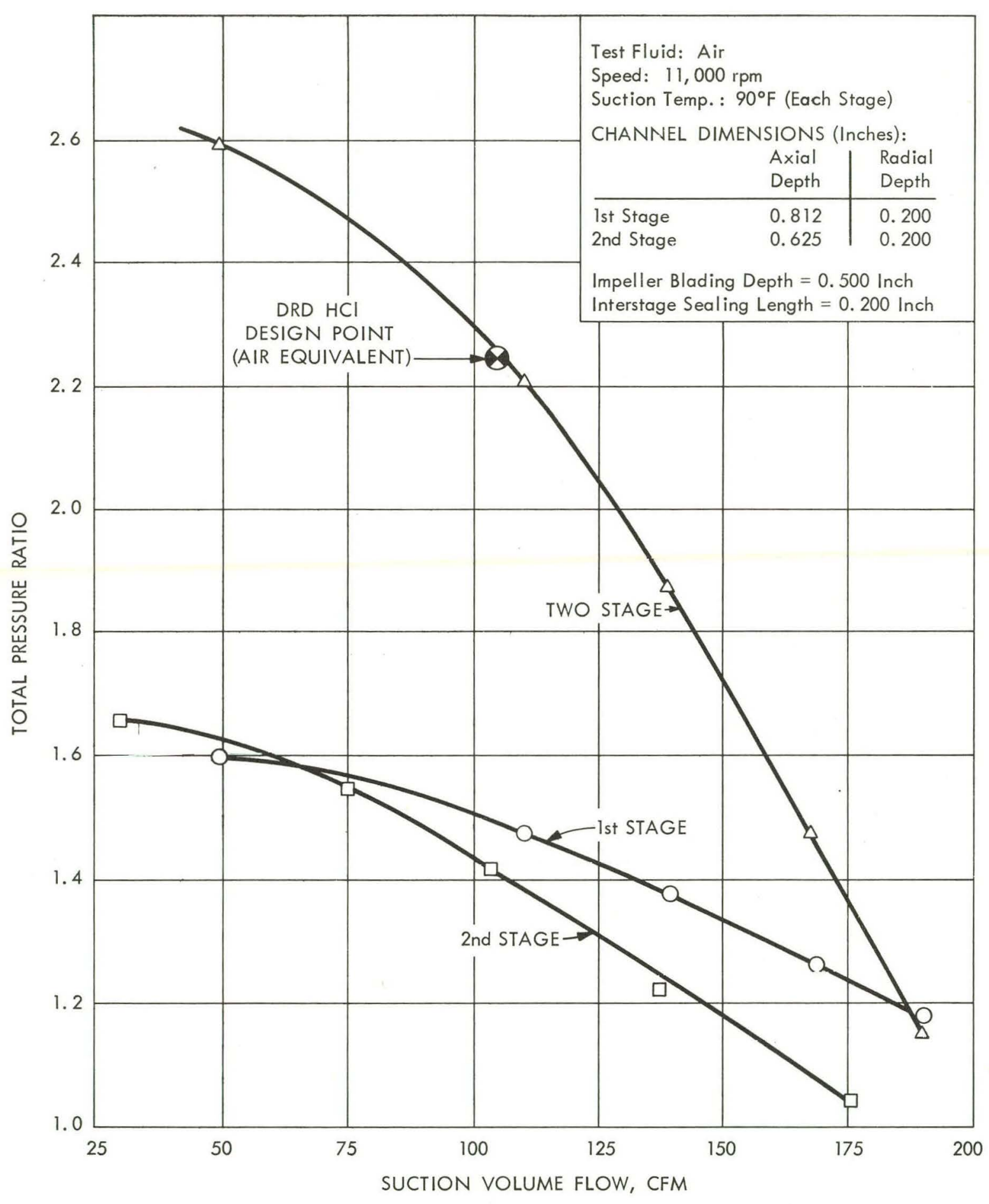

Figure 31

PERIPHERAL COMPRESSOR DUAL STAGE RESULTS 


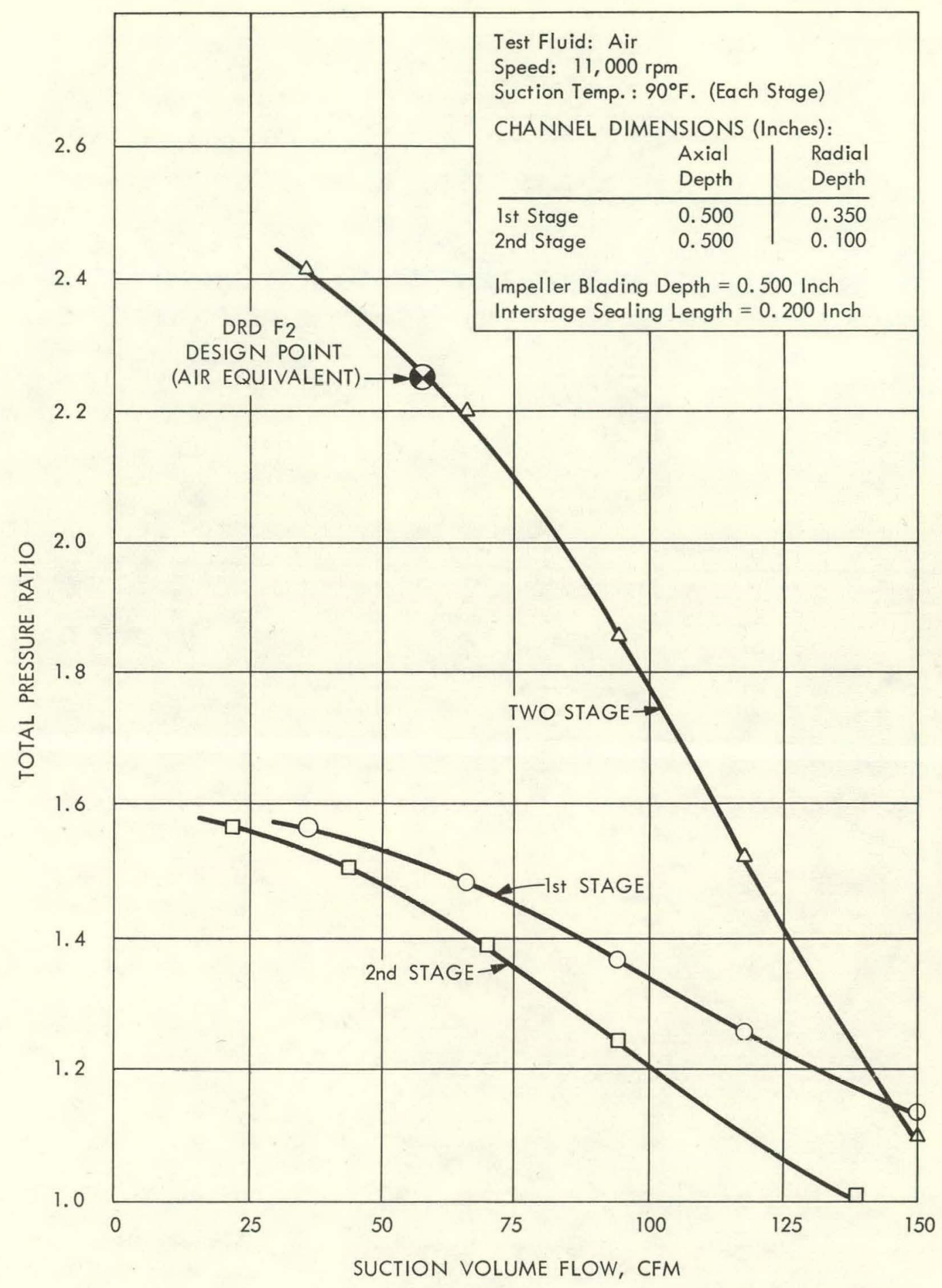

Figure 32

PERIPHERAL COMPRESSOR DUAL STAGE RESULTS 


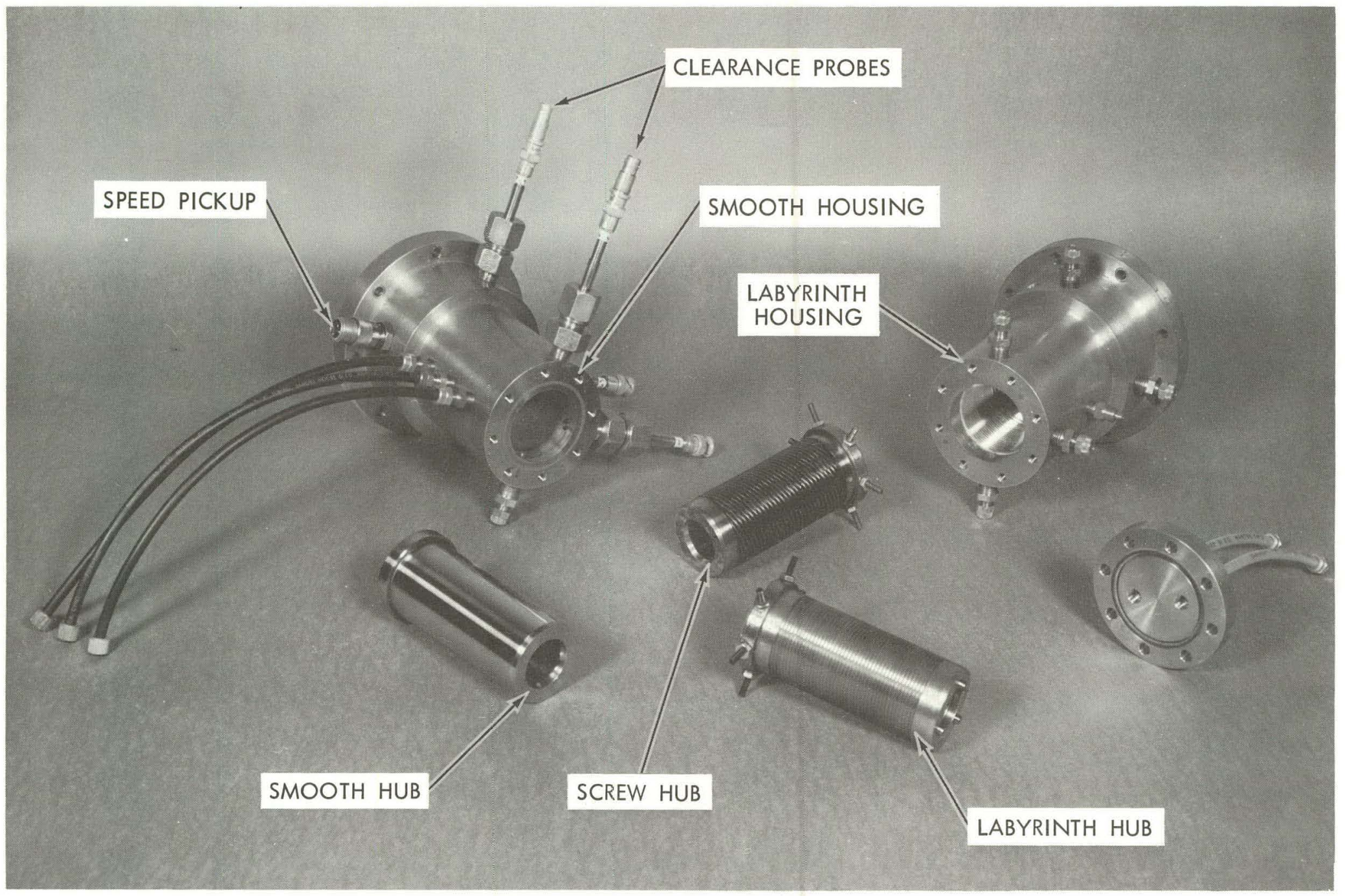

Figure 33

PERIPHERAL SEALS 


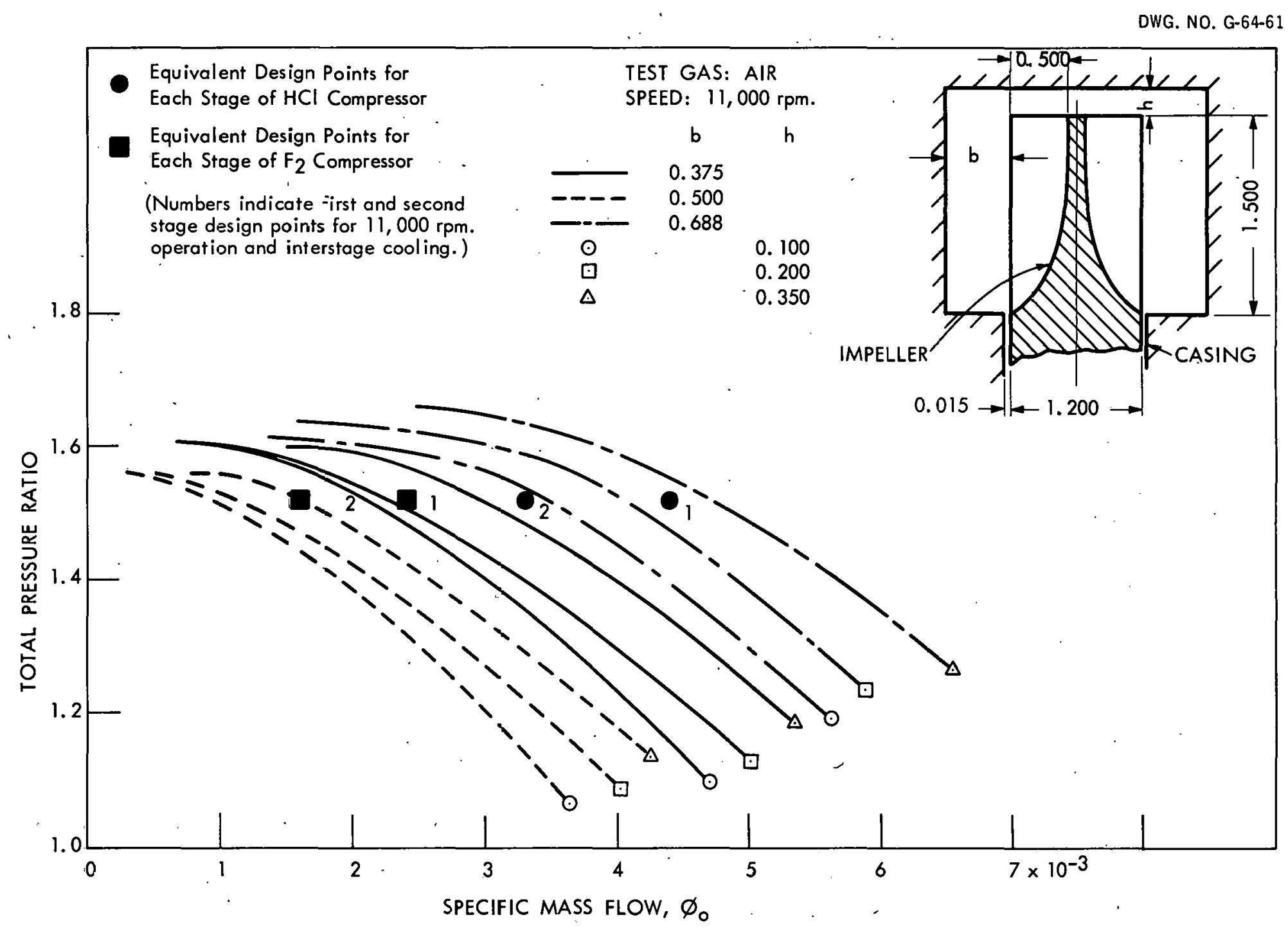

Figure 34

PERIPHERAL COMPRESSOR CHANNEL CHARACTERISTICS 
for each stage of each compressor were included in the figure. These curves point out an important advantage of the peripheral compressor. With a basic impeller and housing design, the performance at a given speed can be varied greatly by the use of simple inserts to change the channel dimensions. These channel data were obtained with 0.015-inch impeller-to-casing clearance, which has proved to be satisfactory both aerodynamically and mechanically.

\section{TABLE XVII}

PERFORMAIVCE OF 1.9375 -INCH DIAMETER BUSHING SEAL

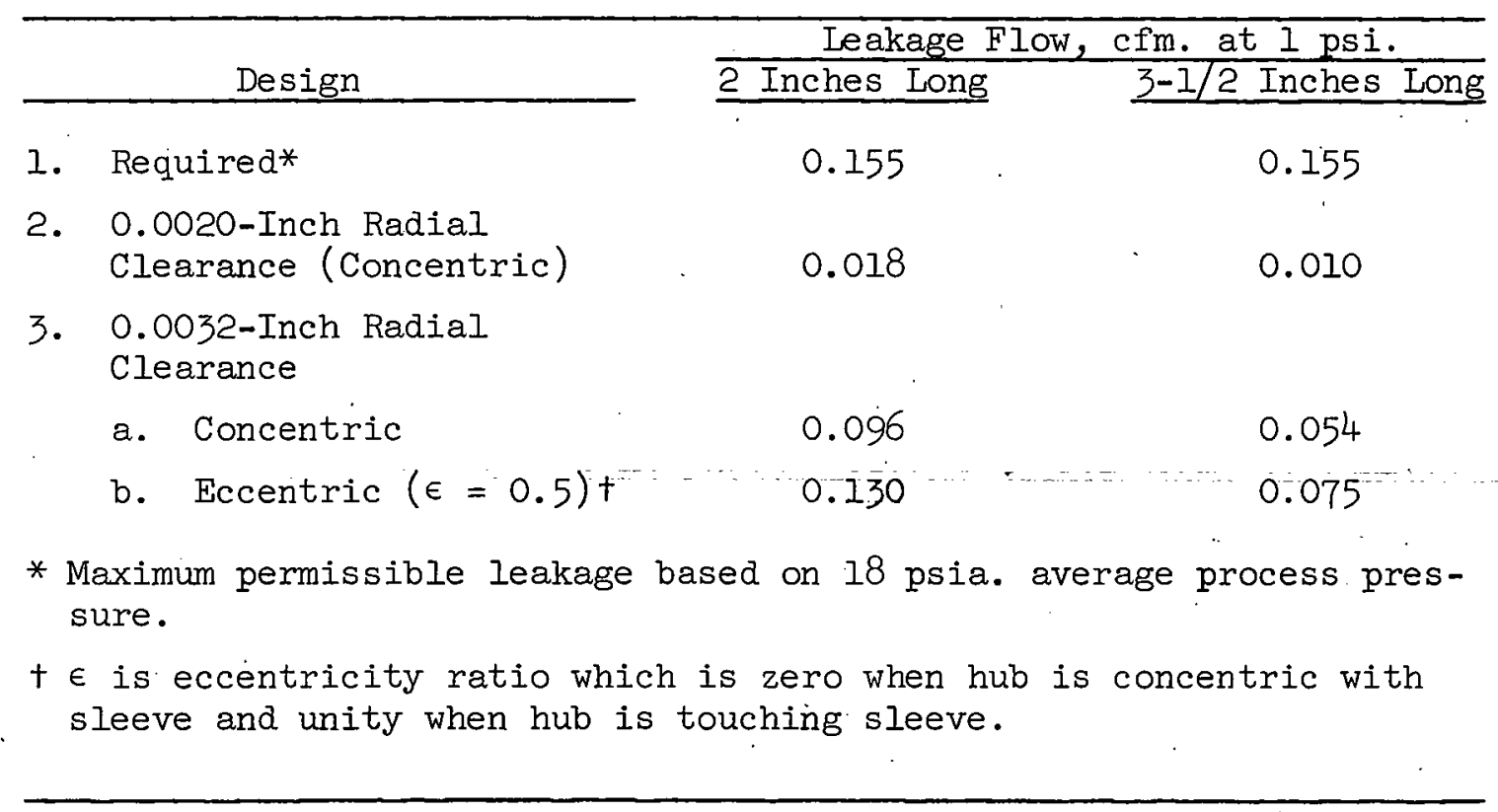

It became apparent early in the program that two stages of compression would be necessary to permit reasonable operating speeds. Since the two sides of a peripheral impeller are independent of each other, mounting two stages on a single wheel with some interstage sealing device seemed feasible. This dual stage, single impeller concept would reduce the overhang moment on the shaft and would improve the rotor dynamic characteristics. The concept proved successful in performance tests and has been incorporated in the compressor designs. The data in figures 31 and 32 were obtained with a single impeller and a labyrinth seal to reduce crossleakage between stages. This concept, along with a comparison of two impeller designs, is shown in figure 35. The new impeller design on the right is only $60 \%$ as heavy and has maximum stresses $59 \%$ as great as the conventional solid disc type impeller shown at left. The new type impeller is included in the prototype compressor design.

Test Rig Evaluation of Design Features. In addition to the development of the seal and compressor aerodynamic designs, it was considered important to study other design features of the compressor in an assembled configuration. These included rotor dynamic characteristics, bearing performance, motor and bearing cooling schemes, and motor performance. 
DWG. NO. G-65-634

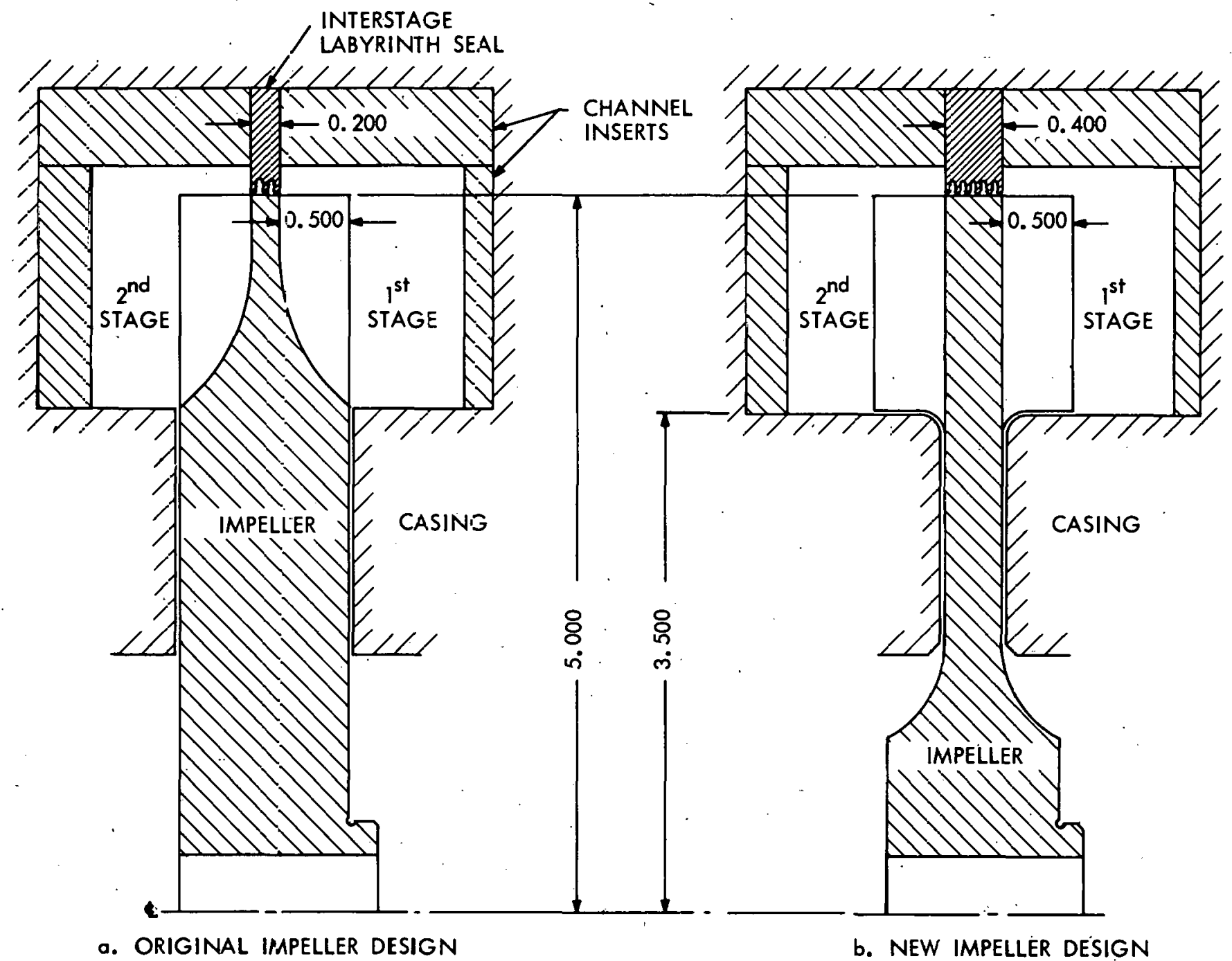

Figure 35

PERIPHERAL COMPRESSOR IMPELLERS 
A test rig, built for other ORGDP programs, was ideally suited for this evaluation. The rig was instrumented with capacitance clearance probes to monitor rotor movement and with thermocouple and stick-on temperature indicators to determine thermal conditions under various modes of operation. The studies to date have verified the mechanical and thermal integrity of the compressor designs. Performance of the high precision angular contact ball bearings packed with Andok-260 grease has been good, and the motor and bearing cooling methods have proved satisfactory. Bearing temperatures less than $80^{\circ} \mathrm{C}$. can be maintained at $11,000 \mathrm{rpm}$. under full load conditions ( temperatures less than $95^{\circ} \mathrm{C}$. are considered acceptable for these applications). Sizing of the motor, $26 \mathrm{hp}$, was adequate, and sufficient motor cooling is provided with a flow of 2 gallons of'water per minute. By maintaining close but practical machining tolerances and by achieving a high quality of rotor balance, no difficulties with rotor performance were encountered. Testing is still in progress to confirm the aerodynamic performance of the new impeller design, figure 35, but preliminary data indicate the performance to be satisfactory. Actually, any discrepancies in either the compressor requirements or the correlation of performance from air to the particular process gas should be easily resolvable by adjustments in channel dimensions in the final installation.

Diaruhagin Cömpressor

Performance specifications for the experimental diaphragm compressor are outlined in table XVIII. Multiple-compressors would be needed for a production line capable of reprocessing I tonne of uranium per day, since there is no available commercial unit capable of satisfying flows and pressures shown in table XVI. The fluorıne service application calls for a dual head assembly with a t'luid media inert to fluorine; uranium hexafluoride; hydrogen fluoride, and chlorine trifluoride between the diaphragms.. All parts exposed to the process gas are constructed of nickel. For hydrogen chloride service, a single diaphragm in contact with the process gas is sufficient. "The diaphragms for the experimental machine are 26 inches in diameter.

TABLE XVIII

CORBLIN COMPRESSOR PERFORMANCE SPECTFICATIUN

\begin{tabular}{|c|c|c|}
\hline Condition & Fluorine Service & HCl Service \\
\hline Capacity, std. cfm. & 12 & 20 \\
\hline Suction Pressure, psia. & 14.7 & 14.7 \\
\hline Suction Temperature, ${ }^{\circ} \mathrm{C}$. & 95 Maximum & -30 to +25 \\
\hline Discharge Pressure, psia. & 30 & 30 \\
\hline Gas to be Pumped & $\mathrm{F}_{2}, \mathrm{~N}_{2}, \mathrm{UF}_{6}$ & $\mathrm{HCl}, \mathrm{H}_{2}, \mathrm{~N}_{2}$ \\
\hline Molecular Weight Range & 28 to 61 & 18 to 35 \\
\hline
\end{tabular}


The compressor was installed in a test loop as shown in the flow diagram, figure 36. A photograph of .the unit is presented as figure 37. The system was arranged to test the remote head arrangement first, i.e., with the fluid volume between the diaphragms in the primary and remote heads filled with a fluorocarbon oil. As received from the vendor, no provision was made to compensate for fluorocarbon oil volume expansion and contraction resulting from temperature fluctuation; therefore, it was necessary to install pressure and vacuum relief valves for liquid volume control.

From the beginning, the pump exhibited an inherent vibration that required. several revisions to the loop to provide flexible couplings on the pump and service headers. Calibrated reactance probes were installed at various positions on the primary and remote heads, and the vibration frequency and amplitude were measured on an oscilloscope. Four vibration pulses per pump revolution are detectable as shown in figure 38 . Vibration movements as great as 0.100 inch on the remote head and 0.060 inch on the primary head were measured. Representatives of the pump vendor were informed of these results, and they stated that such vibration amplitudes were considered normal.

The maximum flow rate obtainable with the remote head was 10 . to $15 \%$ lower than that obtained in the manufacturer's tests before shipment; therefore, transducers were installed at points in the fluorocarbon oil section to investigate the possibility of harmonic pressure pulse development in the length of pipe connecting the primary head to the remote head. Such a condition could affect the pumping performance of the unit. Evidence of some minor wave action was present; however, a maximum pressure pulse occurred simultaneously at all points in the oil system, figure 39. At this writing, it is concluded that the lower rate is probably caused by a small amount of air in the hydraulic fluid in the primary head.

The compressor loop is now being readied for a life test of the pump. It is planned to compress dilute fluorine at the maximum flow rate under suction and discharge pressures of 14.7 and 30 psia., respectively.

REACTOR FABRICATION PROCEDURES - WELDING STUDIES

'The present specification concept for the primary fluid-hed reactor is that low carbon nickel will be used for surfaces in contact with the process. All welds on the equipment should be made using welding rod of the same material so that corrosion problems can be minimized. Considerable experimentation has shown the need for stringent preparation and welding procedures if acceptable welds of nickel-201 with nickel-201 rod that will meet the condition specified in pressure vessel codes are to be produced.

Many welding attempts were made in developing the recommended TIG weld. First, it was found that cleanliness of all components must be of the highest degree, since any nickel oxide present will cause welding difficulties and will create a porous weld. Flash pickling of all materials was found necessary. By dipping the work in a solution of $20 \%$ water-30\% sulfuric acid-50\% nitric acid containing 60 grams of sodium chloride per 


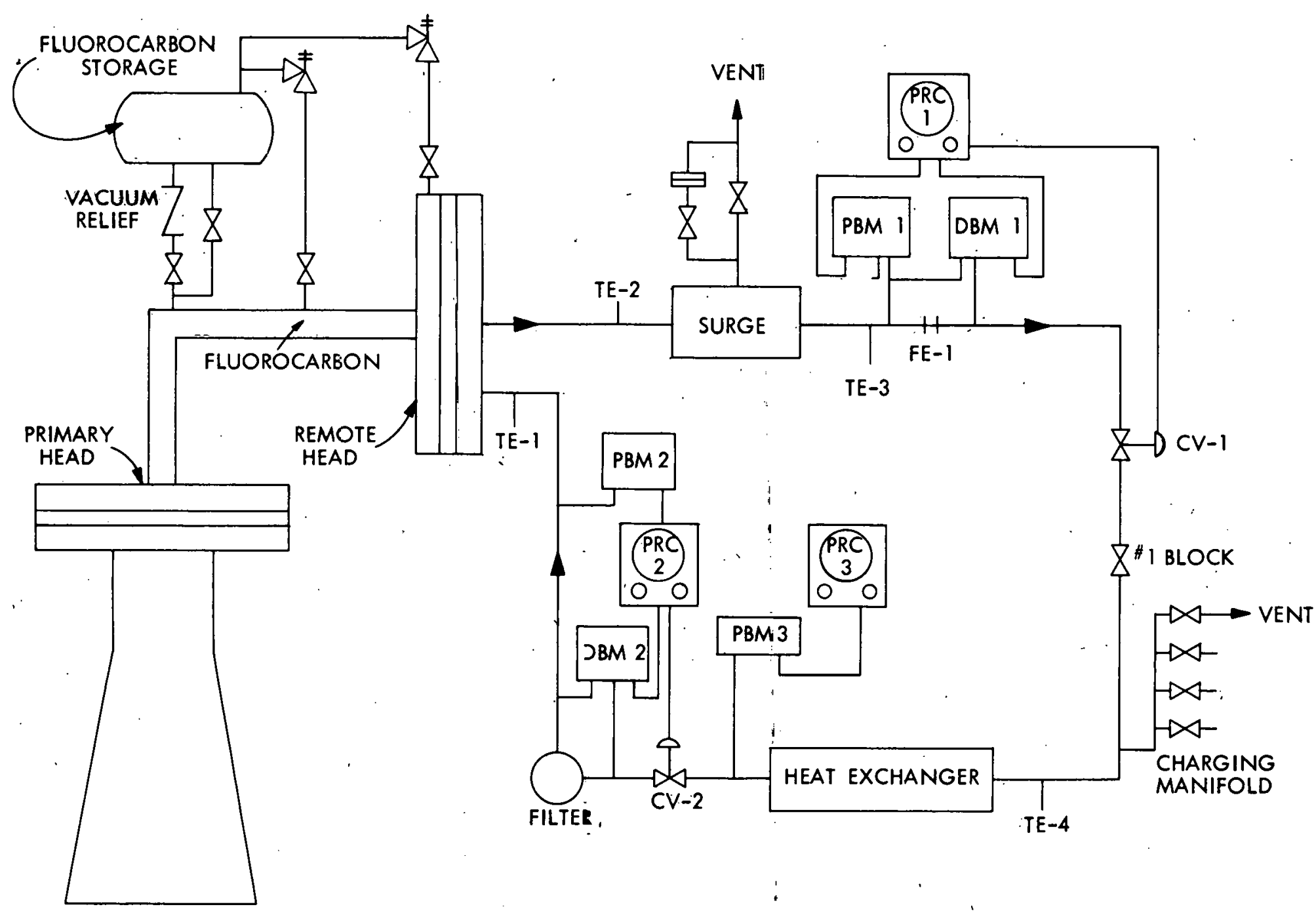

Figure 36

CORBIIN PUMP LOCIP 
PHOTO NO. PH-65-717

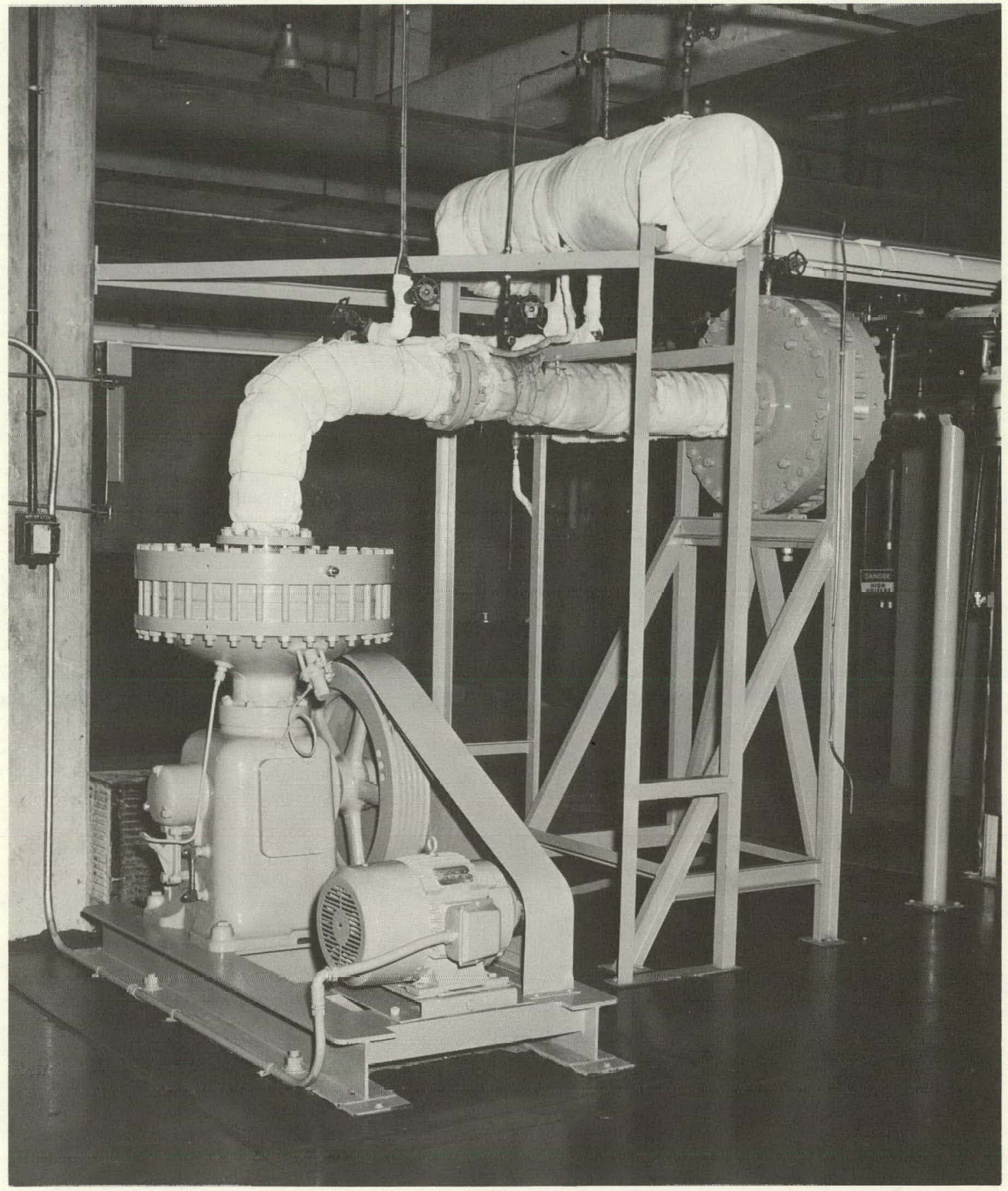

Figure 37

CORBLIN COMPRESSOR 
Vibration Amplitude 19 mils per Division

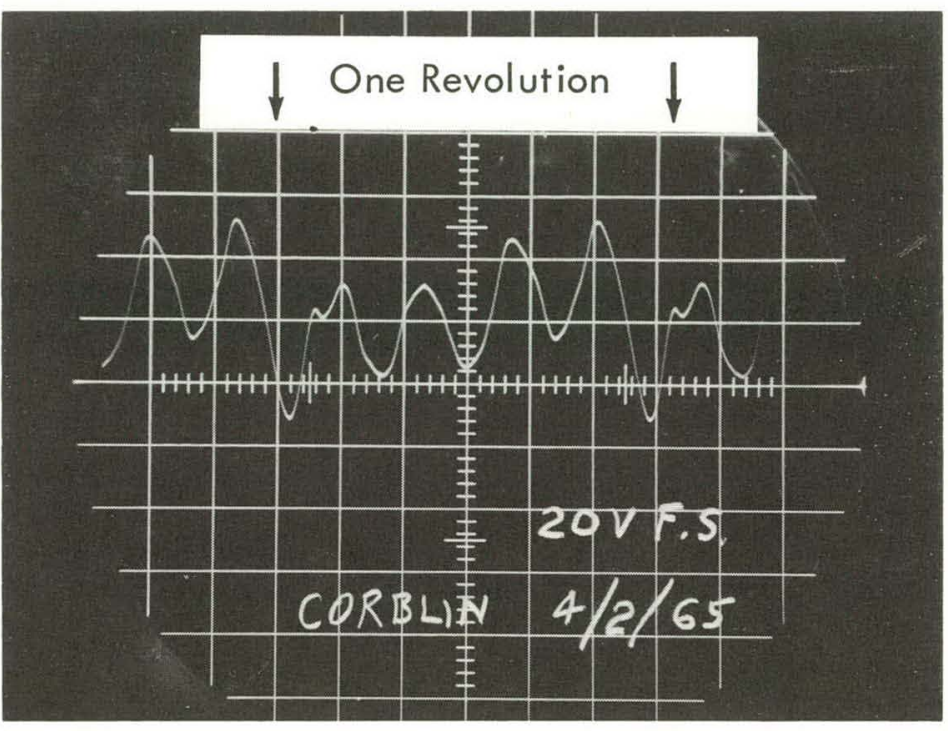

Primary Head

Vibration Amplitude 19 mils per Division

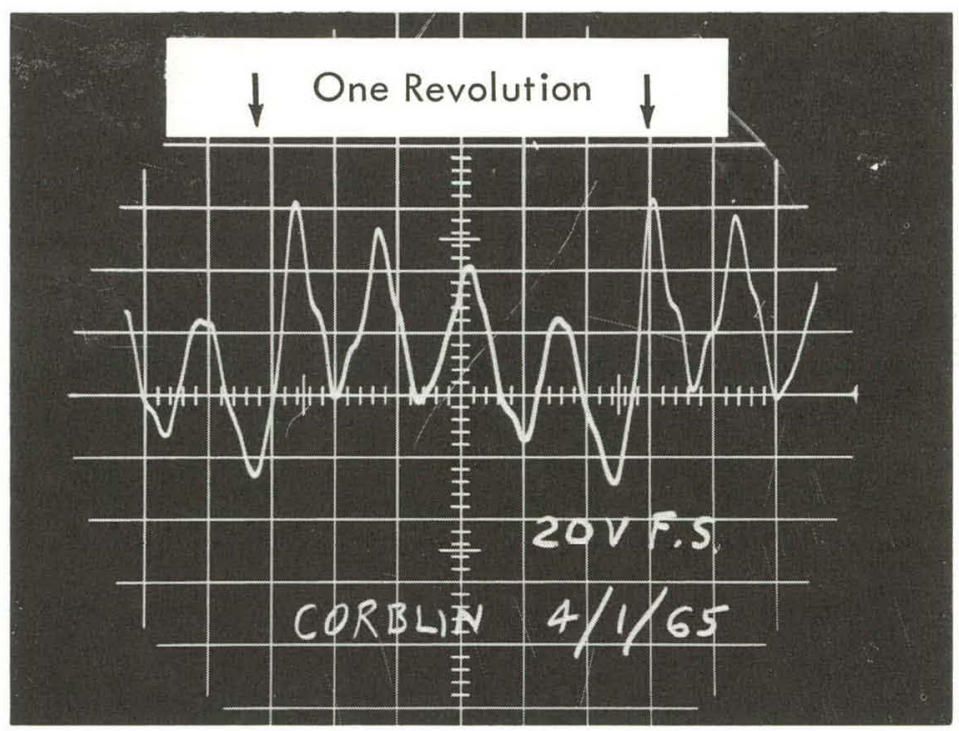

Remote Head

Figure 38

CORBLIN VIBRATION MEASUREMENTS 


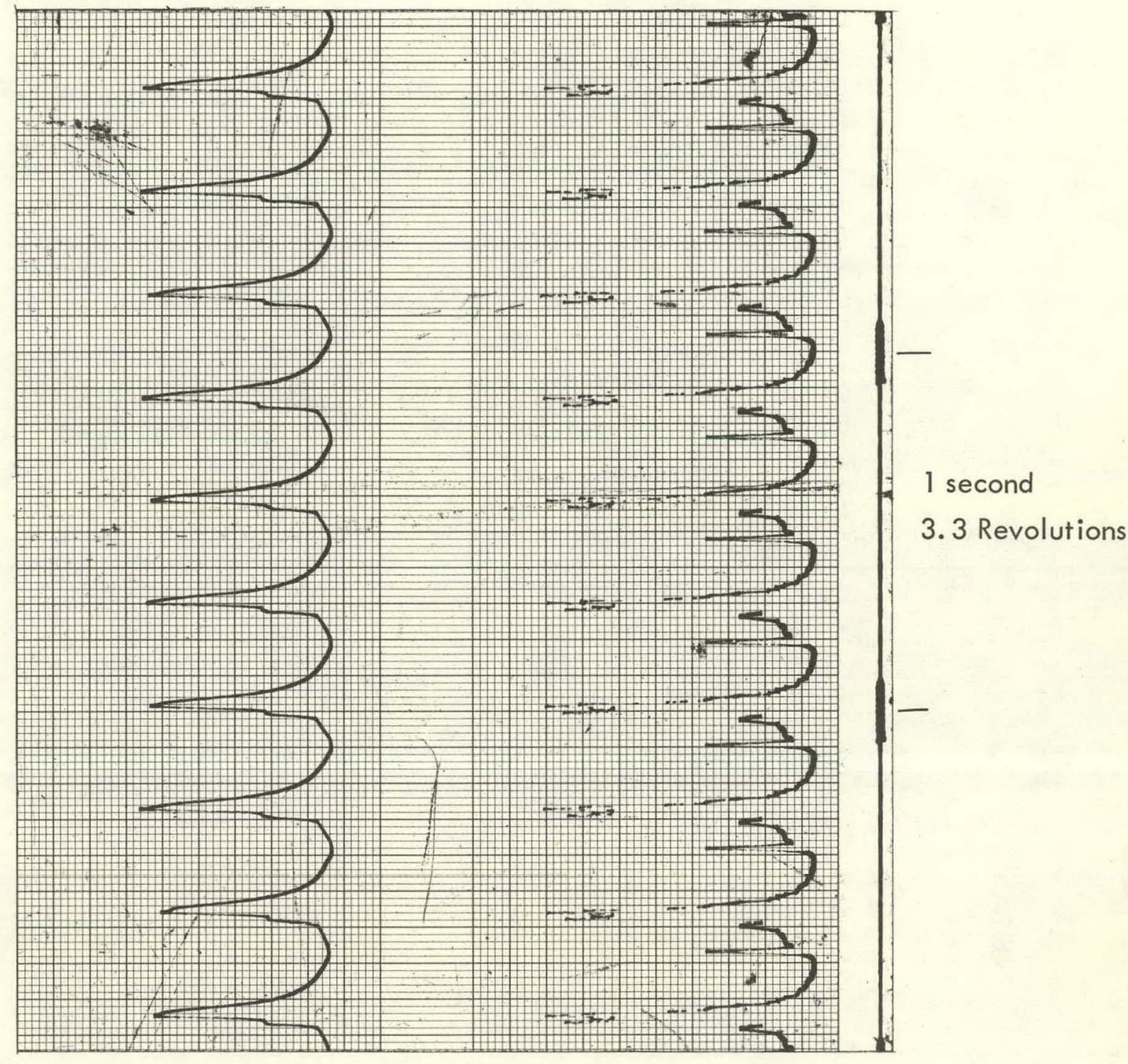

Head

Pipe Center

Pulse Calibration 2.5 psi. per mm.

Figure 39

CORBLIN FLUOROCARBON OIL PRESSURE MEASUREMENTS 
liter and following this with a hot water dip, a bright, lustered surface was attained. Clean, white gloves were worn when handling the components.

Inasmuch as the filler rod is virtually unalloyed, melting and solidification occur abruptly without the incidence of a sluggish puddle. For this reason, the best welding control combination was found to be a high heat input with a fast travel rate. Arc amperages were varied between 50 and 120 amperes; arcs of 100 amperes for the root weld and increasing to 120 amperes for the face welds were necessary in butt welding 3-inch nickel pipe. The rod was fed into the puddle in fast, short jabs, but the tip was never removed from the inert gas shield of the torch, thus reducing the possibility of oxide formation.

A joint bevel angle of 75 degrees and a l/8-inch gap were found to be the ideal conditions for a good weld. Both argon and helium torch and purge gases were employed in the tests with helium superior for both applications. A much higher back purge flow was required for the root pass to prevent oxidation and to provide adequate cooling.

Nickel-201 rods are not available commercially; therefore, nickel-201 sheet was slit, and the strips were swaged to provide a 3/32-inch diameter wire.

Successful welds have been made joining 3-inch nickel-201 pipe in the 2G and 5G welding positions. Face bend and root bend tests on these welds showed no cracking. Radiographs of the joint indicated no porosity or other defects. Tensile strength tests gave ultimate strengths of 55,000 to $60,000 \mathrm{psi}$. and elongations of about $20 \%$. All of the above tests meet the ASME requirements for an acceptable weld; at the present, a formal welding procedure is being prepared for training and qualifying welders.

The future program will include studies of welding Duranickel to nickel200 and to nickel-20l. 